\title{
Design, Synthesis and Biological Evaluation of New Embelin Derivatives as CK2 Inhibitors
}

Sandra Oramas-Royo ${ }^{\mathrm{a}}$, Samer Haidar, ${ }^{\mathrm{b}, \mathrm{c}}$, Ángel Amesty ${ }^{\mathrm{a}}$, Pedro Martín-Acosta ${ }^{\mathrm{a}}$, Gabriela Feresin ${ }^{\mathrm{d}}$, Alejandro Tapia ${ }^{\mathrm{d}}$, Dagmar Aichele ${ }^{\mathrm{b}}$, Joachim Jose ${ }^{\mathrm{b}}$, Ana EstévezBraun $^{\text {a,* }}$

${ }^{a}$ Instituto Universitario de Bio-Orgánica Antonio González (CIBICAN), Departamento de Química Orgánica, Universidad de La Laguna, Avda. Astrofísico Francisco Sánchez $N^{o}$ 2, 38206, La Laguna, Tenerife, Spain

${ }^{b}$ Institut für Pharmazeutische und Medizinische Chemie, PharmaCampus, Westfälische Wilhelms-Universität Münster, Corrensstrasse 48, 48149 Münster, Germany

${ }^{c}$ Faculty of Pharmacy, Damascus University, 17 April Street, Damascus, Syria

${ }^{d}$ Instituto de Biotecnología-Instituto de Ciencias Básicas, Universidad Nacional de San Juan, Av. Libertador General San Martín 1109 (O), CP 5400, San Juan, Argentina 


\begin{abstract}
A new series of furan embelin derivatives was synthesized and characterized as ATPcompetitive CK2 inhibitors. The new compounds were efficiently synthesized using a multicomponent approach from embelin (1), aldehydes and isonitriles through a Knoevenagel condensation/ Michael addition/ heterocyclization. Several compounds with inhibitory activities in the low micromolar or even submicromolar were identified. The most active derivative was compound $4 \mathbf{l}$ (2-(tert-butylamino)-3-(furan-3-yl)-5hydroxy-6-undecylbenzofuran-4,7-dione) with an $\mathrm{IC}_{50}$ value of $0.63 \mu \mathrm{M}$. It turned out to be an ATP competitive CK2 inhibitor with a $\mathrm{K}_{\mathrm{i}}$ value determined to be $0.48 \mu \mathrm{M}$. Docking studies allowed the identification of key ligand-CK2 interactions, which could help to further optimize this family of compounds as CK2 inhibitors.
\end{abstract}




\section{1-Introduction}

Casein kinase II (CK2) it has become one of the most studied protein kinases due to its constitutive activity, ubiquity, and pleiotropy [1]. CK2 typically forms tetrameric complexes consisting of two catalytic $\alpha$ subunits (i.e. $\alpha$ or $\alpha^{\prime}$ ) and two regulatory $\beta$ subunits in a variety of different combinations [2]. Experimental studies have provided evidence that CK2 plays a role in the pathogenesis of cancer [3-7]. Thus, when CK2 is overexpressed in mice acts as an oncogene [4, 6-8].

Many cellular processes, which are deregulated in cancer cells, can be regulated by CK2. In this sense, CK2 increases cell growth [3], cell proliferation [9-10], cell survival [11-12], cellular transformation [6,7], promotes angiogenesis [13,14] and changes cell morphology $[15,16]$. All these properties make the protein kinase CK2 an attractive therapeutic target to discover new antitumor agents [17-19]. So far, only two CK2 inhibitors, CIGB-300 and CX-4945 have entered clinical trials [20]. CIGB-300 is a peptidic inhibitor that binds to the phospho-acceptor domain of CK2 substrates, thus impairing the correct phosphorylation by the enzyme, whereas CX-4945 is an ATP competitive CK2 inhibitor. Among the CK2 inhibitors some quinonic compounds have been identified such as the anthraquinones, emodin, 1,8-dihydroxy-4nitroanthraquinone (HNA) and quinalizarin, and the naphthoquinone THN (2-(3,4dihydroxyphenyl)-5,7-dihydroxynaphthalene-1,4-dione) [21]. In a previous work, a new family of 2-amino-4-phenyl-6-hydroxy-7-alkyl-pyranobenzoquinones as ATPcompetitive CK2 inhibitors (Fig. 1a) was synthesized [22]. SAR studies of this type of compounds revealed that a) the existence of a phenyl or heteroaromatic group at the dihydropyran ring is necessary for the activity b) the presence of a C-11 alkyl chain is important since shortening of this side chain produces a drastic loss of activity c) the free hydroxyl is necessary d) a NH group as an hydrogen bond donor is key for the 
activity. Taking into account the aforementioned, in the present work we design new derivatives. So we decided to replace the dihydropyran ring with a furan ring, which gives a greater planarity to the compounds. Aromatic rings as well as substituted amino groups could also be attached to the furan ring (Fig. 1b). The designed compounds in a flexible docking simulation showed similar poses and similar interactions into the ATPbinding site than those present in the previous dihydropyranbenzoquinones studied.

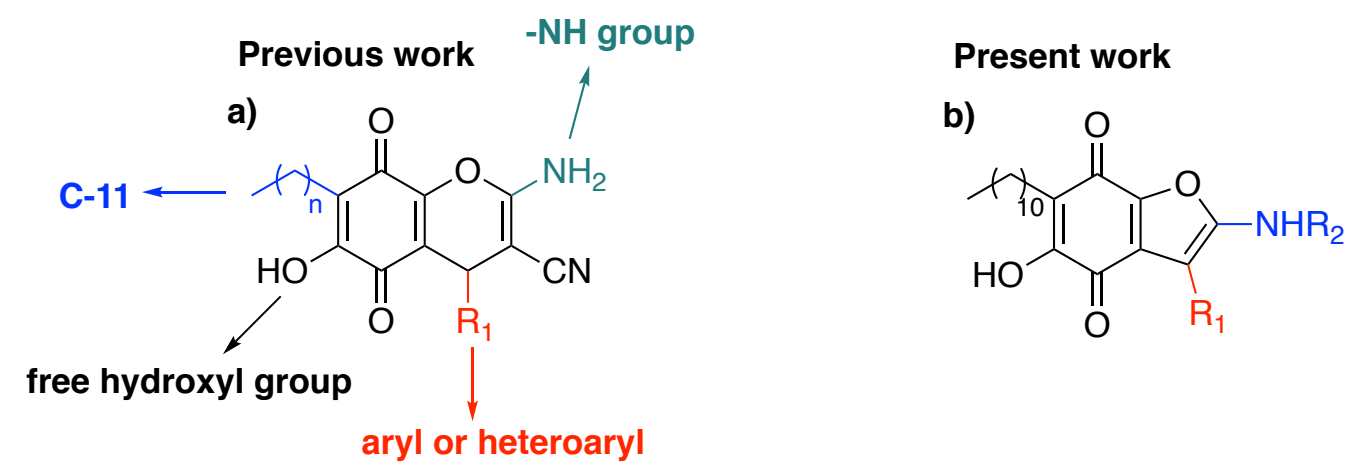

Fig. 1. a) Structure and SAR of previously synthesized benzoquinones as CK2 inhibitors and $b$ ) designed novel benzoquinones.

\section{2-Results and discussion}

\subsection{Chemistry}

The designed compounds could be obtained from a multicomponent reaction involving the natural benzoquinone embeline (1), aldehydes (2) and isonitriles (3) (Scheme 1) [23].

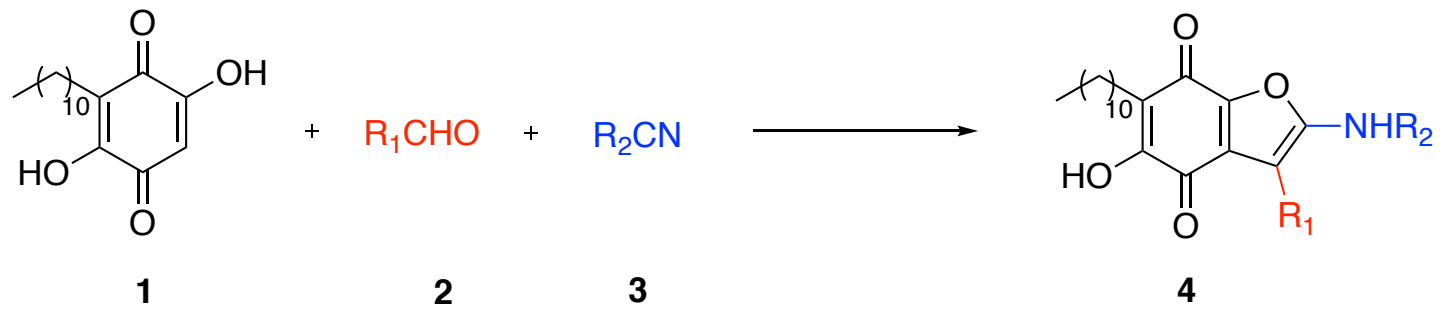

Scheme 1. Synthesis of the designed furanbenzoquinones 
The synthesis of furan-1,4-benzoquinone derivatives can be rationalized by the Knoevenagel condensation of embeline (1) and an aldehyde to yield a conjugated electron-deficient enone (I). Next a plausible [4+1] cycloaddition reaction between the isocyanide and the adduct (I) affords an iminolactone intermediate (II). The posterior isomerization of iminolactone (II) leads to the formation of the corresponding furan embelin derivative (Scheme 2).

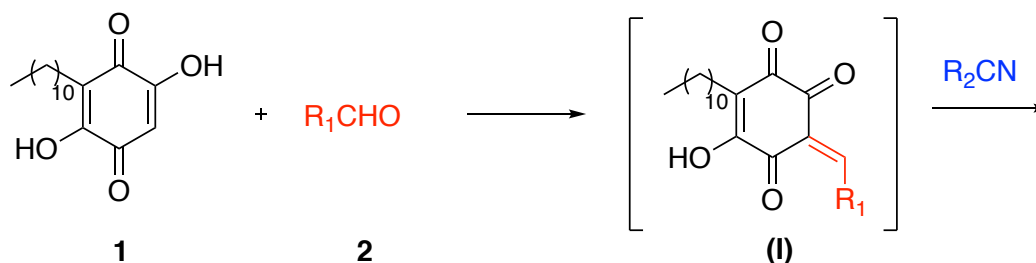<smiles>CCC1=C(O)C(=O)c2c(oc(N)c2Br)C1=O</smiles>

(II)

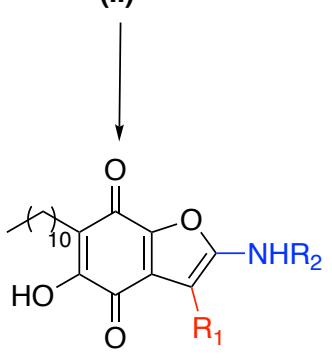

4

Scheme 2. Plausible formation of furan embelin derivatives

The reaction was optimized using embeline (1), $t$-butylisonitrile and $p$ nitrobenzaldehyde as a model. Thus different organocatalysts to favour the Knoevenagel condensation (EDDA, $\mathrm{Et}_{3} \mathrm{~N}$, proline), different ratio of reagents, solvents (DCE, EtOH, $\mathrm{C}_{7} \mathrm{H}_{8}, \mathrm{CH}_{3} \mathrm{CN}$ ), conventional heating and microwave irradiation were employed (Table 1). When the reaction was carried out under reflux with DCE, the desired product was isolated in low yield (7\%, entry 1). The use of MW irradiation at $150^{\circ} \mathrm{C}$ for $30 \mathrm{~min}$ increased the yield $(65 \%$, entry 2$)$. The use of other solvents such as EtOH, $\mathrm{C}_{7} \mathrm{H}_{8}$ or $\mathrm{CH}_{3} \mathrm{CN}$ did not improve the yield (entries 3-5). When the reaction mixture was irradiated at $180^{\circ} \mathrm{C}$ a $70 \%$ yield was obtained (entry 6). Neither longer 
reaction times nor the use of $\mathrm{Et}_{3} \mathrm{~N}$ or proline as catalyst led to improved yields. Therefore, the best yield was obtained when EDDA $10 \mathrm{~mol} \%$ and dichloroethane were used under microwave irradiation at $180^{\circ} \mathrm{C}$ for $15 \min (70 \%)$.

Table 1. Optimization of the reaction conditions

\begin{tabular}{|c|c|c|c|}
\hline Entry & Ratio 1:2:3 & Conditions & yield $^{\mathrm{a}}(\%)$ \\
\hline 1 & $1: 1: 1$ & 10 mol\% EDDA, DCE, reflux, $24 \mathrm{~h}$ & 7 \\
\hline 2 & $1: 1: 1$ & $10 \mathrm{~mol} \% \mathrm{EDDA}, \mathrm{DCE}, \mathrm{MW}, 150^{\circ} \mathrm{C}, 30 \mathrm{~min}$ & 65 \\
\hline 3 & $1: 1: 1$ & $10 \mathrm{~mol} \% \mathrm{EDDA}, \mathrm{EtOH}, \mathrm{MW}, 150^{\circ} \mathrm{C}, 30 \mathrm{~min}$ & 54 \\
\hline 4 & $1: 1: 1$ & $10 \mathrm{~mol} \% \mathrm{EDDA}, \mathrm{C}_{7} \mathrm{H}_{8}, \mathrm{MW}, 150^{\circ} \mathrm{C}, 30 \mathrm{~min}$ & 67 \\
\hline 5 & $1: 1: 1$ & $10 \mathrm{~mol} \% \mathrm{EDDA}, \mathrm{CH}_{3} \mathrm{CN}, \mathrm{MW}, 150^{\circ} \mathrm{C}, 30 \mathrm{~min}$ & 35 \\
\hline 6 & $1: 1: 1$ & $10 \mathrm{~mol} \% \mathrm{EDDA}, \mathrm{DCE}, \mathrm{MW}, 180^{\circ} \mathrm{C}, 15 \mathrm{~min}$ & 70 \\
\hline 7 & $1: 1: 1$ & $10 \mathrm{~mol} \% \mathrm{EDDA}, \mathrm{DCE}, \mathrm{MW}, 180^{\circ} \mathrm{C}, 20 \mathrm{~min}$ & 68 \\
\hline 8 & $1: 1: 2$ & $10 \mathrm{~mol} \% \mathrm{EDDA}, \mathrm{DCE}, \mathrm{MW}, 180^{\circ} \mathrm{C}, 15 \mathrm{~min}$ & 24 \\
\hline 9 & $1: 1: 1$ & $10 \mathrm{~mol}^{\%} \mathrm{Et}_{3} \mathrm{~N}, \mathrm{DCE}, \mathrm{MW}, 180^{\circ} \mathrm{C}, 15 \mathrm{~min}$ & 46 \\
\hline 10 & $1: 1: 1$ & $10 \mathrm{~mol} \%$ L-proline, DCE, MW, $180^{\circ} \mathrm{C}, 15 \mathrm{~min}$ & 48 \\
\hline
\end{tabular}

${ }^{\mathrm{a}}$ Isolated yield

With the optimized protocol in hand, the scope of this multicomponent reaction was then determined through the variation of isonitriles and aldehydes (Table 2). Diversely substituted furan embelin derivatives could be prepared in moderate to good yields. As a general trend, the reaction works with a large variety of aryl-substituted aldehydes with electron-withdrawing and electron-donating groups, heteroaromatic aldehydes and aliphatic aldehydes. Regarding the isonitrile component, the best yields were achieved with the most nucleophilic tert-butylisocyanide. 
Table 2. Structures and yields of furan embelin adducts

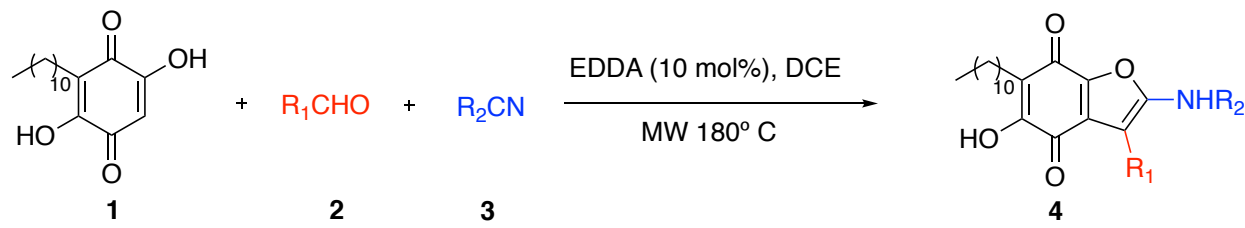<smiles>CCCC1=C(O)C(=O)c2c(oc(NC(C)(C)C)c2-c2ccccc2)C1=O</smiles>

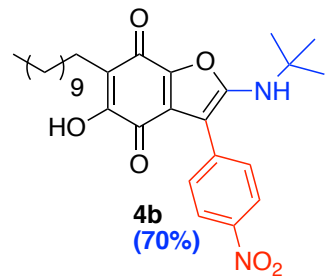

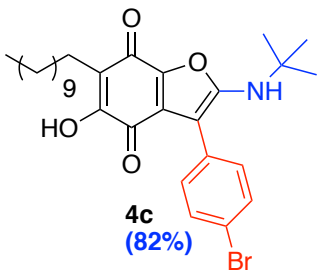

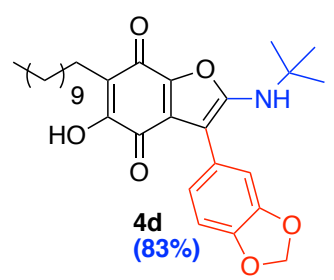

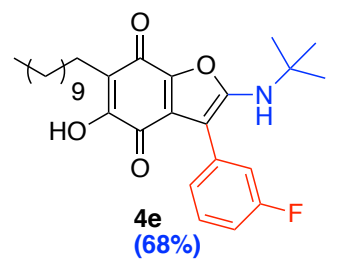

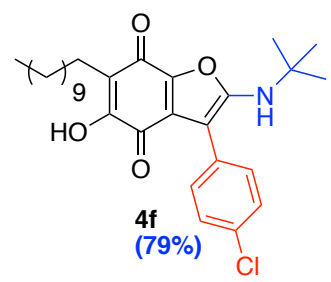

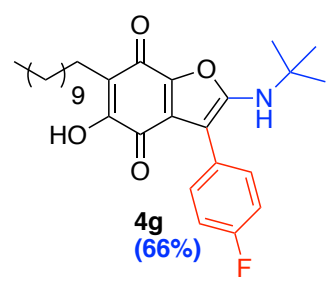

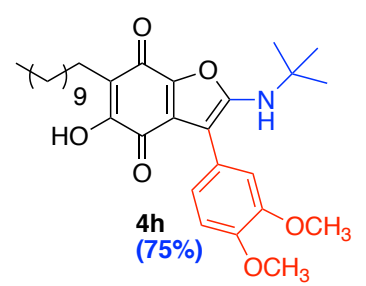

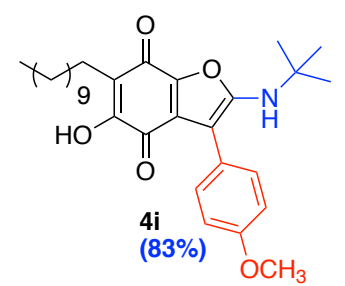

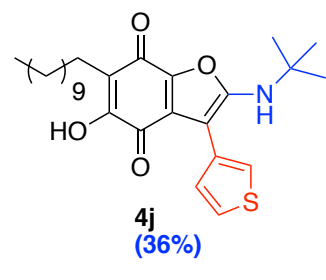<smiles>CCCc1oc2c(c(=O)c1O)C(c1cccnc1)=C(O)C2=O</smiles>

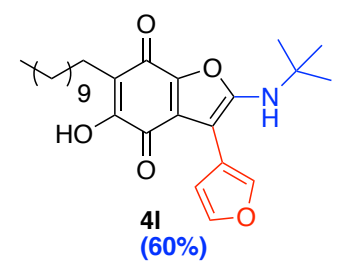<smiles></smiles><smiles>Cc1cccc2c1Cc1ccccc1-2</smiles><smiles>CCCc1c(NC(C)(C)C)oc2c1C(=O)C(O)=C(C(C)(C)C)C2=O</smiles>

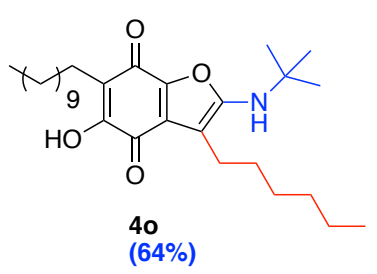



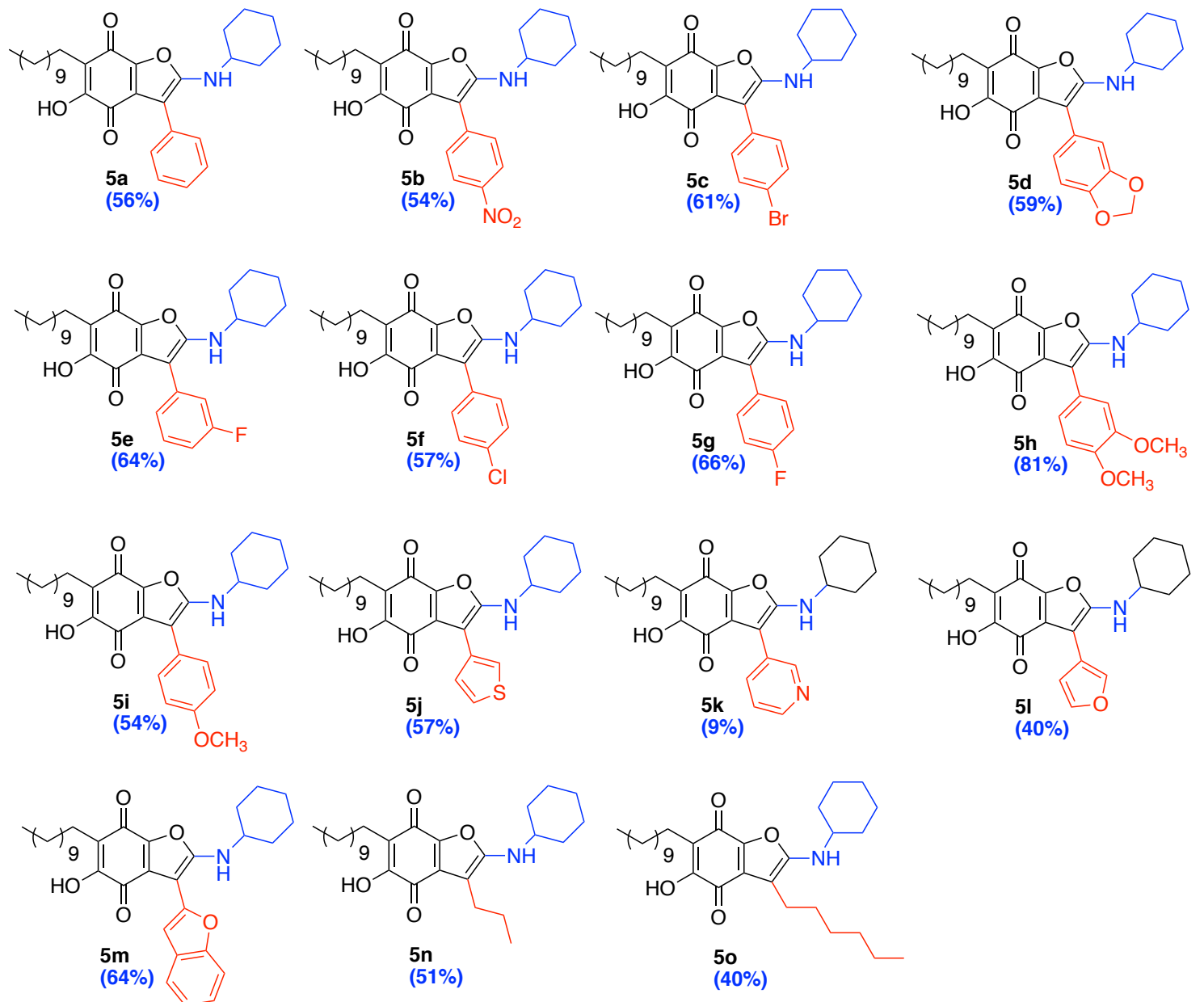


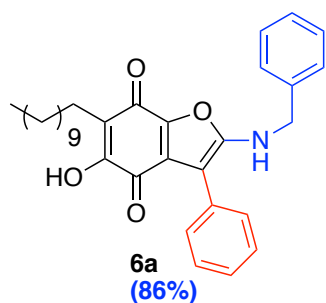

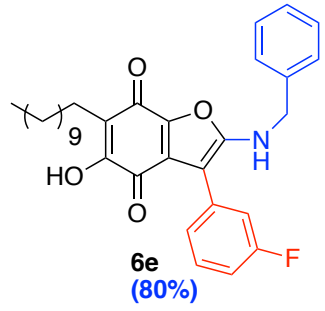

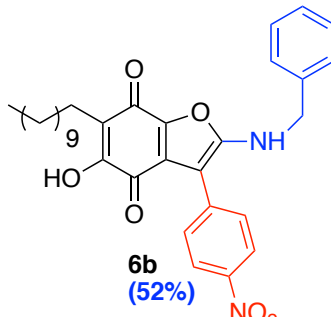

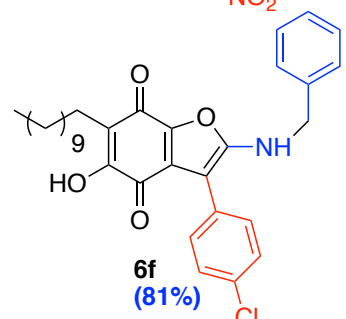
$(81 \%$<smiles>CCCC1C(=O)c2oc(NCc3ccccc3)c(-c3ccc(OC)cc3)c2C(=O)C1O</smiles>

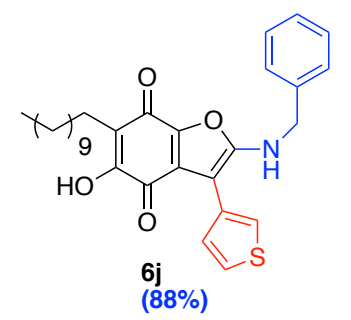

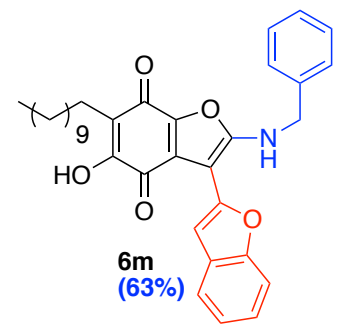
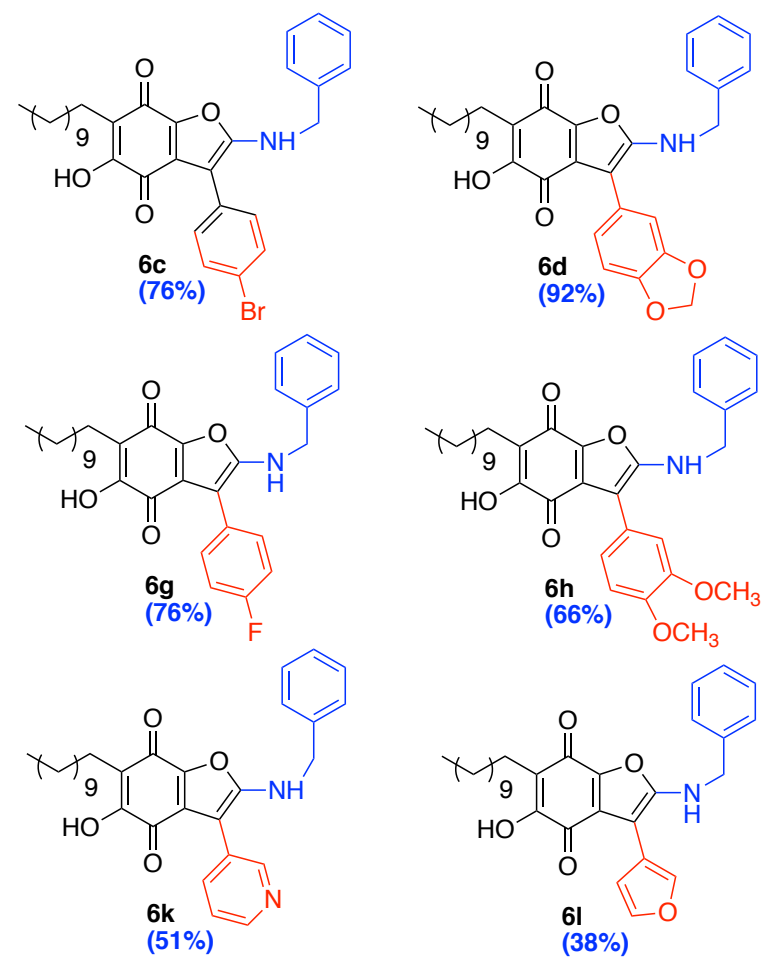

$(38 \%)$

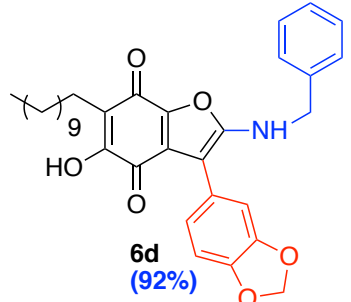

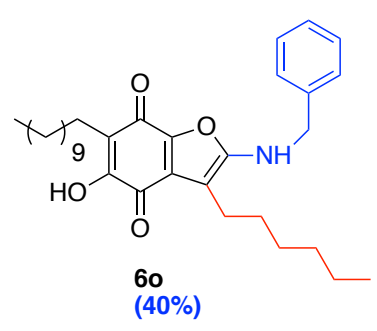

The obtained furan adducts were assayed for their inhibitory activity towards the human CK2 holoenzyme. The percent inhibition of CK2 activity was determined for each compound at a fixed concentration of $10 \mu \mathrm{M}$ using CK2 holoenzyme and following the procedure described earlier [24]. For the best compounds producing at least $70 \%$ inhibition at $10 \mu \mathrm{M}$, the effect of different concentrations was analyzed in order to determine the $\mathrm{IC}_{50}$ value. The results obtained thereby are shown in Table 3. 
Table 3. CK2 inhibitory activity of the tested furanbenzoquinones together with emodin as reference compound.

\begin{tabular}{|c|c|c|}
\hline Compound & Inhibition (\%) & $\mathrm{IC}_{50} \pm \mathrm{SD}(\mu \mathrm{M})$ \\
\hline $4 a$ & 65 & nd $(+)$ \\
\hline $4 b$ & 28 & nd $(+)$ \\
\hline $4 c$ & 66 & nd $(+)$ \\
\hline $4 d$ & 32 & nd $(+)$ \\
\hline $4 e$ & 9 & nd $(+)$ \\
\hline $4 f$ & 28 & nd $(+)$ \\
\hline $4 g$ & 84 & $2.09 \pm 0.20(++)$ \\
\hline $4 \mathrm{~h}$ & 62 & nd $(+)$ \\
\hline $4 \mathrm{i}$ & 61 & nd $(+)$ \\
\hline $4 \mathrm{j}$ & 79 & $2.33 \pm 0.02(++)$ \\
\hline $4 \mathrm{k}$ & 52 & nd $(+)$ \\
\hline 41 & 84 & $0.63 \pm 0.15(+++)$ \\
\hline $4 \mathrm{~m}$ & 51 & nd $(+)$ \\
\hline $4 n$ & 77 & $1.62 \pm 0.02(++)$ \\
\hline 40 & 25 & nd $(+)$ \\
\hline $5 a$ & 70 & $6.52 \pm 0.06(++)$ \\
\hline $5 b$ & 59 & nd $(+)$ \\
\hline $5 c$ & 63 & nd $(+)$ \\
\hline $5 d$ & 51 & nd $(+)$ \\
\hline $5 e$ & 44 & nd $(+)$ \\
\hline $5 f$ & 65 & nd $(+)$ \\
\hline $5 \mathrm{~g}$ & 70 & $8.36 \pm 0.40(++)$ \\
\hline $5 \mathrm{~h}$ & 53 & nd $(+)$ \\
\hline $5 \mathrm{i}$ & 59 & nd $(+)$ \\
\hline $5 \mathrm{j}$ & 59 & nd $(+)$ \\
\hline $5 \mathrm{k}$ & 71 & $0.97 \pm 0.14(+++)$ \\
\hline 51 & 92 & $0.98 \pm 0.10(+++)$ \\
\hline $5 \mathrm{~m}$ & 55 & nd $(+)$ \\
\hline $5 n$ & 73 & $6.10 \pm 0.30(++)$ \\
\hline 50 & 71 & $4.57 \pm 0.40(++)$ \\
\hline $6 a$ & 47 & nd $(+)$ \\
\hline $6 b$ & 34 & nd $(+)$ \\
\hline $6 c$ & 20 & nd $(+)$ \\
\hline $6 \mathrm{~d}$ & 70 & $1.21 \pm 0.09$ \\
\hline $6 e$ & 50 & nd $(+)$ \\
\hline $6 f$ & 65 & nd $(+)$ \\
\hline $6 g$ & 42 & nd $(+)$ \\
\hline $6 \mathrm{~h}$ & 71 & $1.68 \pm 0.06$ \\
\hline $6 \mathrm{i}$ & 37 & nd $(+)$ \\
\hline $6 \mathrm{j}$ & 46 & nd $(+)$ \\
\hline $6 \mathrm{k}$ & 25 & nd $(+)$ \\
\hline 61 & 90 & $0.78 \pm 0.22(+++)$ \\
\hline $6 \mathrm{~m}$ & 43 & nd $(+)$ \\
\hline $6 n$ & 78 & $1.37 \pm 0.02(++)$ \\
\hline 60 & 60 & nd (+) \\
\hline emodin & 96 & $0.60 \pm 0.22$ \\
\hline
\end{tabular}

nd: not determined; $(+)$ inactive; $(++)$ moderately active; $(+++)$ highly active 
Compounds 4a-4o, 5a-5o and 6a-6o were classified by their activity as highly active $\left(\mathrm{IC}_{50}<1 \mu \mathrm{M},+++\right)$, moderately active $\left(1 \mu \mathrm{M}<\mathrm{IC}_{50}<10 \mu \mathrm{M},++\right)$, or inactive $(10 \mu \mathrm{M}>$ IC50,+).

The best inhibitors of CK2 turned out to be compounds $\mathbf{4 1}, \mathbf{5} \mathbf{l}$ and $\mathbf{6}$, obtained from 3-furaldehyde, with $\mathrm{IC}_{50}$ values in the submicromolar range, in the same order of magnitude as the reference compound emodin. With the same aryl substituent at the fused furan ring, the benzyl derivatives produced the highest activities in most cases (i.e. 6d $v s$ 5d and 4d; 6h $v s$ 5h and $4 \mathbf{h} ; \mathbf{6 n} v s$ 5n and 4n).

Based on the effects of the furanbenzoquinones as synthesized on human CK2 holoenzyme, we used a docking computational approach in the next step to assess the potential interactions of different furanembelin derivatives with the narrow ATPbinding site of CK2. The binding pattern of the most actives compounds was analyzed by flexible molecular docking in order to propose the mode of action of the significant inhibitory effects of derivatives $\mathbf{4 l}$ and $\mathbf{6 l}$. Thus, a molecular docking study was carried out using the Glide software [25] on reported crystal structure of human protein kinase CK2 alpha subunit in complex with the inhibitor CX-4945 (PDB 3PE1). According to the hypothetical model for the binding mode of the protein kinase inhibitors proposed by Traxler and Furet [26], the ATP-binding site can be divided into five regions, three hydrophobic regions corresponding to the adenine region and the hydrophobic regions I and II and also two hydrophilic regions that correspond one of them to the sugar pocket and another one to the phosphate binding region. ATP competitive inhibitors of kinases, typically form one to three hydrogen bonds with the backbone of residues of the hinge region. These hydrogen bonds mimic those which are normally formed by the amino group of ATP [27]. These features can be also applied to the CK2 protein. Hence, in order to explore the binding mode of $\mathbf{4 l}$ and $\mathbf{6}$, these compounds have been inserted into 
the narrow ATP binding site of CK2. An analysis of the docking results showed that the compounds fit very well and, as shown in Fig.2, the active site is fully occupied by the compound $\mathbf{4 l}$, the aliphatic chain was located at the edge of the pocket and established hydrophobic interactions with the hydrophobic region I, in the deepest part of the cavity and with the hydrophobic region II at the entrance of the cavity as well as the adenine region. The compound $\mathbf{4 l}$ established hydrophobic interactions and van der Waals contacts involving the hydrophobic surface of the CK2 binding site formed by side chains of Val 53, Val 66, Val 116, Met 163 (adenine region), Leu 45, His 115 (hydrophobic region II), Phe 113, Ile 95 and Ile 174 (hydrophobic region I). Another distinctive feature of CK2 is the presence of a salt bridge between Lys68 and Glu81, this region is one of the most important polar anchoring points for CK2 inhibitors. In this sense, one hydrogen bond was observed between the hydroxyl group of $\mathbf{4 l}$ and Lys 68. In the predicted pose of $\mathbf{4 l}$ another representative interaction was a $\pi$ - $\pi$ stacking between the furan ring with the side chain of His 160 . The high activity achieved by compound $\mathbf{4 l}$ can be also explained on the basis of the existence of one hydrogen bond interactions between the hydroxyl group and Lys 68, and finally the alkyl chain of the compound $4 \mathbf{l}$ and the interactions established with the side chains residues on the hydrophobic surface of the CK2 binding site, reinforce the key role played by the C-11 chain and the apolar forces involving van der Waals contacts interactions between the hydrophobic region I, the adenine region and the hydrophobic region II driving the orientation of the compounds into the ATP binding site as it was reported previously [22]. 


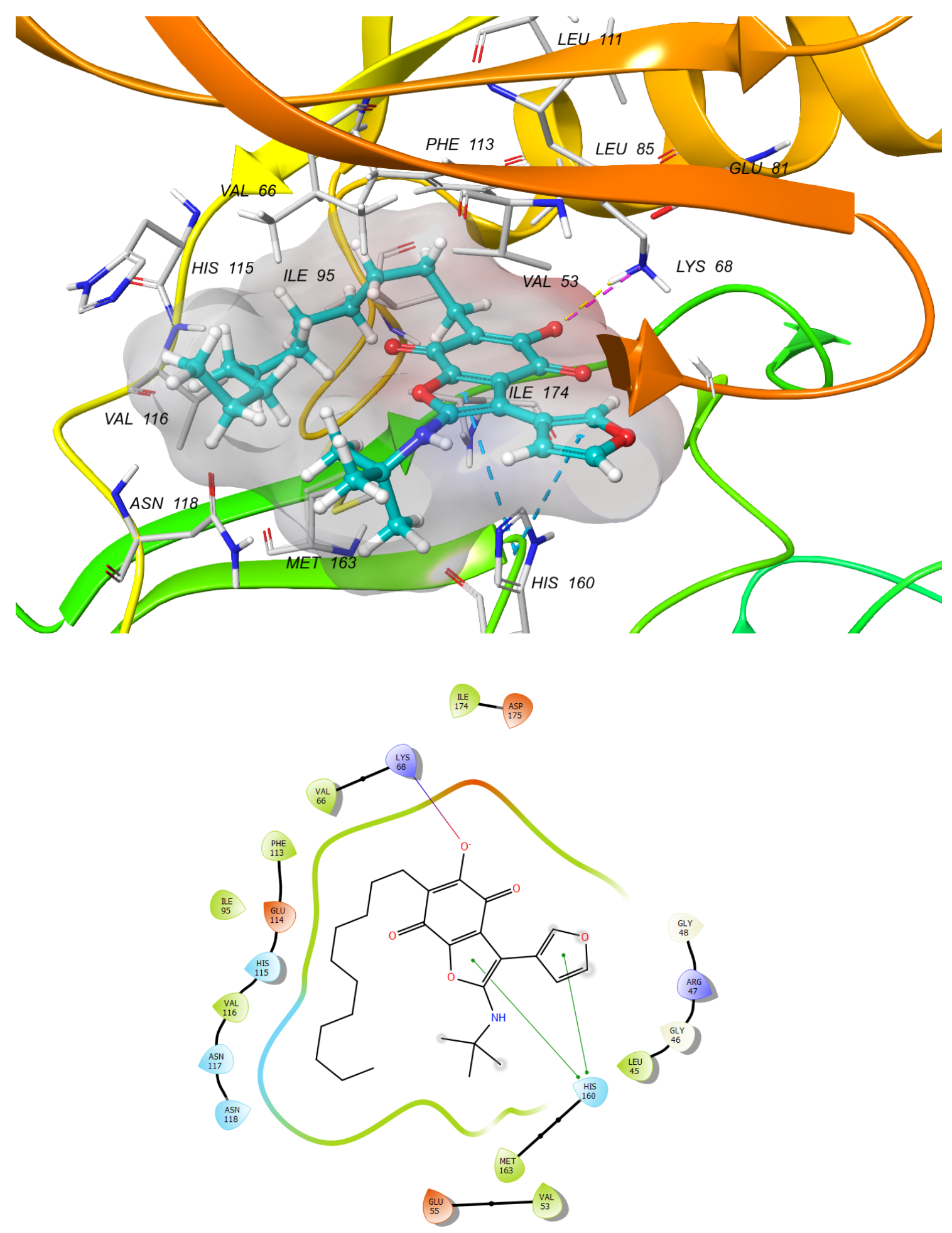

Fig. 2. 3D and 2D representation of the binding mode of $4 \mathbf{l}$ with CK2 (PDB 3PE1).

An analysis of the docking results for compound $\mathbf{6 1}$ showed that the aliphatic chain was located outside the active site, therefore, the hydrophobic surface of the CK2 binding site is not fully occupied. As previously mentioned, according to the 
pharmacophore model for protein kinase inhibitors that bind principally to the hydrophobic adenine region, they constitute the vast majority of the currently available protein kinase ATP-competitive inhibitors. Nevertheless, some protein kinase inhibitors usually show ATP-competitive behavior and preferentially have contacts to the hinge region and they present hydrophobic interactions in a pocket adjacent to the ATPbinding site. In this sense, the activity of this compound on the CK2 protein could be explained by the presence of two hydrogen bonds, one of them between the hydroxyl group of compound $\mathbf{6} \mathbf{1}$ and Lys 68 and another hydrogen bond between the furan ring and Val 116 from the hinge region. The structural portion constituted by a benzyl group established Van der Waals interactions with the side chains of Leu 45, Met 163 and Asn 118. Finally, as shown in Fig. 3 the long lipophilic chain of compound $\mathbf{6 1}$ make hydrophobic contacts in adjacent areas to the active site with Asp 175, Lys 158, Asp 156, Leu 178 and Ala 193.

The predicted binding modes and the presence of different substituents on the amino group of the furanbenzoquinones suggested that the best docked pose for each ligand and the binding mode of these compounds (4I, 5l, and $\mathbf{6 l )}$ to the CK2 protein was driven depending on the degree of steric interactions between the tert-butyl group $(89.56 \AA)$, benzyl group $(115.77 \AA)$ or cyclohexyl group $(110.65 \AA)$ and the corresponding aliphatic chain. This fact reinforces the key role that the C-11 plays driving the properly orientation of the compounds to interact favorably within the lining of the ATP-binding site. 

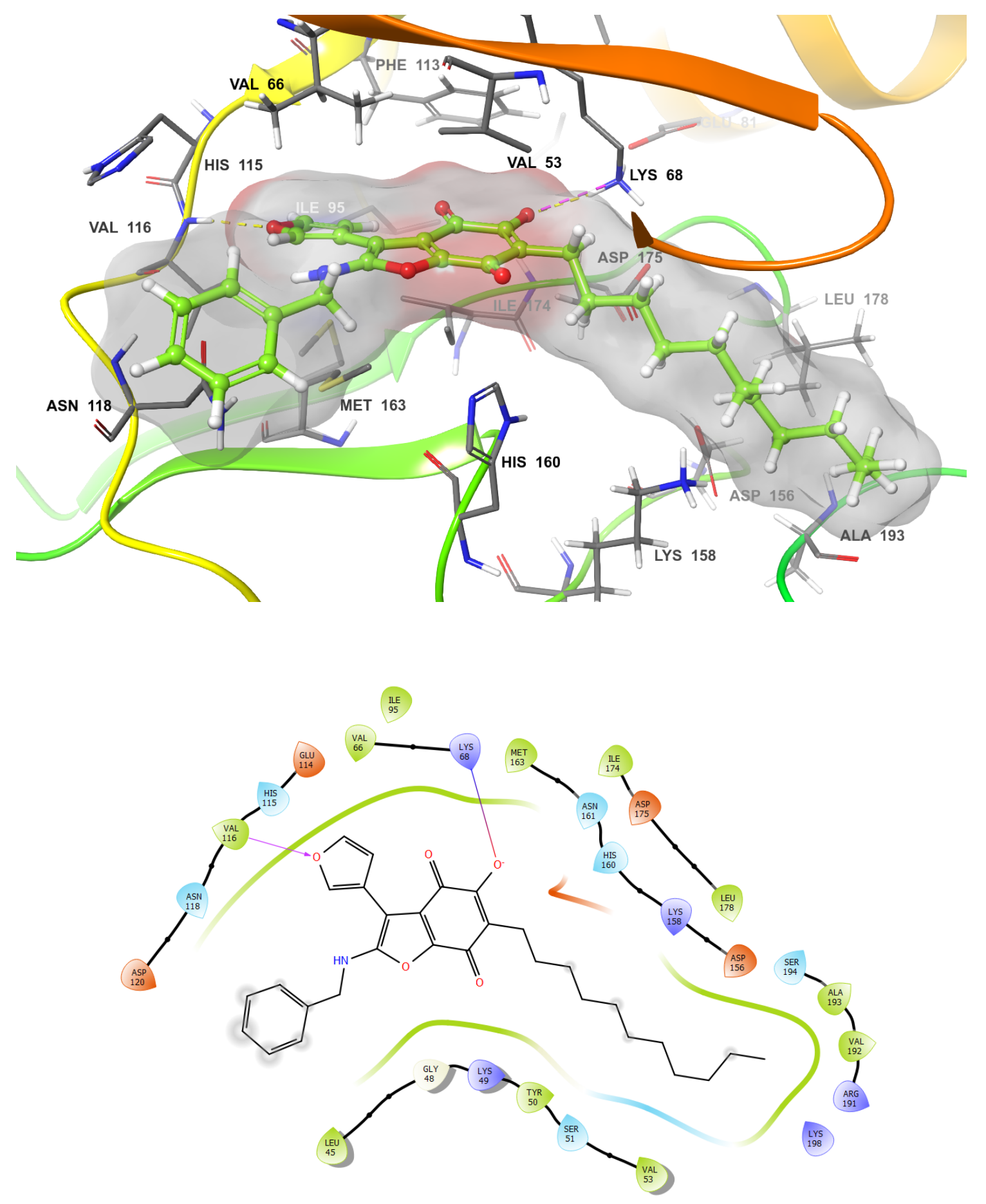

Fig. 3. 3D and 2D representation of the binding mode of $\mathbf{6 l}$ with CK2 (PDB 3PE1).

The mode of action of this set of compounds was also ratified by determining the $\mathrm{IC}_{50}$ values of the most potent inhibitor $\mathbf{4 l}$ at different ATP concentrations. Compound $\mathbf{4 l}$ was selected as a representative inhibitor of this series, and the $\mathrm{IC}_{50}$ values were determined at eight different concentrations of compound $\mathbf{4} \mathbf{l}$, ranging from 
0.001 to $100 \mu \mathrm{M}$, and repeated four times using different ATP concentrations each time. The $\mathrm{IC}_{50}$ values increased linearly with the ATP concentration, which is indicative of an ATP competitive mode of CK2 inhibition (Fig. 4). The $\mathrm{K}_{\mathrm{i}}$ value of CK2 inhibition by compound 4l was determined from the $\mathrm{IC}_{50}$ values obtained at various $\mathrm{ATP}$ concentrations. The regression line showed a $\mathrm{Y}$-axis intercept at an $\mathrm{IC}_{50}$ value of $0.48 \pm$ $0.07 \mu \mathrm{M}$ (Fig. 4) and thereby defined the $\mathrm{K}_{\mathrm{i}}$ value of compound $4 \mathrm{l}$ to be at this concentration.

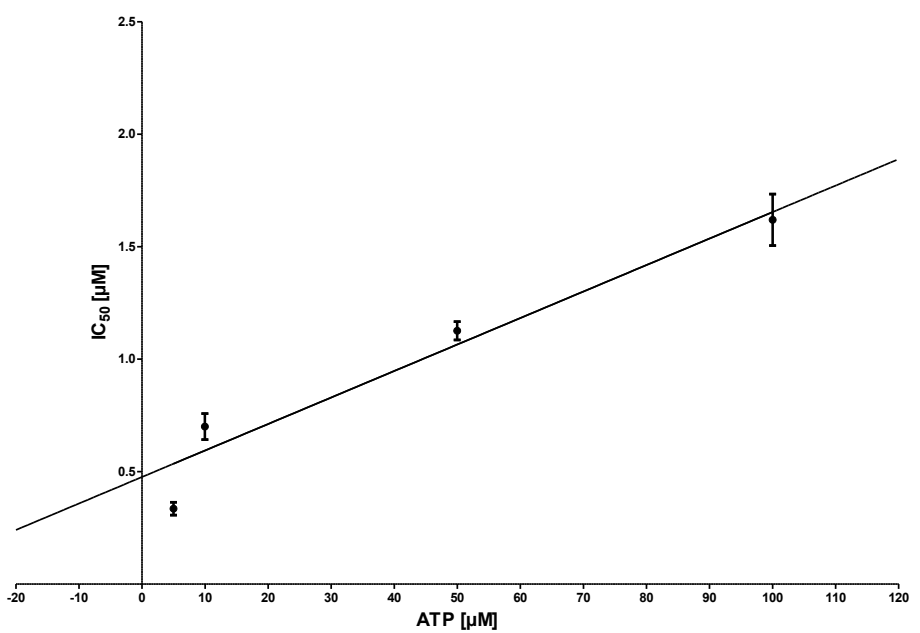

Fig. 4. ATP-competitive inhibition of human CK2 by compound 4l. Four $\mathrm{IC}_{50}$ values with different ATP concentrations were determined using eight different concentration of the inhibitor, ranging from 0.001 to $100 \mu \mathrm{M}$ and plotted against the respective ATP concentrations. Each $\mathrm{IC}_{50}$ value was determined 3 times independently. Mean values with corresponding standard deviation are given. The $\mathrm{K}_{\mathrm{i}}$ value is defined as the $\mathrm{Y}$ intercept and was determined to be $0.48 \pm 0.07 \mu \mathrm{M}\left(\mathrm{R}^{2}=0.90\right)$.

Compounds $\mathbf{4 l}, \mathbf{5} \mathbf{l}$ and $\mathbf{6 l}$, which appeared to be the most potent CK2 inhibitors in the current study with $\mathrm{IC}_{50}$ values of $0.63 \mu \mathrm{M}$ to $0.98 \mu \mathrm{M}$ and $0.78 \mu \mathrm{M}$ respectively, were selected to evaluate the antiproliferative effect of this group of furanbenzoquinones. MCF7 (human breast adenocarcinoma cell line) cells were treated with different concentrations of each compound, cell viability was tested applying MTT assay using the above mentioned cell line. Also the antiproliferative effect of compounds 4l, 5I, and 6I was investigated with the same cells. For this purpose, a commercially available EdU-click assay was applied, resulting in the coupling of a 
TAMRA fluorophore into the nucleic acid of cells performing DNA replication and hence preparing cell division. Proliferating cells can be recognized by a violet fluorescence of their nuclei. The number of proliferating cells was determined after treatment with compounds $\mathbf{4}$, $\mathbf{5} \mathbf{I}$, or $\mathbf{6 I}$ in various concentrations and was set into relation to the total number of cells obtained with the $1 \%$ DMSO control. In both experiments only minor effects were seen with all compounds even at concentration of $100 \mu \mathrm{M}$ (see Supplementary Material).

\section{Conclusion}

A series of furan embelin derivatives were designed and synthesized as CK2 inhibitors from a multicomponent reaction using the natural benzoquinone embelin (1), aldehydes and isonitriles. Some of them inhibited CK2 activity at the micromolar or submicromolar levels. The mode of action was established on the basis of ATP competitive assays. For the most active compounds the key interactions into the ATP binding site of CK2 were analyzed by docking studies, which reinforced the role of the C-11 alkyl chain in the orientation of the compounds to interact favorably. Thus in compounds having the N-t-butyl group, the aliphatic chain occupies the edge of the binding site, while with N-cyclohexyl and N-benzyl group the alkyl chain is located outside of the ATP-binding site. In all these cases the key interaction between the hydroxyl group of the quinone moiety and Lys 68 is present. Based on these results, the design and synthesis of new embelin derivatives will be considered in order to obtain more potent $\mathrm{CK} 2$ inhibitors.

\section{Experimental section}

NMR spectra were recorded in $\mathrm{CDCl}_{3}$ at 500 or $600 \mathrm{MHz}$ for ${ }^{1} \mathrm{H} \mathrm{NMR}$ and 125 or 150 $\mathrm{MHz}$ for ${ }^{13} \mathrm{C}$ NMR. Chemical shifts are given in ( $\left.\delta\right)$ parts per million and coupling 
constants $(J)$ in hertz $(\mathrm{Hz}) .{ }^{1} \mathrm{H}$ and ${ }^{13} \mathrm{C}$ spectra were referenced using the solvent signal as internal standard. Melting points were taken on a capillary melting point apparatus and are uncorrected. HREIMS were recorded using a high-resolution magnetic trisector (EBE) mass analyzer. Analytical thin-layer chromatography plates used were PolygramSil G/UV254. Preparative thin-layer chromatography was carried out with Analtech silica gel GF plates (20 x $20 \mathrm{~cm}, 1000$ Microns) using appropriate mixtures of ethyl acetate and hexanes. All compounds were named using the ACD40 Name-Pro program, which is based on IUPAC rules. The embelin (1) used in the reactions was obtained from Oxalis erythrorhiza Gillies ex Hook. \& Arn. following the procedure described in reference [28].

\subsection{General Procedures for the preparation of dihydropyran embeline derivatives}

To a mixture of $0.1 \mathrm{mmol}$ of the corresponding isocyanide, $0.1 \mathrm{mmol}$ of the corresponding aldehyde, and $10 \mathrm{~mol} \%$ of EDDA in $2 \mathrm{~mL}$ of DCE, were added $30 \mathrm{mg}$ of embelin $(0.1 \mathrm{mmol})$. The reaction mixture was stirred and irradiated for $15 \mathrm{~min}$ at $180^{\circ} \mathrm{C}$. The solvent was removed under vacuum, and the crude product was purified by preparative-TLC to yield the corresponding furan derivative.

\section{2-(tert-butylamino)-5-hydroxy-3-phenyl-6-undecylbenzofuran-4,7-dione (4a)}

Following the general procedure described above, $30 \mathrm{mg}$ of embelin $(0.102 \mathrm{mmol})$, $10.46 \mu \mathrm{L}$ of benzaldehyde $(0.102 \mathrm{mmol}), 11.7 \mu \mathrm{L}$ of $t$-butyl isocyanide $(0.102 \mathrm{mmol})$ and $1.8 \mathrm{mg}$ of EDDA $(10 \mathrm{~mol} \%)$ in $2 \mathrm{~mL}$ of DCE were irradiated for $15 \mathrm{~min}$ at $180^{\circ} \mathrm{C}$. The solvent was removed under vacuum, and the crude product was purified by preparative-TLC with $20 \%$ hexanes/EtOAc to yield $38.2 \mathrm{mg}(80 \%)$ of $\mathbf{4 a}$ as a dark blue oil. ${ }^{1} \mathrm{H}-\mathrm{NMR}\left(500 \mathrm{MHz}, \mathrm{CDCl}_{3}\right) \delta 0.88(\mathrm{t}, J=7.3 \mathrm{~Hz}, 3 \mathrm{H}), 1.25$ (bs, $\left.16 \mathrm{H}\right), 1.42(\mathrm{~s}, 9 \mathrm{H})$, $1.50(\mathrm{~m}, 2 \mathrm{H}), 2.47$ (t, J= 7.5 Hz, 2H), 4.64 (bs, 1H), 6.86 (bs, 1H), 7.33 (m, 1H), 7.43 (m, 4H). ${ }^{13} \mathrm{C}-\mathrm{NMR}\left(150 \mathrm{MHz}, \mathrm{CDCl}_{3}\right) \delta 14.1\left(\mathrm{CH}_{3}\right), 22.6\left(\mathrm{CH}_{2}\right), 22.7\left(\mathrm{CH}_{2}\right), 22.8$ 
$\left(\mathrm{CH}_{3}\right), 27.9\left(\mathrm{CH}_{2}\right), 28.3\left(\mathrm{CH}_{3}\right), 28.4\left(\mathrm{CH}_{3} \mathrm{x}\right), 28.5\left(\mathrm{CH}_{2}\right), 29.3\left(\mathrm{CH}_{2}\right), 29.5\left(\mathrm{CH}_{2}\right)$, $29.6\left(\mathrm{CH}_{2} \times 2\right), 30.1\left(\mathrm{CH}_{2}\right), 31.9\left(\mathrm{CH}_{2}\right), 52.6(\mathrm{C}), 99.6(\mathrm{CH}), 118.7(\mathrm{C}), 119.1(\mathrm{C})$, $125.5(\mathrm{CH}), 128.7(\mathrm{CH}), 130.2(\mathrm{C}), 134.1(\mathrm{CH}), 141.5(\mathrm{C}), 150.3(\mathrm{C}), 157.7(\mathrm{C}), 174.3$ (C), 179.6 (C).EIMS m/z (\%): 465 ([M] $\left.]^{+}, 41\right), 409$ (100), 270 (19), 269 (27), 154 (8). HREIMS: 465.2878 (calcd for $\mathrm{C}_{29} \mathrm{H}_{39} \mathrm{O}_{4} \mathrm{~N},[\mathrm{M}]^{+} 465.2879$ ).

\section{2-(tert-butylamino)-5-hydroxy-3-(4-nitrophenyl)-6-undecylbenzofuran-4,7-dione}

(4b)

Following the general procedure described above, $30 \mathrm{mg}$ of embelin $(0.102 \mathrm{mmol})$, $15.4 \mathrm{mg}$ of aldehyde $(0.102 \mathrm{mmol}), 11.7 \mu \mathrm{L}$ of $t$-butyl isocyanide $(0.102 \mathrm{mmol})$ and 1.8 $\mathrm{mg}$ of EDDA (10 mol\%) in $2 \mathrm{~mL}$ of DCE were irradiated for $15 \mathrm{~min}$ at $180^{\circ} \mathrm{C}$. The solvent was removed under vacuum, and the crude product was purified by preparative-

TLC with $20 \%$ hexanes/EtOAc to yield $36.6 \mathrm{mg}(70 \%)$ of $\mathbf{4 b}$ as a dark green oil. ${ }^{1} \mathrm{H}$ $\operatorname{NMR}\left(500 \mathrm{MHz}, \mathrm{CDCl}_{3}\right) \delta 0.87(\mathrm{t}, J=6.5 \mathrm{~Hz}, 3 \mathrm{H}), 1.25(\mathrm{bs}, 16 \mathrm{H}), 1.46(\mathrm{~s}, 9 \mathrm{H}), 1.52$ (m, 2H), $2.47(\mathrm{t}, \mathrm{J}=7.4 \mathrm{~Hz}, 2 \mathrm{H}), 4.74(\mathrm{~s}, 1 \mathrm{H}), 7.62(\mathrm{~d}, J=8.7 \mathrm{~Hz}, 2 \mathrm{H}), 8.27(\mathrm{~d}, J=8.7$ $\mathrm{Hz}, 2 \mathrm{H}) .{ }^{13} \mathrm{C}-\mathrm{NMR}\left(100 \mathrm{MHz}, \mathrm{CDCl}_{3}\right) \delta 14.1\left(\mathrm{CH}_{3}\right), 22.5\left(\mathrm{CH}_{2}\right), 22.6\left(\mathrm{CH}_{2}\right), 28.5$ $\left(\mathrm{CH}_{2}\right), 29.3\left(\mathrm{CH}_{2}\right), 29.4\left(\mathrm{CH}_{2}\right), 29.5\left(\mathrm{CH}_{2}\right), 29.6\left(\mathrm{CH}_{2}\right), 29.7\left(\mathrm{CH}_{2} \times 2\right), 30.1\left(\mathrm{CH}_{3} \times 3\right)$, $31.9\left(\mathrm{CH}_{2}\right), 54.3(\mathrm{C}), 96.9(\mathrm{C}), 119.2(\mathrm{C}), 123.2(\mathrm{C}), 124.1(\mathrm{CH} \times 2), 129.2(\mathrm{CH} \times 2)$, 137.7 (C), 144.2 (C), 146.3 (C), 150.5 (C), 157.8 (C), 174.5 (C), 179.4 (C).EIMS m/z (\%): $510\left([\mathrm{M}]^{+}, 1\right), 454$ (100), 315 (21), 314 (30), 277 (10).HREIMS: 510.2722 (calcd for $\mathrm{C}_{29} \mathrm{H}_{38} \mathrm{O}_{6} \mathrm{~N}_{2},[\mathrm{M}]^{+}$510.2730).

\section{3-(4-bromophenyl)-2-(tert-butylamino)-5-hydroxy-6-undecylbenzofuran-4,7-dione}

(4c)

Following the general procedure described above, $30 \mathrm{mg}$ of embelin $(0.102 \mathrm{mmol})$, $18.87 \mathrm{mg}$ of aldehyde $(0.102 \mathrm{mmol}), 11.7 \mu \mathrm{L}$ of $t$-butyl isocyanide $(0.102 \mathrm{mmol})$ and $1.8 \mathrm{mg}$ of EDDA (10 mol\%) in $2 \mathrm{~mL}$ of DCE were irradiated for $15 \mathrm{~min}$ at $180^{\circ} \mathrm{C}$. The 
solvent was removed under vacuum, and the crude product was purified by preparativeTLC with $20 \%$ hexanes/EtOAc to yield $45.3 \mathrm{mg}(82 \%)$ of $4 \mathbf{c}$ as a dark green oil. ${ }^{1} \mathrm{H}-$ NMR (500 MHz, CDCl $\left.)_{3}\right) \delta 0.88(\mathrm{t}, J=7.0 \mathrm{~Hz}, 3 \mathrm{H}), 1.25(\mathrm{bs}, 18 \mathrm{H}), 1.42(\mathrm{~s}, 9 \mathrm{H}), 2.46(\mathrm{t}$, $J=7.6 \mathrm{~Hz}, 2 \mathrm{H}), 4.54(\mathrm{bs}, 1 \mathrm{H}), 6.85(\mathrm{bs}, 1 \mathrm{H}), 7.31(\mathrm{~d}, J=8.4 \mathrm{~Hz}, 2 \mathrm{H}), 7.56(\mathrm{~d}, J=8.5 \mathrm{~Hz}$, 2H). ${ }^{13} \mathrm{C}-\mathrm{NMR}\left(150 \mathrm{MHz}, \mathrm{CDCl}_{3}\right) \delta 14.2\left(\mathrm{CH}_{3}\right), 22.5\left(\mathrm{CH}_{2}\right), 27.9\left(\mathrm{CH}_{2}\right), 28.2\left(\mathrm{CH}_{2}\right)$, $28.3\left(\mathrm{CH}_{2}\right), 28.5\left(\mathrm{CH}_{2}\right), 29.3\left(\mathrm{CH}_{2}\right), 29.5\left(\mathrm{CH}_{2}\right), 29.6\left(\mathrm{CH}_{2} \times 2\right), 30.1\left(\mathrm{CH}_{3} \times 3\right), 31.9$ $\left(\mathrm{CH}_{2}\right), 53.9(\mathrm{C}), 60.4(\mathrm{C}), 94.8(\mathrm{C}), 119.2(\mathrm{C}), 121.4(\mathrm{C}), 123.5(\mathrm{C}), 130.5(\mathrm{CH} \times 2)$, 132.1 (CH x 2), 143.6 (C), 150.3 (C), 157.5 (C), 174.3 (C), 179.5 (C).EIMS m/z (\%): $545\left([\mathrm{M}]^{+}, 37\right), 490$ (28), 489 (100), 488 (29), 487 (98), 349 (19), 348 (32), 346 (30), 57 (40).HREIMS: 545.1978 (calcd for $\mathrm{C}_{29} \mathrm{H}_{38} \mathrm{O}_{4} \mathrm{~N}^{81} \mathrm{Br}$, $[\mathrm{M}]^{+}$545.1964) and 543.1966 (calcd for $\mathrm{C}_{29} \mathrm{H}_{38} \mathrm{O}_{4} \mathrm{~N}^{79} \mathrm{Br},[\mathrm{M}]^{+}$543.1984).

\section{3-(benzo[d][1,3]dioxol-5-yl)-2-(tert-butylamino)-5-hydroxy-6-undecylbenzofuran-}

\section{4,7-dione (4d)}

Following the general procedure described above, $30 \mathrm{mg}$ of embelin $(0.102 \mathrm{mmol})$, $15.47 \mathrm{mg}$ of aldehyde $(0.102 \mathrm{mmol}), 11.7 \mu \mathrm{L}$ of $t$-butyl isocyanide $(0.102 \mathrm{mmol})$ and 1.8 $\mathrm{mg}$ of EDDA (10 mol\%) in $2 \mathrm{~mL}$ of DCE were irradiated for $15 \mathrm{~min}$ at $180^{\circ} \mathrm{C}$. The solvent was removed under vacuum, and the crude product was purified by preparativeTLC with $20 \%$ hexanes/EtOAc to yield $43.1 \mathrm{mg}(83 \%)$ of $\mathbf{4 d}$ as a dark green oil. ${ }^{1} \mathrm{H}$ $\operatorname{NMR}\left(400 \mathrm{MHz}, \mathrm{CDCl}_{3}\right) \delta 0.87(\mathrm{t}, J=7.1 \mathrm{~Hz}, 3 \mathrm{H}), 1.25$ (bs, 16H), $1.50(\mathrm{~m}, 2 \mathrm{H}), 1.41$ (s, 9H), $1.46(\mathrm{~m}, 2 \mathrm{H}), 2.46(\mathrm{t}, J=7.4 \mathrm{~Hz}, 2 \mathrm{H}), 4.54(\mathrm{~s}, 1 \mathrm{H}), 6.01(\mathrm{~s}, 2 \mathrm{H}), 6.83(\mathrm{~s}, 1 \mathrm{H})$, $6.86(\mathrm{~d}, J=1.2 \mathrm{~Hz}, 1 \mathrm{H}), 6.91(\mathrm{~d} . J=1.2 \mathrm{~Hz}, 1 \mathrm{H}) .{ }^{13} \mathrm{C}-\mathrm{NMR}\left(100 \mathrm{MHz}, \mathrm{CDCl}_{3}\right) \delta 14.1$ $\left(\mathrm{CH}_{3}\right), 22.6\left(\mathrm{CH}_{2}\right), 22.7\left(\mathrm{CH}_{2}\right), 28.5\left(\mathrm{CH}_{2}\right), 29.3\left(\mathrm{CH}_{2}\right), 29.4\left(\mathrm{CH}_{2}\right), 29.5\left(\mathrm{CH}_{2}\right), 29.6$ $\left(\mathrm{CH}_{2}\right), 29.7\left(\mathrm{CH}_{2} \times 3\right), 30.1\left(\mathrm{CH}_{3} \times 3\right), 31.9\left(\mathrm{CH}_{2}\right), 53.9\left(\mathrm{CH}_{2}\right), 99.5(\mathrm{C}), 101.3\left(\mathrm{CH}_{2}\right)$, $108.7(\mathrm{CH}), 109.6(\mathrm{CH}), 119.1(\mathrm{C}), 122.2(\mathrm{CH}), 123.7(\mathrm{C}), 143.4(\mathrm{C}), 147.2(\mathrm{C}), 148.2$ 
(C), 150.3 (C), 157.7 (C), 174.2 (C), 179.7 (C). EIMS m/z (\%): 509 ([M] $\left.]^{+}, 1\right), 453$

(100), 314 (17), 313 (27). HREIMS: 509.2778 (calcd for $\mathrm{C}_{30} \mathrm{H}_{39} \mathrm{O}_{6} \mathrm{~N},[\mathrm{M}]^{+}$509.2777).

2-(tert-butylamino)-3-(3-fluorophenyl)-5-hydroxy-6-undecylbenzofuran-4,7-dione

(4e)

Following the general procedure described above, $30 \mathrm{mg}$ of embelin $(0.102 \mathrm{mmol})$, $11.05 \mu \mathrm{L}$ of aldehyde $(0.102 \mathrm{mmol}), 11.7 \mu \mathrm{L}$ of $t$-butyl isocyanide $(0.102 \mathrm{mmol})$ and $1.8 \mathrm{mg}$ of EDDA $(10 \mathrm{~mol} \%)$ in $2 \mathrm{~mL}$ of DCE were irradiated for $15 \mathrm{~min}$ at $180^{\circ} \mathrm{C}$. The solvent was removed under vacuum, and the crude product was purified by preparativeTLC with $20 \%$ hexanes/EtOAc to yield $33.7 \mathrm{mg}(68 \%)$ of $\mathbf{4 e}$ as a dark blue oil. ${ }^{1} \mathrm{H}-\mathrm{NMR}$ $\left(400 \mathrm{MHz}, \mathrm{CDCl}_{3}\right) \delta 0.87(\mathrm{t}, J=7.1 \mathrm{~Hz}, 3 \mathrm{H}), 1.25(\mathrm{bs}, 16 \mathrm{H}), 1.43(\mathrm{~s}, 9 \mathrm{H}), 1.50(\mathrm{~m}, 2 \mathrm{H})$, $2.46(\mathrm{t}, \mathrm{J}=7.2 \mathrm{~Hz}, 2 \mathrm{H}), 4.62(\mathrm{~s}, 1 \mathrm{H}), 6.86(\mathrm{~s}, 1 \mathrm{H}), 7.02(\mathrm{dt}, J=8.5,1.8 \mathrm{~Hz}, 1 \mathrm{H}), 7.14$ $(\mathrm{dd}, J=10.1,2.0 \mathrm{~Hz}, 1 \mathrm{H}), 7.20(\mathrm{~d}, J=8.0 \mathrm{~Hz}, 1 \mathrm{H}), 7.40(\mathrm{dd}, J=9.8,1.8 \mathrm{~Hz}, 1 \mathrm{H}) .{ }^{13} \mathrm{C}-$ NMR (100 MHz, $\left.\mathrm{CDCl}_{3}\right) \delta 14.1\left(\mathrm{CH}_{3}\right), 22.6\left(\mathrm{CH}_{2}\right), 22.7\left(\mathrm{CH}_{2}\right), 28.5\left(\mathrm{CH}_{2}\right), 29.3\left(\mathrm{CH}_{2}\right)$, $29.4\left(\mathrm{CH}_{2}\right), 29.5\left(\mathrm{CH}_{2}\right), 29.6\left(\mathrm{CH}_{2}\right), 29.7\left(\mathrm{CH}_{2} \times 2\right), 30.1\left(\mathrm{CH}_{3} \times 3\right), 31.9\left(\mathrm{CH}_{2}\right), 54.0$ (C), $98.2(\mathrm{C}), 114.4\left(\mathrm{CH}, J_{C F}=20.9 \mathrm{~Hz}\right), 115.8\left(\mathrm{CH}, J_{C F}=22.1 \mathrm{~Hz}\right), 119.1(\mathrm{C}), 123.6$ (C), $124.3\left(\mathrm{CH}, J_{C F}=1.7 \mathrm{~Hz}\right), 130.4\left(\mathrm{CH}, J_{C F}=8.9 \mathrm{~Hz}\right), 132.5\left(\mathrm{C}, J_{C F}=8.3 \mathrm{~Hz}\right), 143.7$ (C), $150.4(\mathrm{C}), 157.6(\mathrm{C}), 163.0\left(\mathrm{CH}, J_{C F}=245.2 \mathrm{~Hz}\right), 174.4(\mathrm{C}), 179.5(\mathrm{C}) . \mathrm{EIMS} \mathrm{m} / \mathrm{z}$ (\%): $483\left([\mathrm{M}]^{+}, 1\right), 427$ (100), 294 (38), 288 (22), 287 (33). HREIMS: 483.2763 (calcd for $\mathrm{C}_{29} \mathrm{H}_{38} \mathrm{O}_{4} \mathrm{NF},[\mathrm{M}]^{+}$483.2785).

\section{2-(tert-butylamino)-3-(4-chlorophenyl)-5-hydroxy-6-undecylbenzofuran-4,7-dione}

(4f)

Following the general procedure described above, $30 \mathrm{mg}$ of embelin $(0.102 \mathrm{mmol})$, $14.78 \mathrm{mg}$ of aldehyde $(0.102 \mathrm{mmol}), 11.7 \mu \mathrm{L}$ of $t$-butyl isocyanide $(0.102 \mathrm{mmol})$ and $1.8 \mathrm{mg}$ of EDDA (10 mol\%) in $2 \mathrm{~mL}$ of DCE were irradiated for $15 \mathrm{~min}$ at $180^{\circ} \mathrm{C}$. The solvent was removed under vacuum, and the crude product was purified by preparative- 
TLC with $20 \%$ hexanes/EtOAc to yield $40.1 \mathrm{mg}(79 \%)$ of $\mathbf{4 a}$ as a dark green oil. ${ }^{1} \mathrm{H}-$ NMR (500 MHz, $\left.\mathrm{CDCl}_{3}\right) \delta 0.88(\mathrm{t}, J=6.9 \mathrm{~Hz}, 3 \mathrm{H}), 1.25(\mathrm{bs}, 14 \mathrm{H}), 1.39(\mathrm{~m}, 2 \mathrm{H}), 1.42$ (s, 9H), 1.49 (m, 2H), $2.46(\mathrm{t}, J=7.6 \mathrm{~Hz}, 2 \mathrm{H}), 7.36(\mathrm{~d}, J=8.7 \mathrm{~Hz}, 2 \mathrm{H}), 7.41(\mathrm{~d}, J=8.7$

$\mathrm{Hz}, 2 \mathrm{H}) .{ }^{13} \mathrm{C}-\mathrm{NMR}\left(125 \mathrm{MHz}, \mathrm{CDCl}_{3}\right) \delta 14.1\left(\mathrm{CH}_{3}\right), 22.6\left(\mathrm{CH}_{2}\right), 27.9\left(\mathrm{CH}_{2}\right), 28.3$ $\left(\mathrm{CH}_{2}\right), 28.4\left(\mathrm{CH}_{2}\right), 28.5\left(\mathrm{CH}_{2}\right), 29.3\left(\mathrm{CH}_{2}\right), 29.5\left(\mathrm{CH}_{2}\right), 29.6\left(\mathrm{CH}_{2} \times 2\right), 30.1\left(\mathrm{CH}_{3} \times 3\right)$, $31.9\left(\mathrm{CH}_{2}\right), 54.0(\mathrm{C}), 98.4(\mathrm{C}), 119.2(\mathrm{C}), 123.7(\mathrm{C}), 127.0(\mathrm{C}), 129.1(\mathrm{CH} \times 2), 130.2$ (CH x 2), 133.3 (C), 143.7 (C), 150.4 (C), 157.6 (C), 174.3 (C), 179.6 (C). EIMS m/z (\%): 499 ([M] $\left.]^{+}, 30\right), 445$ (38), 443 (100), 303 (28), 302 (37), 57 (27). HREIMS: 499.2493 (calcd for $\mathrm{C}_{29} \mathrm{H}_{38} \mathrm{O}_{4} \mathrm{NCl},[\mathrm{M}]^{+} 499.2489$ ).

\section{2-(tert-butylamino)-3-(4-fluorophenyl)-5-hydroxy-6-undecylbenzofuran-4,7-dione}

(4g)

Following the general procedure described above, $30 \mathrm{mg}$ of embelin $(0.102 \mathrm{mmol})$, $11.70 \mu \mathrm{L}$ of aldehyde $(0.102 \mathrm{mmol}), 11.7 \mu \mathrm{L}$ of $t$-butyl isocyanide $(0.102 \mathrm{mmol})$ and $1.8 \mathrm{mg}$ of EDDA $(10 \mathrm{~mol} \%)$ in $2 \mathrm{~mL}$ of DCE were irradiated for $15 \mathrm{~min}$ at $180^{\circ} \mathrm{C}$. The solvent was removed under vacuum, and the crude product was purified by preparativeTLC with $20 \%$ hexanes/EtOAc to yield $32.7 \mathrm{mg}(66 \%)$ of $\mathbf{4 g}$ as a dark blue oil. ${ }^{1} \mathrm{H}-$ $\operatorname{NMR}\left(500 \mathrm{MHz}, \mathrm{CDCl}_{3}\right) \delta 0.88(\mathrm{t}, J=6.8 \mathrm{~Hz}, 3 \mathrm{H}), 1.25(\mathrm{bs}, 16 \mathrm{H}), 1.42(\mathrm{~s}, 9 \mathrm{H}), 1.49$ (m, 2H), $2.46(\mathrm{t}, J=7.4 \mathrm{~Hz}, 2 \mathrm{H}), 4.49$ (bs, 1H), 6.83 (bs, 1H), $7.13(\mathrm{t}, J=8.6 \mathrm{~Hz}, 2 \mathrm{H})$, $7.40(\mathrm{~m}, 2 \mathrm{H}) .{ }^{13} \mathrm{C}-\mathrm{NMR}\left(100 \mathrm{MHz}, \mathrm{CDCl}_{3}\right) \delta 14.1\left(\mathrm{CH}_{3}\right), 22.6\left(\mathrm{CH}_{2}\right), 22.7\left(\mathrm{CH}_{2}\right), 28.5$ $\left(\mathrm{CH}_{2}\right), 29.3\left(\mathrm{CH}_{2}\right), 29.4\left(\mathrm{CH}_{2}\right), 39.5\left(\mathrm{CH}_{2}\right), 29.6\left(\mathrm{CH}_{2} \times 2\right), 29.7\left(\mathrm{CH}_{2}\right), 30.1\left(\mathrm{CH}_{3} \times 3\right)$, $31.9\left(\mathrm{CH}_{2}\right), 53.9(\mathrm{C}), 98.8(\mathrm{C}), 115.9\left(\mathrm{CH} x 2, J_{C F}=21.6 \mathrm{~Hz}\right), 119.2(\mathrm{C}), 124.0(\mathrm{C})$, $126.7(\mathrm{C}), 130.7\left(\mathrm{CH}\right.$ x $\left.2, J_{C F}=8.3 \mathrm{~Hz}\right), 143.6(\mathrm{C}), 150.3(\mathrm{C}), 157.5(\mathrm{C}), 162.1\left(\mathrm{C}, J_{C F}=\right.$ $246.5 \mathrm{~Hz}), 174.3$ (C), 179.6 (C). EIMS m/z (\%): 483 ([M] $\left.]^{+}, 1\right), 427$ (100), 294 (38), 288 (7), 287 (11). HREIMS: 483.2771 (calcd for $\mathrm{C}_{29} \mathrm{H}_{38} \mathrm{O}_{4} \mathrm{NF}$, [M] $]^{+}$483.2785). 
2-(tert-butylamino)-3-(3,4-dimethoxyphenyl)-5-hydroxy-6-undecylbenzofuran-4,7dione (4h)

Following the general procedure described above, $30 \mathrm{mg}$ of embelin $(0.102 \mathrm{mmol})$, $16.95 \mathrm{mg}$ of aldehyde $(0.102 \mathrm{mmol}), 11.7 \mu \mathrm{L}$ of $t$-butyl isocyanide $(0.102 \mathrm{mmol})$ and 1.8 $\mathrm{mg}$ of EDDA $(10 \mathrm{~mol} \%)$ in $2 \mathrm{~mL}$ of DCE were irradiated for $15 \mathrm{~min}$ at $180^{\circ} \mathrm{C}$. The solvent was removed under vacuum, and the crude product was purified by preparativeTLC with $20 \%$ hexanes/EtOAc to yield $39.8 \mathrm{mg}(75 \%)$ of $\mathbf{4 h}$ as a dark green oil. ${ }^{1} \mathrm{H}-$ $\operatorname{NMR}\left(500 \mathrm{MHz}, \mathrm{CDCl}_{3}\right) \delta 0.88(\mathrm{t}, J=6.7 \mathrm{~Hz}, 3 \mathrm{H}), 1.25(\mathrm{bs}, 16 \mathrm{H}), 1.45$ (bs, 9H), 1.48 (m, 2H), 2.47 (t, J=7.6 Hz, 2H), 3.91 (s, 3H), 3.93 (s, 3H), 4.62 (bs, 1H), 6.87 (bs, 1H), $6.95(\mathrm{~m}, 2 \mathrm{H}), 7.02$ (bs, 1H). ${ }^{13} \mathrm{C}-\mathrm{NMR}\left(125 \mathrm{MHz}, \mathrm{CDCl}_{3}\right) \delta 14.1\left(\mathrm{CH}_{3}\right), 22.7\left(\mathrm{CH}_{2}\right)$, $28.3\left(\mathrm{CH}_{2}\right), 28.6\left(\mathrm{CH}_{2}\right), 29.3\left(\mathrm{CH}_{2}\right), 29.5\left(\mathrm{CH}_{2}\right), 29.6\left(\mathrm{CH}_{2} \times 2\right), 29.7\left(\mathrm{CH}_{2} \times 2\right), 30.6$ $\left(\mathrm{CH}_{3} \times 3\right), 31.9\left(\mathrm{CH}_{2}\right), 53.9(\mathrm{C}), 55.9\left(\mathrm{CH}_{3}\right), 56.0\left(\mathrm{CH}_{3}\right), 99.9(\mathrm{C}), 111.4(\mathrm{CH}), 112.7$ (CH), $119.1(\mathrm{C}), 120.7(\mathrm{CH}), 122.7$ (C), 123.8 (C), 143.4 (C), 148.5 (C), 149.1 (C), 150.3 (C), 157.7 (C), 174.2 (C), 179.7 (C). EIMS m/z (\%): 525 ([M] $\left.]^{+}, 33\right), 469(60), 300$ (37), 285 (86), 256 (31), 239 (70), 197 (36), 165 (30), 146 (32), 129 (61), 115 (33), 85 (33), 73 (100), 60 (85), 57 (90), 55 (84). HREIMS: 525.3063 (calcd for $\mathrm{C}_{31} \mathrm{H}_{43} \mathrm{O}_{6} \mathrm{~N}$, $[\mathrm{M}]^{+}$525.3090).

2-(tert-butylamino)-5-hydroxy-3-(4-methoxyphenyl)-6-undecylbenzofuran-4,7dione (4i)

Following the general procedure described above, $30 \mathrm{mg}$ of embelin $(0.102 \mathrm{mmol})$, $12.72 \mu \mathrm{L}$ of aldehyde $(0.102 \mathrm{mmol}), 11.7 \mu \mathrm{L}$ of $t$-butyl isocyanide $(0.102 \mathrm{mmol})$ and $1.8 \mathrm{mg}$ of EDDA (10 mol\%) in $2 \mathrm{~mL}$ of DCE were irradiated for $15 \mathrm{~min}$ at $180^{\circ} \mathrm{C}$. The solvent was removed under vacuum, and the crude product was purified by preparativeTLC with $20 \%$ hexanes/EtOAc to yield $41.7 \mathrm{mg}(83 \%)$ of $\mathbf{4 i}$ as a dark green oil. ${ }^{1} \mathrm{H}$ $\operatorname{NMR}\left(500 \mathrm{MHz}, \mathrm{CDCl}_{3}\right) \delta 0.87(\mathrm{t}, J=6.8 \mathrm{~Hz}, 3 \mathrm{H}), 1.25(\mathrm{bs}, 18 \mathrm{H}), 1.41(\mathrm{~s}, 9 \mathrm{H}), 2.46(\mathrm{t}$, 
$J=7.6 \mathrm{~Hz}, 2 \mathrm{H}), 3.85(\mathrm{~s}, 3 \mathrm{H}), 4.51(\mathrm{bs}, 1 \mathrm{H}), 6.82(\mathrm{bs}, 1 \mathrm{H}), 6.97(\mathrm{~d}, J=8.7 \mathrm{~Hz}, 2 \mathrm{H}), 7.35$ $(\mathrm{d}, J=8.7 \mathrm{~Hz}, 2 \mathrm{H}) .{ }^{13} \mathrm{C}-\mathrm{NMR}\left(125 \mathrm{MHz}, \mathrm{CDCl}_{3}\right) \delta 14.1\left(\mathrm{CH}_{3}\right), 22.6\left(\mathrm{CH}_{2}\right), 22.7\left(\mathrm{CH}_{2}\right)$, $28.6\left(\mathrm{CH}_{2}\right), 29.3\left(\mathrm{CH}_{2}\right), 29.5\left(\mathrm{CH}_{2}\right), 29.6\left(\mathrm{CH}_{2} \times 2\right), 29.7\left(\mathrm{CH}_{2} \times 2\right), 30.2\left(\mathrm{CH}_{3} \times 3\right)$, $31.9\left(\mathrm{CH}_{2}\right), 53.9(\mathrm{C}), 55.3\left(\mathrm{CH}_{3}\right), 99.8(\mathrm{C}), 114.3(\mathrm{CH} x 2), 119.2(\mathrm{C}), 122.2(\mathrm{C}), 124.0$ (C), 130.1 (CH x 2), 132.0 (C), 143.4 (C), 150.3 (C), 157.7 (C), 159.0 (C), 174.1 (C), EIMS m/z (\%): $495\left([\mathrm{M}]^{+}, 42\right), 439$ (100), 299 (50), 285 (65), 239 (47), 129 (42), 73 (72), 60 (57). HREIMS: 495.2987 (calcd for $\mathrm{C}_{30} \mathrm{H}_{41} \mathrm{O}_{5} \mathrm{~N},[\mathrm{M}]^{+}$495.2985).

\section{2-(tert-butylamino)-5-hydroxy-3-(thiophen-3-yl)-6-undecylbenzofuran-4,7-dione}

(4j)

Following the general procedure described above, $30 \mathrm{mg}$ of embelin $(0.102 \mathrm{mmol}), 9.10$ $\mu \mathrm{L}$ of aldehyde $(0.102 \mathrm{mmol}), 11.7 \mu \mathrm{L}$ of $t$-butyl isocyanide $(0.102 \mathrm{mmol})$ and $1.8 \mathrm{mg}$ of EDDA (10 mol\%) in $2 \mathrm{~mL}$ of DCE were irradiated for $15 \mathrm{~min}$ at $180^{\circ} \mathrm{C}$. The solvent was removed under vacuum, and the crude product was purified by preparative-TLC with $20 \%$ hexanes/EtOAc to yield $17.2 \mathrm{mg}(36 \%)$ of $\mathbf{4 j}$ as a dark blue oil. ${ }^{1} \mathrm{H}-\mathrm{NMR}$ (400 $\left.\mathrm{MHz}, \mathrm{CDCl}_{3}\right) \delta 0.87(\mathrm{t}, J=6.4 \mathrm{~Hz}, 3 \mathrm{H}), 1.25(\mathrm{bs}, 16 \mathrm{H}), 1.44(\mathrm{~s}, 9 \mathrm{H}), 1.49(\mathrm{~m}, 2 \mathrm{H}), 2.47$ $(\mathrm{t}, \mathrm{J}=7.4 \mathrm{~Hz}, 2 \mathrm{H}), 4.62(\mathrm{~s}, 1 \mathrm{H}), 7.33(\mathrm{dd}, J=4.8,0.8 \mathrm{~Hz}, 1 \mathrm{H}), 7.42(\mathrm{~m}, 1 \mathrm{H}), 7.46(\mathrm{dd}, J=$ 2.8, $1.2 \mathrm{~Hz}, 1 \mathrm{H}) .{ }^{13} \mathrm{C}-\mathrm{NMR}\left(100 \mathrm{MHz}, \mathrm{CDCl}_{3}\right) \delta 14.1\left(\mathrm{CH}_{3}\right), 22.6\left(\mathrm{CH}_{2}\right), 22.7\left(\mathrm{CH}_{2}\right)$, $28.3\left(\mathrm{CH}_{2}\right), 28.5\left(\mathrm{CH}_{2}\right), 29.3\left(\mathrm{CH}_{2}\right), 29.4\left(\mathrm{CH}_{2}\right), 29.5\left(\mathrm{CH}_{2}\right), 29.6\left(\mathrm{CH}_{2}\right), 29.7\left(\mathrm{CH}_{2}\right)$, $30.1\left(\mathrm{CH}_{3} \times 3\right), 31.9\left(\mathrm{CH}_{2}\right), 53.9(\mathrm{C}), 95.5(\mathrm{C}), 119.2(\mathrm{C}), 122.9(\mathrm{CH}), 126.1(\mathrm{CH}), 127.9$ (CH), 128.9 (C), $130.4(\mathrm{C}), 143.4(\mathrm{C}), 150.5$ (C), 157.7 (C), 174.2 (C), 179.6 (C). EIMS m/z (\%): 471 ([M] $\left.]^{+}, 1\right), 415$ (100), 294 (12), 276 (21), 275 (29). HREIMS: 471.2448 (calcd for $\mathrm{C}_{27} \mathrm{H}_{37} \mathrm{O}_{4} \mathrm{NS},[\mathrm{M}]^{+}$471.2443).

2-(tert-butylamino)-5-hydroxy-3-(pyridin-3-yl)-6-undecylbenzofuran-4,7-dione (4k)

Following the general procedure described above, $30 \mathrm{mg}$ of embelin $(0.102 \mathrm{mmol})$, $10.00 \mu \mathrm{L}$ of aldehyde $(0.102 \mathrm{mmol}), 11.7 \mu \mathrm{L}$ of $t$-butyl isocyanide $(0.102 \mathrm{mmol})$ and 
$1.8 \mathrm{mg}$ of EDDA $(10 \mathrm{~mol} \%)$ in $2 \mathrm{~mL}$ of DCE were irradiated for $15 \mathrm{~min}$ at $180^{\circ} \mathrm{C}$. The solvent was removed under vacuum, and the crude product was purified by preparativeTLC with $20 \%$ hexanes/EtOAc to yield $14.8 \mathrm{mg}(31 \%)$ of $\mathbf{4 k}$ as a dark green oil. ${ }^{1} \mathrm{H}$ $\operatorname{NMR}\left(400 \mathrm{MHz}, \mathrm{CDCl}_{3}\right) \delta 0.87(\mathrm{t}, J=6.7 \mathrm{~Hz}, 3 \mathrm{H}), 1.25(\mathrm{bs}, 16 \mathrm{H}), 1.43(\mathrm{~s}, 9 \mathrm{H}), 1.50$ (m, 2H), $2.48(\mathrm{t}, J=7.4 \mathrm{~Hz}, 2 \mathrm{H}), 4.55(\mathrm{~s}, 1 \mathrm{H}), 7.38(\mathrm{dd}, J=8.5,5.5 \mathrm{~Hz}, 1 \mathrm{H}), 7.80(\mathrm{td}, J=$ 8.2, $1.7 \mathrm{~Hz}, 1 \mathrm{H}), 8.56(\mathrm{dd}, J=7.4,1.2 \mathrm{~Hz}, 1 \mathrm{H}), 8.71(\mathrm{~d}, J=1.6 \mathrm{~Hz}, 1 \mathrm{H}) .{ }^{13} \mathrm{C}-\mathrm{NMR}(100$ $\left.\mathrm{MHz}, \mathrm{CDCl}_{3}\right) \delta 14.1\left(\mathrm{CH}_{3}\right), 22.6\left(\mathrm{CH}_{2}\right), 22.7\left(\mathrm{CH}_{2}\right), 28.5\left(\mathrm{CH}_{2}\right), 29.3\left(\mathrm{CH}_{2}\right), 29.4$ $\left(\mathrm{CH}_{2}\right), 29.5\left(\mathrm{CH}_{2}\right), 29.6\left(\mathrm{CH}_{2}\right), 29.7\left(\mathrm{CH}_{2} \times 2\right), 30.1\left(\mathrm{CH}_{3} \times 3\right), 31.9\left(\mathrm{CH}_{2}\right), 54.2(\mathrm{C})$, 95.9 (C), $119.3(\mathrm{C}), 123.6(\mathrm{CH}), 123.7$ (C), 126.8 (C), $136.7(\mathrm{CH}), 144.1(\mathrm{C}), 148.3$ (CH), $149.3(\mathrm{CH}), 150.7$ (C), 157.7 (C), 174.5 (C), 179.6 (C). EIMS m/z (\%): 466 $\left([\mathrm{M}]^{+}, 1\right), 410$ (100), 270 (18), 269 (27), 268 (12). HREIMS: 466.2822 (calcd for $\mathrm{C}_{28} \mathrm{H}_{38} \mathrm{O}_{4} \mathrm{~N}_{2},[\mathrm{M}]^{+}$466.2832).

\section{2-(tert-butylamino)-3-(furan-3-yl)-5-hydroxy-6-undecylbenzofuran-4,7-dione (4l)}

Following the general procedure described above, $30 \mathrm{mg}$ of embelin $(0.102 \mathrm{mmol}), 8.78$ $\mu \mathrm{L}$ of aldehyde $(0.102 \mathrm{mmol}), 11.7 \mu \mathrm{L}$ of $t$-butyl isocyanide $(0.102 \mathrm{mmol})$ and $1.8 \mathrm{mg}$ of EDDA (10 mol\%) in $2 \mathrm{~mL}$ of DCE were irradiated for $15 \mathrm{~min}$ at $180^{\circ} \mathrm{C}$. The solvent was removed under vacuum, and the crude product was purified by preparative-TLC with $20 \%$ hexanes/EtOAc to yield $27.6 \mathrm{mg}(60 \%)$ of $\mathbf{4 l}$ as a dark blue oil. ${ }^{1} \mathrm{H}-\mathrm{NMR}$ (400 $\left.\mathrm{MHz}, \mathrm{CDCl}_{3}\right) \delta 0.87(\mathrm{t}, J=6.2 \mathrm{~Hz}, 3 \mathrm{H}), 1.25(\mathrm{bs}, 16 \mathrm{H}), 1.44(\mathrm{~s}, 9 \mathrm{H}), 1.51(\mathrm{~m}, 2 \mathrm{H}), 2.46$ $(\mathrm{t}, J=8.0 \mathrm{~Hz}, 2 \mathrm{H}), 6.74(\mathrm{~d}, J=1.2 \mathrm{~Hz}, 1 \mathrm{H}), 7.51(\mathrm{t}, J=1.5 \mathrm{~Hz}, 1 \mathrm{H}), 7.85(\mathrm{~d}, J=0.7 \mathrm{~Hz}$

1H). ${ }^{13} \mathrm{C}-\mathrm{NMR}\left(100 \mathrm{MHz}, \mathrm{CDCl}_{3}\right) \delta 14.1\left(\mathrm{CH}_{3}\right), 22.6\left(\mathrm{CH}_{2}\right), 22.7\left(\mathrm{CH}_{2}\right), 28.3\left(\mathrm{CH}_{2}\right)$, $28.4\left(\mathrm{CH}_{2}\right), 28.5\left(\mathrm{CH}_{2}\right), 29.3\left(\mathrm{CH}_{2}\right), 29.4\left(\mathrm{CH}_{2}\right), 29.5\left(\mathrm{CH}_{2}\right), 29.7\left(\mathrm{CH}_{2}\right), 30.1\left(\mathrm{CH}_{3} \mathrm{x}\right.$ 3), $31.9\left(\mathrm{CH}_{2}\right), 54.1(\mathrm{C}), 92.6(\mathrm{C}), 109.9(\mathrm{CH}), 114.9(\mathrm{CH}), 119.2(\mathrm{C}), 123.6(\mathrm{C}), 140.8$ (CH), $143.3(\mathrm{CH}), 150.3(\mathrm{C}), 153.3(\mathrm{C}), 157.2(\mathrm{C}), 174.4(\mathrm{C}), 179.5(\mathrm{C})$. EIMS m/z (\%): 
$455\left([\mathrm{M}]^{+}, 1\right), 400(23), 399$ (100), 315 (22), 258 (5). HREIMS: 455.2668 (calcd for $\mathrm{C}_{27} \mathrm{H}_{37} \mathrm{O}_{5} \mathrm{~N},[\mathrm{M}]^{+}$455.2672).

2'-(tert-butylamino)-5'-hydroxy-6'-undecyl-[2,3'-bibenzofuran]-4',7'-dione (4m)

Following the general procedure described above, $30 \mathrm{mg}$ of embelin $(0.102 \mathrm{mmol})$, $12.36 \mu \mathrm{L}$ of aldehyde $(0.102 \mathrm{mmol}), 11.7 \mu \mathrm{L}$ of $t$-butyl isocyanide $(0.102 \mathrm{mmol})$ and $1.8 \mathrm{mg}$ of EDDA (10 mol\%) in $2 \mathrm{~mL}$ of DCE were irradiated for $15 \mathrm{~min}$ at $180^{\circ} \mathrm{C}$. The solvent was removed under vacuum, and the crude product was purified by preparativeTLC with $20 \%$ hexanes/EtOAc to yield $30.4 \mathrm{mg}(59 \%)$ of $\mathbf{4 m}$ as a dark blue oil. ${ }^{1} \mathrm{H}-$ $\operatorname{NMR}\left(500 \mathrm{MHz}, \mathrm{CDCl}_{3}\right) \delta 0.87(\mathrm{t}, J=6.8 \mathrm{~Hz}, 3 \mathrm{H}), 1.25(\mathrm{bs}, 16 \mathrm{H}), 1.55(\mathrm{~s}, 9 \mathrm{H}), 1.49$ (m, 2H), $2.48(\mathrm{t}, J=7.6 \mathrm{~Hz}, 2 \mathrm{H}), 6.45(\mathrm{bs}, 1 \mathrm{H}), 6.98(\mathrm{bs}, 1 \mathrm{H}), 7.23(\mathrm{~m}, 2 \mathrm{H}), 7.39(\mathrm{~m}$, 1H), $7.56(\mathrm{~m}, 1 \mathrm{H}), 7.63(\mathrm{~s}, 1 \mathrm{H}) .{ }^{13} \mathrm{C}-\mathrm{NMR}\left(125 \mathrm{MHz}, \mathrm{CDCl}_{3}\right) \delta 14.1\left(\mathrm{CH}_{3}\right), 22.6\left(\mathrm{CH}_{2}\right)$, $22.7\left(\mathrm{CH}_{2}\right), 28.3\left(\mathrm{CH}_{2}\right), 28.5\left(\mathrm{CH}_{2}\right), 29.4\left(\mathrm{CH}_{2}\right), 29.5\left(\mathrm{CH}_{2}\right), 29.6\left(\mathrm{CH}_{2}\right), 29.7\left(\mathrm{CH}_{2}\right)$, $30.0\left(\mathrm{CH}_{2}\right), 30.0\left(\mathrm{CH}_{3} \times 3\right), 31.9\left(\mathrm{CH}_{2}\right), 54.0(\mathrm{C}), 89.2(\mathrm{C}), 103.6(\mathrm{CH}), 110.2(\mathrm{CH})$, $119.3(\mathrm{C}), 120.9(\mathrm{CH}), 121.9(\mathrm{C}), 123.4(\mathrm{CH}), 123.8(\mathrm{CH}), 128.9(\mathrm{C}), 143.1(\mathrm{C}), 148.9$ (C), 150.2 (C), 153.4 (C), 158.3 (C), 173.8 (C), 179.1 (C). EIMS m/z (\%): 505 ([M] $]^{+}$, 44), 449 (100), 309 (20), 308 (32), 57 (8). HREIMS: 505.2803 (calcd for $\mathrm{C}_{31} \mathrm{H}_{39} \mathrm{O}_{5} \mathrm{~N}$, $[\mathrm{M}]^{+}$505.2828).

\section{2-(tert-butylamino)-5-hydroxy-3-propyl-6-undecylbenzofuran-4,7-dione (4n)}

Following the general procedure described above, $30 \mathrm{mg}$ of embelin $(0.102 \mathrm{mmol}), 9.20$ $\mu \mathrm{L}$ of aldehyde $(0.102 \mathrm{mmol}), 11.7 \mu \mathrm{L}$ of $t$-butyl isocyanide $(0.102 \mathrm{mmol})$ and $1.8 \mathrm{mg}$ of EDDA (10 mol\%) in $2 \mathrm{~mL}$ of DCE were irradiated for $15 \mathrm{~min}$ at $180^{\circ} \mathrm{C}$. The solvent was removed under vacuum, and the crude product was purified by preparative-TLC with $20 \%$ hexanes/EtOAc to yield $30.2 \mathrm{mg}(69 \%)$ of $\mathbf{4 n}$ as a dark green oil. ${ }^{1} \mathrm{H}-\mathrm{NMR}$ $\left(400 \mathrm{MHz}, \mathrm{CDCl}_{3}\right) \delta 0.87(\mathrm{t}, J=6.5 \mathrm{~Hz}, 3 \mathrm{H}), 0.92(\mathrm{t}, J=7.4 \mathrm{~Hz}, 3 \mathrm{H}), 1.25$ (bs, 16H), $1.36(\mathrm{bs}, 9 \mathrm{H}), 1.45(\mathrm{~m}, 2 \mathrm{H}), 1.56(\mathrm{~m}, 2 \mathrm{H}), 2.44(\mathrm{~m}, 4 \mathrm{H}), 6.84(\mathrm{~s}, 1 \mathrm{H}) .{ }^{13} \mathrm{C}-\mathrm{NMR}(100$ 
$\left.\mathrm{MHz}, \mathrm{CDCl}_{3}\right) \delta 13.8\left(\mathrm{CH}_{3}\right), 13.9\left(\mathrm{CH}_{3}\right), 22.5\left(\mathrm{CH}_{2}\right), 24.9\left(\mathrm{CH}_{2}\right), 27.9\left(\mathrm{CH}_{2}\right), 28.2$ $\left(\mathrm{CH}_{2}\right), 28.5\left(\mathrm{CH}_{2}\right), 29.3\left(\mathrm{CH}_{2}\right), 29.4\left(\mathrm{CH}_{2} \times 2\right), 29.6\left(\mathrm{CH}_{2} \times 3\right), 30.2\left(\mathrm{CH}_{3} \times 3\right), 31.9$ $\left(\mathrm{CH}_{2}\right), 53.9(\mathrm{C}), 103.5(\mathrm{C}), 119.4(\mathrm{C}), 125.1(\mathrm{C}), 144.2(\mathrm{C}), 150.3(\mathrm{C}), 157.3(\mathrm{C}), 174.5$ (C), 180.2 (C).EIMS m/z (\%): 431 ([M] $\left.]^{+}, 15\right), 375$ (100), 346 (12), 235 (24), 234 (25), 57 (15).HREIMS: 431.3052 (calcd for $\mathrm{C}_{26} \mathrm{H}_{41} \mathrm{O}_{4} \mathrm{~N}$, [M] $]^{+}$431.3036).

\section{2-(tert-butylamino)-3-hexyl-5-hydroxy-6-undecylbenzofuran-4,7-dione (40)}

Following the general procedure described above, $30 \mathrm{mg}$ of embelin $(0.102 \mathrm{mmol})$, $14.98 \mu \mathrm{L}$ of aldehyde $(0.102 \mathrm{mmol}), 11.7 \mu \mathrm{L}$ of $t$-butyl isocyanide $(0.102 \mathrm{mmol})$ and $1.8 \mathrm{mg}$ of EDDA $(10 \mathrm{~mol} \%)$ in $2 \mathrm{~mL}$ of DCE were irradiated for $15 \mathrm{~min}$ at $180^{\circ} \mathrm{C}$. The solvent was removed under vacuum, and the crude product was purified by preparativeTLC with $20 \%$ hexanes/EtOAc to yield $30.7 \mathrm{mg}(64 \%)$ of 40 as a brown oil. ${ }^{1} \mathrm{H}-\mathrm{NMR}$ $\left(400 \mathrm{MHz}, \mathrm{CDCl}_{3}\right) \delta 0.88(\mathrm{t}, J=6.1 \mathrm{~Hz}, 6 \mathrm{H}), 1.25(\mathrm{bs}, 14 \mathrm{H}), 1.36(\mathrm{~s}, 9 \mathrm{H}), 1.48(\mathrm{~m}, 4 \mathrm{H})$,

$2.44(\mathrm{t}, J=7.4 \mathrm{~Hz}, 4 \mathrm{H}), 3.67(\mathrm{~s}, 1 \mathrm{H}), 6.83(\mathrm{~s}, 1 \mathrm{H}) .{ }^{13} \mathrm{C}-\mathrm{NMR}\left(100 \mathrm{MHz}, \mathrm{CDCl}_{3}\right) \delta 14.0$ $\left(\mathrm{CH}_{3}\right), 14.1\left(\mathrm{CH}_{2}\right), 22.6\left(\mathrm{CH}_{2}\right), 22.7\left(\mathrm{CH}_{2}\right), 22.9\left(\mathrm{CH}_{2}\right), 28.5\left(\mathrm{CH}_{2}\right), 29.0\left(\mathrm{CH}_{2}\right), 29.3$ $\left(\mathrm{CH}_{2} \times 2\right), 29.4\left(\mathrm{CH}_{2}\right), 29.5\left(\mathrm{CH}_{2}\right), 29.6\left(\mathrm{CH}_{2} \times 2\right), 29.7\left(\mathrm{CH}_{2} \times 2\right), 30.3\left(\mathrm{CH}_{3} \times 3\right), 31.6$ $\left(\mathrm{CH}_{2}\right), 31.9\left(\mathrm{CH}_{2}\right), 53.9(\mathrm{C}), 103.9(\mathrm{C}), 119.4(\mathrm{C}), 125.0(\mathrm{C}), 144.3(\mathrm{C}), 150.3(\mathrm{C})$, 157.3 (C), 174.4 (C), 180.2 (C).EIMS m/z (\%): 473 ([M] $\left.]^{+}, 1\right), 417$ (100), $416(10), 346$ (10), 277 (16), 276 (12). HREIMS: 473.3488 (calcd for $\mathrm{C}_{29} \mathrm{H}_{47} \mathrm{O}_{4} \mathrm{~N},[\mathrm{M}]^{+}$473.3505).

\section{2-(cyclohexylamino)-5-hydroxy-3-phenyl-6-undecylbenzofuran-4,7-dione (5a)}

Following the general procedure described above, $30 \mathrm{mg}$ of embelin $(0.102 \mathrm{mmol})$, $10.46 \mu \mathrm{L}$ of aldehyde $(0.102 \mathrm{mmol}), 13.0 \mu \mathrm{L}$ of cyclohexyl isocyanide $(0.102 \mathrm{mmol})$ and $1.8 \mathrm{mg}$ of EDDA $(10 \mathrm{~mol} \%)$ in $2 \mathrm{~mL}$ of DCE were irradiated for $15 \mathrm{~min}$ at $180^{\circ} \mathrm{C}$. The solvent was removed under vacuum, and the crude product was purified by preparative-TLC with $20 \%$ hexanes/EtOAc to yield $28.1 \mathrm{mg}(56 \%)$ of $\mathbf{5 a}$ as a dark blue oil. ${ }^{1} \mathrm{H}-\mathrm{NMR}\left(500 \mathrm{MHz}, \mathrm{CDCl}_{3}\right) \delta 0.88(\mathrm{t}, J=7.1 \mathrm{~Hz}, 3 \mathrm{H}), 1.25$ (bs, $\left.18 \mathrm{H}\right), 1.37(\mathrm{~m}, 3 \mathrm{H})$, 
$1.50(\mathrm{~m}, 2 \mathrm{H}), 1.63(\mathrm{~m}, 1 \mathrm{H}), 1.73(\mathrm{~m}, 2 \mathrm{H}), 2.03(\mathrm{~m}, 2 \mathrm{H}), 2.47(\mathrm{t}, J=7.6 \mathrm{~Hz}, 2 \mathrm{H}), 3.70$ $(\mathrm{m}, 1 \mathrm{H}), 4.61(\mathrm{~d}, J=8.5 \mathrm{~Hz}, 1 \mathrm{H}), 6.83(\mathrm{bs}, 1 \mathrm{H}), 7.32(\mathrm{~m}, 1 \mathrm{H}), 7.44(\mathrm{~d}, J=4.4 \mathrm{~Hz}$ 4H). ${ }^{13} \mathrm{C}-\mathrm{NMR}\left(125 \mathrm{MHz}, \mathrm{CDCl}_{3}\right) \delta 14.1\left(\mathrm{CH}_{3}\right), 22.6\left(\mathrm{CH}_{2}\right), 22.7\left(\mathrm{CH}_{2}\right), 24.7\left(\mathrm{CH}_{2}\right)$, $25.4\left(\mathrm{CH}_{2}\right), 28.6\left(\mathrm{CH}_{2}\right), 29.3\left(\mathrm{CH}_{2}\right), 29.5\left(\mathrm{CH}_{2}\right), 29.6\left(\mathrm{CH}_{2} \times 3\right), 29.7\left(\mathrm{CH}_{2} \times 3\right), 31.9$ $\left(\mathrm{CH}_{2}\right), 34.0\left(\mathrm{CH}_{2}\right), 52.5(\mathrm{CH}), 97.3(\mathrm{C}), 119.1(\mathrm{C}), 124.6(\mathrm{C}), 127.4(\mathrm{CH}), 128.7(\mathrm{CH} x$ 2), $128.8(\mathrm{CH} \times 2), 130.2$ (C), 142.6 (C), 150.2 (C), 157.5 (C), 174.2 (C), 179.7 (C).EIMS m/z (\%): 491 ([M] $\left.]^{+}, 100\right), 409$ (45), 351 (53), 268 (62), 212 (13), 83 (19), 55 (58). HREIMS: 491.3072 (calcd for $\mathrm{C}_{31} \mathrm{H}_{41} \mathrm{O}_{4} \mathrm{~N},[\mathrm{M}]^{+}$491.3036).

\section{2-(cyclohexylamino)-5-hydroxy-3-(4-nitrophenyl)-6-undecylbenzofuran-4,7-dione}

(5b)

Following the general procedure described above, $30 \mathrm{mg}$ of embelin $(0.102 \mathrm{mmol})$, $15.40 \mathrm{mg}$ of aldehyde $(0.102 \mathrm{mmol}), 13.0 \mu \mathrm{L}$ of cyclohexyl isocyanide $(0.102 \mathrm{mmol})$ and $1.8 \mathrm{mg}$ of EDDA $(10 \mathrm{~mol} \%)$ in $2 \mathrm{~mL}$ of DCE were irradiated for $15 \mathrm{~min}$ at $180^{\circ} \mathrm{C}$. The solvent was removed under vacuum, and the crude product was purified by preparative-TLC with $20 \%$ hexanes/EtOAc to yield $29.5 \mathrm{mg}(54 \%)$ of $\mathbf{5 b}$ as a dark green oil. ${ }^{1} \mathrm{H}-\mathrm{NMR}\left(500 \mathrm{MHz}, \mathrm{CDCl}_{3}\right) \delta 0.88(\mathrm{t}, J=7.2 \mathrm{~Hz}, 3 \mathrm{H}), 1.25(\mathrm{bs}, 18 \mathrm{H}), 1.39$ (m, 3H), $1.77(\mathrm{~m}, 2 \mathrm{H}), 1.66(\mathrm{~m}, 1 \mathrm{H}), 1.76(\mathrm{~m}, 2 \mathrm{H}), 2.06(\mathrm{~m}, 2 \mathrm{H}), 2.47(\mathrm{t}, J=7.6 \mathrm{~Hz}$ 2H), $3.76(\mathrm{~m}, 1 \mathrm{H}), 4.85(\mathrm{~d}, J=8.1 \mathrm{~Hz}, 1 \mathrm{H}), 6.88$ (bs, 1H), $7.62(\mathrm{~d}, J=8.6 \mathrm{~Hz}, 2 \mathrm{H}), 8.24$ $(\mathrm{d}, J=8.5 \mathrm{~Hz}, 2 \mathrm{H}) .{ }^{13} \mathrm{C}-\mathrm{NMR}\left(125 \mathrm{MHz}, \mathrm{CDCl}_{3}\right) \delta 14.1\left(\mathrm{CH}_{3}\right), 22.6\left(\mathrm{CH}_{2}\right), 22.7\left(\mathrm{CH}_{2}\right)$, 24.7 $\left(\mathrm{CH}_{2}\right), 25.3\left(\mathrm{CH}_{2}\right), 28.5\left(\mathrm{CH}_{2}\right), 29.3\left(\mathrm{CH}_{2}\right), 29.5\left(\mathrm{CH}_{2}\right), 29.6\left(\mathrm{CH}_{2}\right.$ x 3$), 29.7\left(\mathrm{CH}_{2}\right.$ x 3), $31.9\left(\mathrm{CH}_{2}\right), 33.9\left(\mathrm{CH}_{2}\right), 52.5(\mathrm{CH}), 94.8(\mathrm{C}), 119.2(\mathrm{C}), 123.9(\mathrm{C}), 124.1(\mathrm{CHx} 2)$, 129.1 (CHx2), 137.7 (C), 143.3 (C), 146.1 (C), 150.5 (C), 157.7 (C), 174.5 (C), 179.5 (C). EIMS m/z (\%): 536 ([M] $\left.]^{+}, 100\right), 491$ (61), 454 (51), 396 (70), 314 (65), 83 (33), 55 (74). HREIMS: 536.2919 (calcd for $\mathrm{C}_{31} \mathrm{H}_{40} \mathrm{O}_{6} \mathrm{~N}_{2},[\mathrm{M}]^{+}$536.2886). 


\section{3-(4-bromophenyl)-2-(cyclohexylamino)-5-hydroxy-6-undecylbenzofuran-4,7-dione}

(5c)

Following the general procedure described above, $30 \mathrm{mg}$ of embelin $(0.102 \mathrm{mmol})$, $18.87 \mathrm{mg}$ of aldehyde $(0.102 \mathrm{mmol}), 13.0 \mu \mathrm{L}$ of cyclohexyl isocyanide $(0.102 \mathrm{mmol})$ and $1.8 \mathrm{mg}$ of EDDA $(10 \mathrm{~mol} \%)$ in $2 \mathrm{~mL}$ of DCE were irradiated for $15 \mathrm{~min}$ at $180^{\circ} \mathrm{C}$. The solvent was removed under vacuum, and the crude product was purified by preparative-TLC with $20 \%$ hexanes/EtOAc to yield $35.1 \mathrm{mg}(61 \%)$ of $\mathbf{5 c}$ as a dark green oil. ${ }^{1} \mathrm{H}-\mathrm{NMR}\left(500 \mathrm{MHz}, \mathrm{CDCl}_{3}\right) \delta 0.87(\mathrm{t}, J=7.0 \mathrm{~Hz}, 3 \mathrm{H}), 1.25(\mathrm{bs}, 18 \mathrm{H}), 1.38$ (m, 3H), $1.48(\mathrm{~m}, 2 \mathrm{H}), 1.63(\mathrm{~m}, 1 \mathrm{H}), 1.73(\mathrm{~m}, 2 \mathrm{H}), 2.02(\mathrm{~m}, 2 \mathrm{H}), 2.46(\mathrm{t}, J=7.4 \mathrm{~Hz}$, 2H), $3.69(\mathrm{~m}, 1 \mathrm{H}), 4.57$ (d, $J=8.6 \mathrm{~Hz}, 1 \mathrm{H}), 6.83(\mathrm{bs}, 1 \mathrm{H}), 7.31(\mathrm{~d}, J=8.5 \mathrm{~Hz}, 2 \mathrm{H}), 7.54$ $(\mathrm{d}, J=8.3 \mathrm{~Hz}, 2 \mathrm{H}) .{ }^{13} \mathrm{C}-\mathrm{NMR}\left(125 \mathrm{MHz}, \mathrm{CDCl}_{3}\right) \delta 14.1\left(\mathrm{CH}_{3}\right), 22.5\left(\mathrm{CH}_{2}\right), 22.7\left(\mathrm{CH}_{2}\right)$, $24.7\left(\mathrm{CH}_{2}\right), 25.3\left(\mathrm{CH}_{2}\right), 28.5\left(\mathrm{CH}_{2}\right), 29.3\left(\mathrm{CH}_{2}\right), 29.5\left(\mathrm{CH}_{2}\right), 29.6\left(\mathrm{CH}_{2}\right.$ x 3$), 29.7\left(\mathrm{CH}_{2}\right.$ x 3), $31.9\left(\mathrm{CH}_{2}\right), 33.9\left(\mathrm{CH}_{2}\right), 52.7(\mathrm{CH}), 94.8(\mathrm{C}), 119.2(\mathrm{C}), 123.9(\mathrm{C}), 124.1(\mathrm{CH}$ x 2), 129.1 (CH x 2), 137.7 (C), 143.3 (C), 146.1 (C), 150.5 (C), 157.7 (C), 174.5 (C), 179.5 (C). EIMS m/z (\%): 571 ([M] $\left.]^{+}, 100\right), 569$ (98), 430 (44), 428 (42), 348 (41), 346 (39),

83 (42), 55 (90). HREIMS: 571.2165 (calcd for $\mathrm{C}_{31} \mathrm{H}_{40} \mathrm{O}_{4} \mathrm{~N}^{81} \mathrm{Br},[\mathrm{M}]^{+}$571.2120) and 569.2117 (calcd for $\mathrm{C}_{31} \mathrm{H}_{40} \mathrm{O}_{4} \mathrm{~N}^{79} \mathrm{Br},[\mathrm{M}]^{+}$569.2141).

3-(benzo[d][1,3]dioxol-5-yl)-2-(cyclohexylamino)-5-hydroxy-6-undecylbenzofuran-

\section{4,7-dione (5d)}

Following the general procedure described above, $30 \mathrm{mg}$ of embelin $(0.102 \mathrm{mmol})$, $15.47 \mathrm{mg}$ of aldehyde $(0.102 \mathrm{mmol}), 13.0 \mu \mathrm{L}$ of cyclohexyl isocyanide $(0.102 \mathrm{mmol})$ and $1.8 \mathrm{mg}$ of EDDA (10 mol\%) in $2 \mathrm{~mL}$ of DCE were irradiated for $15 \mathrm{~min}$ at $180^{\circ} \mathrm{C}$. The solvent was removed under vacuum, and the crude product was purified by preparative-TLC with $20 \%$ hexanes/EtOAc to yield $32.2 \mathrm{mg}(59 \%)$ of $\mathbf{5 d}$ as a dark green oil. ${ }^{1} \mathrm{H}-\mathrm{NMR}\left(500 \mathrm{MHz}, \mathrm{CDCl}_{3}\right) \delta 0.88(\mathrm{t}, J=7.0 \mathrm{~Hz}, 3 \mathrm{H}), 1.25(\mathrm{bs}, 18 \mathrm{H}), 1.39$ 
(m, 3H), $1.49(\mathrm{~m}, 2 \mathrm{H}), 1.63(\mathrm{~m}, 1 \mathrm{H}), 1.73(\mathrm{~m}, 2 \mathrm{H}), 2.02(\mathrm{~m}, 2 \mathrm{H}), 2.46(\mathrm{t}, J=7.6 \mathrm{~Hz}$ 2H), $3.69(\mathrm{~m}, 1 \mathrm{H}), 4.57(\mathrm{~d}, J=8.4 \mathrm{~Hz}, 1 \mathrm{H}), 6.00(\mathrm{bs}, 1 \mathrm{H}), 6.86(\mathrm{bs}, 2 \mathrm{H}), 6.91(\mathrm{bs}, 2 \mathrm{H})$. ${ }^{13} \mathrm{C}-\mathrm{NMR}\left(125 \mathrm{MHz}, \mathrm{CDCl}_{3}\right) \delta 14.1\left(\mathrm{CH}_{3}\right), 22.6\left(\mathrm{CH}_{2}\right), 22.7\left(\mathrm{CH}_{2}\right), 24.7\left(\mathrm{CH}_{2}\right), 25.4$ $\left(\mathrm{CH}_{2}\right), 28.6\left(\mathrm{CH}_{2}\right), 29.3\left(\mathrm{CH}_{2}\right), 29.5\left(\mathrm{CH}_{2}\right), 29.6\left(\mathrm{CH}_{2} \times 3\right), 29.7\left(\mathrm{CH}_{2} \times 3\right), 31.9\left(\mathrm{CH}_{2}\right)$, $34.0\left(\mathrm{CH}_{2}\right), 52.5(\mathrm{CH}), 97.2(\mathrm{C}), 101.3\left(\mathrm{CH}_{2}\right), 108.7(\mathrm{CH}), 109.6(\mathrm{CH}), 119.2(\mathrm{C}), 122.2$ (CH x 2), 123.7 (C), 124.6 (C), 142.3 (C), 147.0 (C), 148.0 (C), 150.1 (C), 157.5 (C), 174.0 (C), 179.8 (C). EIMS m/z (\%): 535 ([M] $\left.]^{+}, 88\right), 534$ (100), 452 (70), 395 (46), 312 (59), 256 (32), 172 (27), 121 (45), 83 (60). HREIMS: 535.2922 (calcd for $\mathrm{C}_{32} \mathrm{H}_{41} \mathrm{O}_{6} \mathrm{~N}$, $[\mathrm{M}]^{+}$535.2934).

\section{2-(cyclohexylamino)-3-(3-fluorophenyl)-5-hydroxy-6-undecylbenzofuran-4,7-dione} (5e)

Following the general procedure described above, $30 \mathrm{mg}$ of embelin $(0.102 \mathrm{mmol})$, $11.05 \mu \mathrm{L}$ of aldehyde $(0.102 \mathrm{mmol}), 13.0 \mu \mathrm{L}$ of cyclohexyl isocyanide $(0.102 \mathrm{mmol})$ and $1.8 \mathrm{mg}$ of EDDA $(10 \mathrm{~mol} \%)$ in $2 \mathrm{~mL}$ of DCE were irradiated for $15 \mathrm{~min}$ at $180^{\circ} \mathrm{C}$. The solvent was removed under vacuum, and the crude product was purified by preparative-TLC with $20 \%$ hexanes/EtOAc to yield $33.1 \mathrm{mg}(64 \%)$ of $\mathbf{5 e}$ as a dark blue oil. ${ }^{1} \mathrm{H}-\mathrm{NMR}\left(500 \mathrm{MHz}, \mathrm{CDCl}_{3}\right) \delta 0.88(\mathrm{t}, J=7.0 \mathrm{~Hz}, 3 \mathrm{H}), 1.25$ (bs, $\left.18 \mathrm{H}\right), 1.38(\mathrm{~m}, 3 \mathrm{H})$, $1.48(\mathrm{~m}, 2 \mathrm{H}), 1.64(\mathrm{~m}, 1 \mathrm{H}), 1.74(\mathrm{~m}, 2 \mathrm{H}), 2.03(\mathrm{~m}, 2 \mathrm{H}), 2.46(\mathrm{t}, J=7.7 \mathrm{~Hz}, 2 \mathrm{H}), 3.71$ $(\mathrm{m}, 1 \mathrm{H}), 4.62(\mathrm{~d}, J=7.9 \mathrm{~Hz}, 1 \mathrm{H}), 6.86(\mathrm{bs}, 1 \mathrm{H}), 7.17(\mathrm{~m}, 1 \mathrm{H}), 7.21(\mathrm{~d}, J=7.9 \mathrm{~Hz}, 1 \mathrm{H})$, $7.31(\mathrm{~m}, 1 \mathrm{H}), 7.39(\mathrm{~m}, 1 \mathrm{H}) .{ }^{13} \mathrm{C}-\mathrm{NMR}\left(125 \mathrm{MHz}, \mathrm{CDCl}_{3}\right) \delta 14.1\left(\mathrm{CH}_{3}\right), 22.5\left(\mathrm{CH}_{2}\right)$, $22.7\left(\mathrm{CH}_{2}\right), 24.7\left(\mathrm{CH}_{2}\right), 25.4\left(\mathrm{CH}_{2}\right), 28.5\left(\mathrm{CH}_{2}\right), 29.3\left(\mathrm{CH}_{2}\right), 29.5\left(\mathrm{CH}_{2}\right), 29.6\left(\mathrm{CH}_{2} \mathrm{x}\right.$ 3), $29.7\left(\mathrm{CH}_{2} \times 3\right), 31.9\left(\mathrm{CH}_{2}\right), 34.0\left(\mathrm{CH}_{2}\right), 52.5(\mathrm{CH}), 96.0(\mathrm{C}), 114.3\left(\mathrm{CH}, J_{C F}=21.0\right.$ $\mathrm{Hz}), 115.8\left(\mathrm{CH}, J_{C F}=22.1 \mathrm{~Hz}\right), 119.1(\mathrm{C}), 121.2(\mathrm{C}), 124.3\left(\mathrm{CH}, J_{C F}=2.8 \mathrm{~Hz}\right), 130.3$ $\left(\mathrm{CH}, J_{C F}=8.5 \mathrm{~Hz}\right), 132.4\left(\mathrm{C}, J_{C F}=8.5 \mathrm{~Hz}\right), 142.8(\mathrm{C}), 150.3(\mathrm{C}), 157.4(\mathrm{C}), 163.0(\mathrm{C}$, $\left.J_{C F}=241.3 \mathrm{~Hz}\right), 174.3(\mathrm{C}), 179.6(\mathrm{C}) . \operatorname{EIMS~m} / \mathrm{z}(\%): 509$ ([M] $\left.]^{+}, 100\right), 427(44), 369$ 
(62), 286 (58), 83 (21), 55 (59). HREIMS: 509.2910 (calcd for $\mathrm{C}_{31} \mathrm{H}_{40} \mathrm{O}_{4} \mathrm{NF},[\mathrm{M}]^{+}$ 509.2941).

\section{3-(4-chlorophenyl)-2-(cyclohexylamino)-5-hydroxy-6-undecylbenzofuran-4,7-dione} (5f)

Following the general procedure described above, $30 \mathrm{mg}$ of embelin $(0.102 \mathrm{mmol})$, $14.78 \mathrm{mg}$ of aldehyde $(0.102 \mathrm{mmol}), 13.0 \mu \mathrm{L}$ of cyclohexyl isocyanide $(0.102 \mathrm{mmol})$ and $1.8 \mathrm{mg}$ of EDDA $(10 \mathrm{~mol} \%)$ in $2 \mathrm{~mL}$ of DCE were irradiated for $15 \mathrm{~min}$ at $180^{\circ} \mathrm{C}$. The solvent was removed under vacuum, and the crude product was purified by preparative-TLC with $20 \%$ hexanes/EtOAc to yield $31.2 \mathrm{mg}(57 \%)$ of $\mathbf{5 f}$ as a dark blue oil. ${ }^{1} \mathrm{H}-\mathrm{NMR}\left(500 \mathrm{MHz}, \mathrm{CDCl}_{3}\right) \delta 0.87$ (t, $\left.J=7.1 \mathrm{~Hz}, 3 \mathrm{H}\right), 1.24$ (bs, $\left.18 \mathrm{H}\right), 1.42(\mathrm{~m}, 3 \mathrm{H})$, $1.63(\mathrm{~m}, 2 \mathrm{H}), 1.73(\mathrm{~m}, 2 \mathrm{H}), 2.02(\mathrm{~m}, 2 \mathrm{H}), 2.45(\mathrm{t}, \mathrm{J}=7.8 \mathrm{~Hz}, 2 \mathrm{H}), 4.50(\mathrm{~d}, J=8.4 \mathrm{~Hz}$, $1 \mathrm{H}), 6.79(\mathrm{bs}, 1 \mathrm{H}), 7.44(\mathrm{dd}, \mathrm{J}=8.7,1.9 \mathrm{~Hz}, 2 \mathrm{H}), 8.32(\mathrm{dd}, J=8.7,1.9 \mathrm{~Hz}, 2 \mathrm{H}) .{ }^{13} \mathrm{C}-$ NMR (250 MHz, $\left.\mathrm{CDCl}_{3}\right) \delta 14.1\left(\mathrm{CH}_{3}\right), 22.6\left(\mathrm{CH}_{2}\right), 22.7\left(\mathrm{CH}_{2}\right), 24.7\left(\mathrm{CH}_{2}\right), 25.3\left(\mathrm{CH}_{2}\right)$, $28.5\left(\mathrm{CH}_{2}\right), 29.3\left(\mathrm{CH}_{2}\right), 29.5\left(\mathrm{CH}_{2}\right), 29.6\left(\mathrm{CH}_{2} \times 3\right), 29.7\left(\mathrm{CH}_{2} \times 3\right), 31.9\left(\mathrm{CH}_{2}\right), 33.9$ $\left(\mathrm{CH}_{2}\right), 52.5(\mathrm{CH}), 96.1(\mathrm{C}), 119.2(\mathrm{C}), 124.4(\mathrm{C}), 126.9(\mathrm{C}), 128.6(\mathrm{CH} \times 2), 130.1(\mathrm{CH}$ x 2), 140.1 (C), 142.7 (C), 150.2 (C), 157.4 (C), 174.3 (C), 179.7 (C). EIMS m/z (\%): $526\left([\mathrm{M}]^{+}, 100\right), 294$ (96), 265 (30), 153 (95), 126 (55), 110 (25), 83 (87), 55 (73). HREIMS: 526.2654 (calcd for $\mathrm{C}_{31} \mathrm{H}_{40} \mathrm{O}_{4} \mathrm{NCl},[\mathrm{M}]^{+}$526.2646).

2-(cyclohexylamino)-3-(4-fluorophenyl)-5-hydroxy-6-undecylbenzofuran-4,7-dione $(5 \mathrm{~g})$

Following the general procedure described above, $30 \mathrm{mg}$ of embelin $(0.102 \mathrm{mmol})$, $11.16 \mu \mathrm{L}$ of aldehyde $(0.102 \mathrm{mmol}), 13.0 \mu \mathrm{L}$ of cyclohexyl isocyanide $(0.102 \mathrm{mmol})$ and $1.8 \mathrm{mg}$ of EDDA $(10 \mathrm{~mol} \%)$ in $2 \mathrm{~mL}$ of DCE were irradiated for $15 \mathrm{~min}$ at $180^{\circ} \mathrm{C}$. The solvent was removed under vacuum, and the crude product was purified by preparative-TLC with $20 \%$ hexanes/EtOAc to yield $34.8 \mathrm{mg}(66 \%)$ of $\mathbf{5 g}$ as a dark blue 
oil. ${ }^{1} \mathrm{H}-\mathrm{NMR}\left(500 \mathrm{MHz}, \mathrm{CDCl}_{3}\right) \delta 0.88(\mathrm{t}, J=7.0 \mathrm{~Hz}, 3 \mathrm{H}), 1.25$ (bs, $\left.18 \mathrm{H}\right), 1.36(\mathrm{~m}, 3 \mathrm{H})$, $1.49(\mathrm{~m}, 2 \mathrm{H}), 1.63(\mathrm{~m}, 1 \mathrm{H}), 1.73(\mathrm{~m}, 2 \mathrm{H}), 2.02(\mathrm{~m}, 2 \mathrm{H}), 2.46(\mathrm{t}, J=7.4 \mathrm{~Hz}, 2 \mathrm{H}), 3.69$ (m, 1H), 4.50 (bs, 1H), $6.81(\mathrm{bs}, 1 \mathrm{H}), 7.12(\mathrm{t}, J=8.7 \mathrm{~Hz}, 2 \mathrm{H}), 7.40(\mathrm{dd}, J=8.7,5.3 \mathrm{~Hz}$, 2H). ${ }^{13} \mathrm{C}-\mathrm{NMR}\left(125 \mathrm{MHz}, \mathrm{CDCl}_{3}\right) \delta 14.1\left(\mathrm{CH}_{3}\right), 22.6\left(\mathrm{CH}_{2}\right), 22.7\left(\mathrm{CH}_{2}\right), 24.7\left(\mathrm{CH}_{2}\right)$, $25.4\left(\mathrm{CH}_{2}\right), 28.5\left(\mathrm{CH}_{2}\right), 29.4\left(\mathrm{CH}_{2}\right), 29.5\left(\mathrm{CH}_{2} \times 2\right), 29.6\left(\mathrm{CH}_{2} \times 2\right), 29.7\left(\mathrm{CH}_{2} \times 2\right)$, $32.0\left(\mathrm{CH}_{2}\right), 34.0\left(\mathrm{CH}_{2}\right), 52.5(\mathrm{CH}), 96.4(\mathrm{C}), 115.7\left(\mathrm{CH}\right.$ x $\left.2, J_{C F}=21.6 \mathrm{~Hz}\right), 119.2(\mathrm{C})$, 124.5(C), $126.1(\mathrm{C}), 127.4(\mathrm{C}), 130.6\left(\mathrm{CH} \mathrm{x} \mathrm{2,} J_{C F}=8.1 \mathrm{~Hz}\right), 142.6(\mathrm{C}), 150.2(\mathrm{C})$, $157.4(\mathrm{C}), 161.2\left(\mathrm{C}, J_{C F}=246.3 \mathrm{~Hz}\right), 174.2(\mathrm{C}), 179.8$ (C). EIMS m/z (\%): 509 ([M] $]^{+}$, 100), 426 (45), 368 (56), 286 (55), 83 (31), 55 (64). HREIMS: 509.2910 (calcd for $\mathrm{C}_{31} \mathrm{H}_{40} \mathrm{O}_{4} \mathrm{NF},[\mathrm{M}]^{+}$509.2941).

\section{2-(cyclohexylamino)-3-(3,4-dimethoxyphenyl)-5-hydroxy-6-undecylbenzofuran-}

\section{4,7-dione (5h)}

Following the general procedure described above, $30 \mathrm{mg}$ of embelin $(0.102 \mathrm{mmol})$, $15.47 \mathrm{mg}$ of aldehyde $(0.102 \mathrm{mmol}), 13.0 \mu \mathrm{L}$ of cyclohexyl isocyanide $(0.102 \mathrm{mmol})$ and $1.8 \mathrm{mg}$ of EDDA $(10 \mathrm{~mol} \%)$ in $2 \mathrm{~mL}$ of DCE were irradiated for $15 \mathrm{~min}$ at $180^{\circ} \mathrm{C}$. The solvent was removed under vacuum, and the crude product was purified by preparative-TLC with $20 \%$ hexanes/EtOAc to yield $32.2 \mathrm{mg}(59 \%)$ of $\mathbf{5 h}$ as a dark green oil. ${ }^{1} \mathrm{H}-\mathrm{NMR}\left(500 \mathrm{MHz}, \mathrm{CDCl}_{3}\right) \delta 0.88(\mathrm{t}, J=7.0 \mathrm{~Hz}, 3 \mathrm{H}), 1.25(\mathrm{bs}, 18 \mathrm{H}), 1.39$ (m, 3H), $1.49(\mathrm{~m}, 2 \mathrm{H}), 1.63(\mathrm{~m}, 1 \mathrm{H}), 1.73(\mathrm{~m}, 2 \mathrm{H}), 2.03(\mathrm{~m}, 2 \mathrm{H}), 2.46(\mathrm{t}, J=7.7 \mathrm{~Hz}$, 2H), $3.70(\mathrm{~m}, 1 \mathrm{H}), 3.91(\mathrm{~s}, 6 \mathrm{H}), 4.64(\mathrm{~d}, J=8.5 \mathrm{~Hz}, 1 \mathrm{H}), 6.86$ (bs, 1H), 6.92 (bd, $J=8.3$ $\mathrm{Hz}, 1 \mathrm{H}), 6.95(\mathrm{dd}, J=8.2,1.9 \mathrm{~Hz}, 1 \mathrm{H}), 7.04(\mathrm{~d}, J=1.8 \mathrm{~Hz}, 1 \mathrm{H}) .{ }^{13} \mathrm{C}-\mathrm{NMR}(125 \mathrm{MHz}$, $\left.\mathrm{CDCl}_{3}\right) \delta 14.1\left(\mathrm{CH}_{3}\right), 22.6\left(\mathrm{CH}_{2}\right), 22.7\left(\mathrm{CH}_{2}\right), 24.7\left(\mathrm{CH}_{2}\right), 25.4\left(\mathrm{CH}_{2}\right), 28.6\left(\mathrm{CH}_{2}\right), 29.3$ $\left(\mathrm{CH}_{2}\right), 29.5\left(\mathrm{CH}_{2}\right), 29.6\left(\mathrm{CH}_{2} \times 3\right), 29.7\left(\mathrm{CH}_{2} \times 3\right), 34.0\left(\mathrm{CH}_{2}\right), 52.4(\mathrm{CH}), 56.0\left(\mathrm{CH}_{3} \mathrm{x}\right.$ 2), $97.5(\mathrm{C}), 111.4(\mathrm{CH}), 112.7(\mathrm{CH}), 119.1(\mathrm{CH}), 120.7(\mathrm{CH}), 122.6(\mathrm{C}), 124.6(\mathrm{C})$, 130.2 (C), 142.4 (C), 148.4 (C), 149.1 (C), 150.2 (C), 157.5 (C), 174.0 (C), 179.8 (C). 
EIMS m/z (\%): 551 ([M] $\left.]^{+}, 100\right), 469$ (11), 411 (16), 328 (11), 294 (15), 164 (25), 153 (26), 83 (10), 55 (25). HREIMS: 551.3206 (calcd for $\mathrm{C}_{33} \mathrm{H}_{45} \mathrm{O}_{6} \mathrm{~N},[\mathrm{M}]^{+}$551.3247).

2-(cyclohexylamino)-5-hydroxy-3-(4-methoxyphenyl)-6-undecylbenzofuran-4,7dione (5i)

Following the general procedure described above, $30 \mathrm{mg}$ of embelin $(0.102 \mathrm{mmol})$, $12.72 \mu \mathrm{L}$ of aldehyde $(0.102 \mathrm{mmol}), 13.0 \mu \mathrm{L}$ of cyclohexyl isocyanide $(0.102 \mathrm{mmol})$ and $1.8 \mathrm{mg}$ of EDDA (10 mol\%) in $2 \mathrm{~mL}$ of DCE were irradiated for $15 \mathrm{~min}$ at $180^{\circ} \mathrm{C}$. The solvent was removed under vacuum, and the crude product was purified by preparative-TLC with $20 \%$ hexanes/EtOAc to yield $29.7 \mathrm{mg}(56 \%)$ of $\mathbf{5 i}$ as a dark green oil. ${ }^{1} \mathrm{H}-\mathrm{NMR}\left(500 \mathrm{MHz}, \mathrm{CDCl}_{3}\right) \delta 0.88(\mathrm{t}, J=7.1 \mathrm{~Hz}, 3 \mathrm{H}), 1.25$ (bs, $\left.18 \mathrm{H}\right), 1.36(\mathrm{~m}, 3 \mathrm{H})$, $1.49(\mathrm{~m}, 2 \mathrm{H}), 1.63(\mathrm{~m}, 1 \mathrm{H}), 1.72(\mathrm{~m}, 2 \mathrm{H}), 2.02(\mathrm{~m}, 2 \mathrm{H}), 2.46(\mathrm{t}, J=7.6 \mathrm{~Hz}, 2 \mathrm{H}), 3.69$ (m, 1H), $3.84(\mathrm{~s}, 3 \mathrm{H}), 4.55(\mathrm{~d}, J=8.4 \mathrm{~Hz}, 1 \mathrm{H}), 6.83(\mathrm{bs}, 1 \mathrm{H}), 6.97(\mathrm{~d}, J=8.8 \mathrm{~Hz}, 2 \mathrm{H})$, $7.36(\mathrm{~d}, J=8.8 \mathrm{~Hz}, 2 \mathrm{H}) .{ }^{13} \mathrm{C}-\mathrm{NMR}\left(125 \mathrm{MHz}, \mathrm{CDCl}_{3}\right) \delta 14.1\left(\mathrm{CH}_{3}\right), 22.6\left(\mathrm{CH}_{2}\right), 22.7$ $\left(\mathrm{CH}_{2}\right), 24.7\left(\mathrm{CH}_{2}\right), 25.4\left(\mathrm{CH}_{2}\right), 28.6\left(\mathrm{CH}_{2}\right), 29.3\left(\mathrm{CH}_{2}\right), 29.5\left(\mathrm{CH}_{2}\right), 29.6\left(\mathrm{CH}_{2} \times 3\right)$, $29.7\left(\mathrm{CH}_{2} \times 3\right), 31.2\left(\mathrm{CH}_{2}\right), 34.0\left(\mathrm{CH}_{2}\right), 52.5(\mathrm{CH}), 55.3\left(\mathrm{CH}_{3}\right), 97.4(\mathrm{C}), 114.3(\mathrm{CH} x$ 2), 119.2 (C), 122.2 (C), 124.7 (C), 130.1(CH x 2), 142.4 (C), 150.1 (C), 157.4 (C), 158.9 (C), 174.0 (C), 179.8 (C). EIMS m/z (\%): 521 ([M] $\left.]^{+}, 100\right), 381$ (15), 299 (13), 294 (35), 153 (46), 135 (37), 83 (13), 56 (25), 55 (28). HREIMS: 521.3154 (calcd for $\mathrm{C}_{32} \mathrm{H}_{43} \mathrm{O}_{5} \mathrm{~N},[\mathrm{M}]^{+}$521.3141).

\section{2-(cyclohexylamino)-5-hydroxy-3-(thiophen-3-yl)-6-undecylbenzofuran-4,7-dione}

$(\mathbf{5 j})$

Following the general procedure described above, $30 \mathrm{mg}$ of embelin $(0.102 \mathrm{mmol}), 9.10$ $\mu \mathrm{L}$ of aldehyde $(0.102 \mathrm{mmol}), 13.0 \mu \mathrm{L}$ of cyclohexyl isocyanide $(0.102 \mathrm{mmol})$ and 1.8 $\mathrm{mg}$ of EDDA (10 mol\%) in $2 \mathrm{~mL}$ of DCE were irradiated for $15 \mathrm{~min}$ at $180^{\circ} \mathrm{C}$. The solvent was removed under vacuum, and the crude product was purified by preparative- 
TLC with $20 \%$ hexanes/EtOAc to yield $28.9 \mathrm{mg}(57 \%)$ of $\mathbf{5 j}$ as a dark green oil. ${ }^{1} \mathrm{H}-$ NMR (500 MHz, $\left.\mathrm{CDCl}_{3}\right) \delta 0.88(\mathrm{t}, J=7.0 \mathrm{~Hz}, 3 \mathrm{H}), 1.25(\mathrm{bs}, 18 \mathrm{H}), 1.39$ (m, 3H), 1.49 (m, 2H), $1.63(\mathrm{~m}, 1 \mathrm{H}), 1.73(\mathrm{~m}, 2 \mathrm{H}), 2.03(\mathrm{~m}, 2 \mathrm{H}), 2.46(\mathrm{t}, J=7.7 \mathrm{~Hz}, 2 \mathrm{H}), 3.70(\mathrm{~m}$, 1H), 3.91 (s, 6H), 4.64 (d, $J=8.5 \mathrm{~Hz}, 1 \mathrm{H}), 6.86$ (bs, 1H), $6.92(\mathrm{bd}, 1 \mathrm{H}), 6.95$ (d, $J=1.9$ $\mathrm{Hz}, 1 \mathrm{H}), 7.04(\mathrm{~d}, J=1.8 \mathrm{~Hz}, 1 \mathrm{H}) .{ }^{13} \mathrm{C}-\mathrm{NMR}\left(125 \mathrm{MHz}, \mathrm{CDCl}_{3}\right) \delta 14.1\left(\mathrm{CH}_{3}\right), 22.6$ $\left(\mathrm{CH}_{2}\right), 22.7\left(\mathrm{CH}_{2}\right), 24.7\left(\mathrm{CH}_{2}\right), 25.4\left(\mathrm{CH}_{2}\right), 28.6\left(\mathrm{CH}_{2}\right), 29.3\left(\mathrm{CH}_{2}\right), 29.5\left(\mathrm{CH}_{2}\right), 29.6$ $\left(\mathrm{CH}_{2} \times 3\right), 29.7\left(\mathrm{CH}_{2} \times 3\right), 31.9\left(\mathrm{CH}_{2}\right), 52.5(\mathrm{CH}), 93.2(\mathrm{C}), 119.2(\mathrm{C}), 122.5(\mathrm{CH})$, $125.5(\mathrm{CH}), 128.7(\mathrm{C}), 130.2(\mathrm{C}), 139.5(\mathrm{CH}), 142.3(\mathrm{C}), 150.2(\mathrm{C}), 157.3(\mathrm{C}), 174.1$ (C), 179.8 (C). EIMS m/z (\%): 497 ([M] $\left.]^{+}, 38\right), 448$ (21), 300 (31), 294 (61), 285 (76), 253 (29), 239 (53), 197 (32), 155 (42), 153 (92), 129 (40), 97 (33), 83 (44), 72 (60), 55 (100). HREIMS: 497.2577 (calcd for $\mathrm{C}_{29} \mathrm{H}_{39} \mathrm{O}_{4} \mathrm{NS},[\mathrm{M}]^{+}$497.2600).

\section{2-(cyclohexylamino)-5-hydroxy-3-(pyridine-3-yl)-6-undecylbenzofuran-4,7-dione} $(5 \mathbf{k})$

Following the general procedure described above, $30 \mathrm{mg}$ of embelin $(0.102 \mathrm{mmol})$, $10.00 \mu \mathrm{L}$ of aldehyde $(0.102 \mathrm{mmol}), 13.0 \mu \mathrm{L}$ of cyclohexyl isocyanide $(0.102 \mathrm{mmol})$ and $1.8 \mathrm{mg}$ of EDDA $(10 \mathrm{~mol} \%)$ in $2 \mathrm{~mL}$ of DCE were irradiated for $15 \mathrm{~min}$ at $180^{\circ} \mathrm{C}$. The solvent was removed under vacuum, and the crude product was purified by preparative-TLC with $20 \%$ hexanes/EtOAc to yield $4.3 \mathrm{mg}(9 \%)$ of $\mathbf{5 k}$ as a dark greenoil. ${ }^{1} \mathrm{H}-\mathrm{NMR}\left(500 \mathrm{MHz}, \mathrm{CDCl}_{3}\right) \delta 0.88(\mathrm{t}, J=7.0 \mathrm{~Hz}, 3 \mathrm{H}), 1.25(\mathrm{bs}, 18 \mathrm{H}), 1.38(\mathrm{~m}$, 3H), $1.50(\mathrm{~m}, 2 \mathrm{H}), 1.64(\mathrm{~m}, 1 \mathrm{H}), 1.74(\mathrm{~m}, 2 \mathrm{H}), 2.04(\mathrm{~m}, 2 \mathrm{H}), 2.48(\mathrm{t}, J=7.6 \mathrm{~Hz}, 2 \mathrm{H})$, $3.71(\mathrm{~m}, 1 \mathrm{H}), 4.71(\mathrm{~d}, J=8.0 \mathrm{~Hz}, 1 \mathrm{H}), 7.36(\mathrm{~m}, 1 \mathrm{H}), 7.81(\mathrm{~d}, J=7.6 \mathrm{~Hz}, 1 \mathrm{H}), 8.51$ (bs, 1H), 8.76 (bs, $1 \mathrm{H}) .{ }^{13} \mathrm{C}-\mathrm{NMR}\left(125 \mathrm{MHz}, \mathrm{CDCl}_{3}\right) \delta 14.1\left(\mathrm{CH}_{3}\right), 22.6\left(\mathrm{CH}_{2}\right), 22.7\left(\mathrm{CH}_{2}\right)$, $24.7\left(\mathrm{CH}_{2}\right), 25.3\left(\mathrm{CH}_{2}\right), 28.6\left(\mathrm{CH}_{2}\right), 29.3\left(\mathrm{CH}_{2}\right), 29.5\left(\mathrm{CH}_{2}\right), 29.6\left(\mathrm{CH}_{2}\right.$ x 2$), 29.7\left(\mathrm{CH}_{2}\right.$ x 4), $31.9\left(\mathrm{CH}_{2}\right), 33.9\left(\mathrm{CH}_{2}\right), 52.6(\mathrm{CH}), 93.2(\mathrm{C}), 119.4(\mathrm{C}), 123.6(\mathrm{C}), 124.4(\mathrm{CH})$, $127.0(\mathrm{C}), 136.6(\mathrm{CH}), 143.2(\mathrm{C}), 147.7(\mathrm{CH}), 149.2(\mathrm{CH}), 150.9(\mathrm{C}), 157.5(\mathrm{C}), 174.5$ 
(C), 179.8 (C). EIMS m/z (\%): 492 ([M] $\left.]^{+}, 100\right), 269$ (16), 268 (11), 163 (6), 91 (5), 83

(9), 67 (23), 55 (25). HREIMS: 492.2990 (calcd for $\mathrm{C}_{30} \mathrm{H}_{40} \mathrm{O}_{4} \mathrm{~N}_{2}$, [M] $]^{+}$492.2988).

2-(cyclohexylamino)-3-(furan-3-yl)-5-hydroxy-6-undecylbenzofuran-4,7-dione (5l)

Following the general procedure described above, $30 \mathrm{mg}$ of embelin $(0.102 \mathrm{mmol}), 8.78$ $\mu \mathrm{L}$ of aldehyde $(0.102 \mathrm{mmol}), 13.0 \mu \mathrm{L}$ of cyclohexyl isocyanide $(0.102 \mathrm{mmol})$ and 1.8 $\mathrm{mg}$ of EDDA $(10 \mathrm{~mol} \%)$ in $2 \mathrm{~mL}$ of $\mathrm{DCE}$ were irradiated for $15 \mathrm{~min}$ at $180^{\circ} \mathrm{C}$. The solvent was removed under vacuum, and the crude product was purified by preparativeTLC with $20 \%$ hexanes/EtOAc to yield $19.6 \mathrm{mg}(40 \%)$ of $\mathbf{5 l}$ as a dark green oil. ${ }^{1} \mathrm{H}-$ $\operatorname{NMR}\left(500 \mathrm{MHz}, \mathrm{CDCl}_{3}\right) \delta 0.88(\mathrm{t}, J=7.0 \mathrm{~Hz}, 3 \mathrm{H}), 1.25$ (bs, 18H), 1.39 (m, 3H), 1.49 (m, 2H), $1.63(\mathrm{~m}, 1 \mathrm{H}), 1.73(\mathrm{~m}, 2 \mathrm{H}), 2.06(\mathrm{~m}, 2 \mathrm{H}), 2.46(\mathrm{t}, J=7.6 \mathrm{~Hz}, 2 \mathrm{H}), 3.70(\mathrm{~m}$, $1 \mathrm{H}), 4.41(\mathrm{~d}, J=8.1 \mathrm{~Hz}, 1 \mathrm{H}), 6.71(\mathrm{~d}, J=0.9 \mathrm{~Hz}, 1 \mathrm{H}), 7.52(\mathrm{bs}, 1 \mathrm{H}), 7.82(\mathrm{bs}, 1 \mathrm{H}) .{ }^{13} \mathrm{C}-$ NMR (125 MHz, $\left.\mathrm{CDCl}_{3}\right) \delta 14.1\left(\mathrm{CH}_{3}\right), 22.6\left(\mathrm{CH}_{2}\right), 22.7\left(\mathrm{CH}_{2}\right), 24.7\left(\mathrm{CH}_{2}\right), 25.4\left(\mathrm{CH}_{2}\right)$, $28.5\left(\mathrm{CH}_{2}\right), 29.3\left(\mathrm{CH}_{2}\right), 29.5\left(\mathrm{CH}_{2}\right), 29.6\left(\mathrm{CH}_{2} \times 3\right), 29.7\left(\mathrm{CH}_{2} \mathrm{x} 3\right), 31.9\left(\mathrm{CH}_{2}\right), 34.0$ $\left(\mathrm{CH}_{2}\right), 52.6(\mathrm{CH}), 89.5(\mathrm{C}), 110.0(\mathrm{CH}), 114.8(\mathrm{C}), 119.3(\mathrm{C}), 124.4(\mathrm{C}), 140.6(\mathrm{CH})$, 142.7 (C), 143.3 (CH), 150.2 (C), 157.3 (C), 174.1 (C), 179.7 (C). EIMS m/z (\%): 481 $\left([\mathrm{M}]^{+}, 53\right), 415$ (14), 259 (9), 153 (10), 99 (16), 83 (17), 67 (28), 56 (100). HREIMS: 481.2810 (calcd for $\mathrm{C}_{29} \mathrm{H}_{39} \mathrm{O}_{5} \mathrm{~N},[\mathrm{M}]^{+}$481.2828).

\section{2'-(cyclohexylamino)-5'-hydroxy-6'-undecyl-[2,3'-bibenzofuran]-4',7'-dione (5m)}

Following the general procedure described above, $30 \mathrm{mg}$ of embelin $(0.102 \mathrm{mmol})$, $12.36 \mu \mathrm{L}$ of aldehyde $(0.102 \mathrm{mmol}), 13.0 \mu \mathrm{L}$ of cyclohexyl isocyanide $(0.102 \mathrm{mmol})$ and $1.8 \mathrm{mg}$ of EDDA (10 mol\%) in $2 \mathrm{~mL}$ of DCE were irradiated for $15 \mathrm{~min}$ at $180^{\circ} \mathrm{C}$. The solvent was removed under vacuum, and the crude product was purified by preparative-TLC with $20 \%$ hexanes/EtOAc to yield $34.5 \mathrm{mg}(64 \%)$ of $\mathbf{5 m}$ as a dark green oil. ${ }^{1} \mathrm{H}-\mathrm{NMR}\left(500 \mathrm{MHz}, \mathrm{CDCl}_{3}\right) \delta 0.87(\mathrm{t}, J=6.8 \mathrm{~Hz}, 3 \mathrm{H}), 1.25(\mathrm{bs}, 18 \mathrm{H}), 1.47$ (m, 5H), $1.66(\mathrm{~m}, 1 \mathrm{H}), 1.79(\mathrm{~m}, 2 \mathrm{H}), 2.11(\mathrm{~m}, 2 \mathrm{H}), 2.47(\mathrm{t}, J=7.6 \mathrm{~Hz}, 2 \mathrm{H}), 3.87(\mathrm{~m}$, 
1H), $6.29(\mathrm{~d}, J=8.2 \mathrm{~Hz}, 1 \mathrm{H}), 6.95(\mathrm{bs}, 1 \mathrm{H}), 7.23(\mathrm{~m}, 2 \mathrm{H}), 7.41(\mathrm{~m}, 1 \mathrm{H}), 7.56(\mathrm{~m}, 1 \mathrm{H})$, $7.61(\mathrm{~s}, 1 \mathrm{H}) .{ }^{13} \mathrm{C}-\mathrm{NMR}\left(125 \mathrm{MHz}, \mathrm{CDCl}_{3}\right) \delta 14.1\left(\mathrm{CH}_{3}\right), 22.6\left(\mathrm{CH}_{2}\right), 22.7\left(\mathrm{CH}_{2}\right), 24.6$ $\left(\mathrm{CH}_{2}\right), 25.4\left(\mathrm{CH}_{2}\right), 28.5\left(\mathrm{CH}_{2}\right), 29.4\left(\mathrm{CH}_{2}\right), 29.5\left(\mathrm{CH}_{2}\right), 29.6\left(\mathrm{CH}_{2}\right.$ x 2$), 29.6\left(\mathrm{CH}_{2}\right)$, $29.7\left(\mathrm{CH}_{2} \times 3\right), 31.9\left(\mathrm{CH}_{2}\right), 33.7\left(\mathrm{CH}_{2}\right), 52.2(\mathrm{CH}), 88.0(\mathrm{C}), 103.4(\mathrm{CH}), 110.2(\mathrm{CH})$, $119.3(\mathrm{C}), 120.8(\mathrm{CH}), 122.5(\mathrm{C}), 123.4(\mathrm{CH}), 123.7(\mathrm{CH}), 129.0(\mathrm{C}), 142.3(\mathrm{C}), 149.0$ (C), 150.1 (C), 153.5 (C), 158.0 (C), 173.8 (C), 179.1 (C). EIMS m/z (\%): 531 ([M] $]^{+}$, 100), 449 (71), 391 (49), 391 (49), 308 (77), 252 (15), 118 (15), 83 (16), 55 (52).HREIMS: 531.2979 (calcd for $\mathrm{C}_{33} \mathrm{H}_{41} \mathrm{O}_{5} \mathrm{~N},[\mathrm{M}]^{+}$531.2985).

\section{2-(cyclohexylamino)-5-hydroxy-3-propyl-6-undecylbenzofuran-4,7-dione (5n)}

Following the general procedure described above, $30 \mathrm{mg}$ of embelin $(0.102 \mathrm{mmol}), 9.20$ $\mu \mathrm{L}$ of aldehyde $(0.102 \mathrm{mmol}), 13.0 \mu \mathrm{L}$ of cyclohexyl isocyanide $(0.102 \mathrm{mmol})$ and 1.8 $\mathrm{mg}$ of EDDA (10 mol\%) in $2 \mathrm{~mL}$ of DCE were irradiated for $15 \mathrm{~min}$ at $180^{\circ} \mathrm{C}$. The solvent was removed under vacuum, and the crude product was purified by preparativeTLC with $20 \%$ hexanes/EtOAc to yield $23.7 \mathrm{mg}(51 \%)$ of $\mathbf{5 n}$ as a dark blue oil. ${ }^{1} \mathrm{H}$ NMR (500 MHz, $\left.\mathrm{CDCl}_{3}\right) \delta 0.88(\mathrm{t}, J=7.2 \mathrm{~Hz}, 3 \mathrm{H}), 0.91(\mathrm{t}, J=7.6 \mathrm{~Hz}, 3 \mathrm{H}), 1.25(\mathrm{bs}$, 18H), $1.39(\mathrm{~m}, 6 \mathrm{H}), 1.47(\mathrm{~m}, 2 \mathrm{H}), 1.66(\mathrm{~m}, 1 \mathrm{H}), 1.77(\mathrm{~m}, 2 \mathrm{H}), 2.06(\mathrm{~m}, 2 \mathrm{H}), 2.46(\mathrm{~m}$, 4H), 6.85 (bs, 1H). ${ }^{13} \mathrm{C}-\mathrm{NMR}\left(125 \mathrm{MHz}, \mathrm{CDCl}_{3}\right) \delta 14.1\left(\mathrm{CH}_{3}\right), 14.3\left(\mathrm{CH}_{3}\right), 22.6\left(\mathrm{CH}_{2}\right)$, $22.7\left(\mathrm{CH}_{2} \times 2\right), 24.7\left(\mathrm{CH}_{2}\right), 24.7\left(\mathrm{CH}_{2}\right), 25.6\left(\mathrm{CH}_{2}\right), 27.8\left(\mathrm{CH}_{2}\right), 28.5\left(\mathrm{CH}_{2}\right), 29.3$ $\left(\mathrm{CH}_{2}\right), 29.5\left(\mathrm{CH}_{2}\right), 29.6\left(\mathrm{CH}_{2} \times 3\right), 29.7\left(\mathrm{CH}_{2} \times 2\right), 31.9\left(\mathrm{CH}_{2}\right), 34.2\left(\mathrm{CH}_{2}\right), 52.9(\mathrm{CH})$, 98.5 (C), 119.5 (C), 126.3 (C), 142.3 (C), 149.8 (C), 157.8 (C), 173.8 (C), 180.5 (C). EIMS m/z (\%): $457\left([\mathrm{M}]^{+}, 100\right), 374$ (23), 359 (35), 317 (35), 233 (36), 56 (65). HREIMS: 457.3185 (calcd for $\mathrm{C}_{28} \mathrm{H}_{43} \mathrm{O}_{4} \mathrm{~N},[\mathrm{M}]^{+}$457.3192).

\section{2-(cyclohexylamino)-3-hexyl-5-hydroxy-6-undecylbenzofuran-4,7-dione (5o)}

Following the general procedure described above, $30 \mathrm{mg}$ of embelin $(0.102 \mathrm{mmol})$, $15.00 \mu \mathrm{L}$ of aldehyde $(0.102 \mathrm{mmol}), 13.0 \mu \mathrm{L}$ of cyclohexyl isocyanide $(0.102 \mathrm{mmol})$ 
and $1.8 \mathrm{mg}$ of EDDA $(10 \mathrm{~mol} \%)$ in $2 \mathrm{~mL}$ of DCE were irradiated for $15 \mathrm{~min}$ at $180^{\circ} \mathrm{C}$. The solvent was removed under vacuum, and the crude product was purified by preparative-TLC with $20 \%$ hexanes/EtOAc to yield $20.7 \mathrm{mg}(40 \%)$ of $\mathbf{5 0}$ as a dark blue

oil. ${ }^{1} \mathrm{H}-\mathrm{NMR}\left(500 \mathrm{MHz}, \mathrm{CDCl}_{3}\right) \delta 0.88(\mathrm{~m}, 6 \mathrm{H}), 1.25$ (bs, 18H), 1.29 (bs, 10H), 1.38 (m, 3H), $1.49(\mathrm{~m}, 2 \mathrm{H}), 1.63(\mathrm{~m}, 2 \mathrm{H}), 1.75(\mathrm{~m}, 2 \mathrm{H}), 2.02(\mathrm{~m}, 1 \mathrm{H}), 2.44(\mathrm{~m}, 2 \mathrm{H}), 3.60$ (bs, 1H). 3.86 (bs, 1H), 6.77 (bs, 1H). ${ }^{13} \mathrm{C}-\mathrm{NMR}\left(150 \mathrm{MHz}, \mathrm{CDCl}_{3}\right) \delta 14.1\left(\mathrm{CH}_{3} \mathrm{x} 2\right)$, $22.6\left(\mathrm{CH}_{2}\right), 22.7\left(\mathrm{CH}_{2} \times 3\right), 24.8\left(\mathrm{CH}_{2}\right), 25.5\left(\mathrm{CH}_{2}\right), 28.6\left(\mathrm{CH}_{2}\right), 29.0\left(\mathrm{CH}_{2}\right), 29.3$ $\left(\mathrm{CH}_{2}\right), 29.4\left(\mathrm{CH}_{2} \times 2\right), 29.5\left(\mathrm{CH}_{2}\right), 29.6\left(\mathrm{CH}_{2} \times 2\right), 29.7\left(\mathrm{CH}_{2} \times 3\right), 31.6\left(\mathrm{CH}_{2}\right), 31.9$ $\left(\mathrm{CH}_{2}\right), 34.2\left(\mathrm{CH}_{2}\right), 52.9(\mathrm{CH}), 98.9(\mathrm{C}), 119.5(\mathrm{C}), 126.2(\mathrm{C}), 142.3(\mathrm{C}), 149.8(\mathrm{C})$, 157.7 (C), 173.8 (C), 180.5 (C). EIMS m/z (\%): 457 ([M] $\left.]^{+}, 100\right), 374$ (23), 359 (35), 317 (35), 233 (36), 56 (65). HREIMS: 499.3661 (calcd for $\mathrm{C}_{31} \mathrm{H}_{49} \mathrm{O}_{4} \mathrm{~N},[\mathrm{M}]^{+}$499.3662).

\section{2-(benzylamino)-5-hydroxy-3-phenyl-6-undecylbenzofuran-4,7-dione}

Following the general procedure described above, $20 \mathrm{mg}$ of embelin $(0.068 \mathrm{mmol}), 6.9$ $\mu \mathrm{L}$ of benzaldehyde $(0.068 \mathrm{mmol}), 8.3 \mu \mathrm{L}$ of $t$-butyl isocyanide $(0.068 \mathrm{mmol})$ and 1.2 $\mathrm{mg}$ of EDDA $(10 \mathrm{~mol} \%)$ in $2 \mathrm{~mL}$ of $\mathrm{DCE}$ were irradiated for $15 \mathrm{~min}$ at $180^{\circ} \mathrm{C}$. The solvent was removed under vacuum, and the crude product was purified by preparativeTLC with $20 \%$ hexanes/EtOAc to yield $29.2 \mathrm{mg}(86 \%)$ of $\mathbf{6 a}$ as a dark green oil. ${ }^{1} \mathrm{H}$ $\operatorname{NMR}\left(500 \mathrm{MHz}, \mathrm{CDCl}_{3}\right) \delta 0.88(\mathrm{t}, J=7.1 \mathrm{~Hz}, 3 \mathrm{H}), 1.26(\mathrm{bs}, 16 \mathrm{H}), 1.50(\mathrm{~m}, 2 \mathrm{H}), 2.47$ $(\mathrm{t}, J=7.7 \mathrm{~Hz}, 2 \mathrm{H}), 4.57(\mathrm{~d}, J=6.0 \mathrm{~Hz}, 2 \mathrm{H}), 5.04(\mathrm{t}, J=6.0 \mathrm{~Hz}, 1 \mathrm{H}), 7.33(\mathrm{~m}, 6 \mathrm{H}), 7.41$ (m, 4H). ${ }^{13} \mathrm{C}-\mathrm{NMR}\left(150 \mathrm{MHz}, \mathrm{CDCl}_{3}\right) \delta 14.1\left(\mathrm{CH}_{3}\right), 22.6\left(\mathrm{CH}_{2}\right), 22.7\left(\mathrm{CH}_{2}\right), 28.5$ $\left(\mathrm{CH}_{2}\right), 29.3\left(\mathrm{CH}_{2}\right), 29.4\left(\mathrm{CH}_{2}\right), 29.6\left(\mathrm{CH}_{2} \times 2\right), 29.7\left(\mathrm{CH}_{2} \times 2\right), 31.9\left(\mathrm{CH}_{2}\right), 47.6\left(\mathrm{CH}_{2}\right)$, $97.6(\mathrm{C}), 119.1(\mathrm{C}), 127.6(\mathrm{CH}), 127.7(\mathrm{C}), 127.8(\mathrm{CH} x)$ 2), $128.0(\mathrm{CH}), 128.7(\mathrm{CH} x$ 2), 128.8 (CH x 2), 128.9 (CH x 2), 129.8 (C), 137.6 (C), 142.9 (C), 150.4 (C), 157.3 (C), 174.4 (C), 179.6 (C); EIMS m/z (\%) 499 (M+, 55), 351 (21), 153 (40), 90 (100); HREIMS 499.2722 (calcd. for $\mathrm{C}_{32} \mathrm{H}_{37} \mathrm{O}_{4} \mathrm{~N}\left(\mathrm{M}^{+}\right)$499.2723). 


\section{2-(benzylamino)-5-hydroxy-3-(4-nitrophenyl)-6-undecylbenzofuran-4,7-dione (6b)}

Following the general procedure described above, $20 \mathrm{mg}$ of embelin $(0.068 \mathrm{mmol}), 10.3$ $\mathrm{mg}$ of 4-nitrobenzaldehyde $(0.068 \mathrm{mmol}), 8.3 \mu \mathrm{L}$ of $t$-butyl isocyanide $(0.068 \mathrm{mmol})$ and $1.2 \mathrm{mg}$ of EDDA $(10 \mathrm{~mol} \%)$ in $2 \mathrm{~mL}$ of DCE were irradiated for $15 \mathrm{~min}$ at $180^{\circ} \mathrm{C}$. The solvent was removed under vacuum, and the crude product was purified by preparative-TLC with DCM to yield $19.4 \mathrm{mg}(52 \%)$ of $\mathbf{6 b}$ as a dark green oil. ${ }^{1} \mathrm{H}-\mathrm{NMR}$ $\left(500 \mathrm{MHz}, \mathrm{CDCl}_{3}\right) \delta 0.88(\mathrm{t}, J=7.1 \mathrm{~Hz}, 3 \mathrm{H}), 1.26(\mathrm{bs}, 16 \mathrm{H}), 1.48(\mathrm{~m}, 2 \mathrm{H}), 2.47(\mathrm{t}, J=$ $7.7 \mathrm{~Hz}, 2 \mathrm{H}), 4.61$ (d, J=5.8 Hz, 2H), 5.16 (t, $J=5.8 \mathrm{~Hz}, 1 \mathrm{H}), 6.87$ (bs, 1H), 7.34 (m, 5H), $7.61(\mathrm{~d}, J=8.6 \mathrm{~Hz}, 1 \mathrm{H}), 8.24(\mathrm{~d}, J=8.6 \mathrm{~Hz}, 1 \mathrm{H}) ;{ }^{13} \mathrm{C}-\mathrm{NMR}\left(150 \mathrm{MHz}, \mathrm{CDCl}_{3}\right) \delta$ $14.1\left(\mathrm{CH}_{3}\right), 22.5\left(\mathrm{CH}_{2}\right), 22.7\left(\mathrm{CH}_{2}\right), 28.5\left(\mathrm{CH}_{2}\right), 29.3\left(\mathrm{CH}_{2}\right), 29.5\left(\mathrm{CH}_{2}\right), 29.6\left(\mathrm{CH}_{2} \mathrm{x}\right.$ 2), $29.7\left(\mathrm{CH}_{2}\right.$ x 2), $31.9\left(\mathrm{CH}_{2}\right), 47.7\left(\mathrm{CH}_{2}\right), 95.3(\mathrm{C}), 119.2(\mathrm{C}), 123.8(\mathrm{C}), 124.1(\mathrm{CH} \mathrm{x}$ 2), $127.8(\mathrm{CH} \times 2), 128.3(\mathrm{CH}), 129.0(\mathrm{CH} \times 2), 129.1(\mathrm{CH} \times 2), 137.0(\mathrm{C}), 137.2(\mathrm{C})$, 143.6 (C), 146.3 (C), 150.6 (C), 157.5 (C), 174.7 (C), 179.4 (C); EIMS m/z (\%) 544 $\left(\mathrm{M}^{+}, 55\right), 403$ (24), 294 (13); HREIMS 544.2574 (calcd. for $\mathrm{C}_{32} \mathrm{H}_{36} \mathrm{O}_{6} \mathrm{~N}_{2}\left(\mathrm{M}^{+}\right.$) $544.2573)$.

\section{2-(benzylamino)-3-(4-bromophenyl)-5-hydroxy-6-undecylbenzofuran-4,7-dione}

(6c)

Following the general procedure described above, $20 \mathrm{mg}$ of embelin $(0.068 \mathrm{mmol}), 12.3$ $\mathrm{mg}$ of 4-bromobenzaldehyde $(0.068 \mathrm{mmol}), 8.3 \mu \mathrm{L}$ of $t$-butyl isocyanide $(0.068 \mathrm{mmol})$ and $1.2 \mathrm{mg}$ of EDDA $(10 \mathrm{~mol} \%)$ in $2 \mathrm{~mL}$ of DCE were irradiated for $15 \mathrm{~min}$ at $180^{\circ} \mathrm{C}$. The solvent was removed under vacuum, and the crude product was purified by preparative-TLC with $20 \%$ hexanes/EtOAc to yield $29.7 \mathrm{mg}(76 \%)$ of $\mathbf{6 c}$ as a dark green oil. ${ }^{1} \mathrm{H}-\mathrm{NMR}\left(500 \mathrm{MHz}, \mathrm{CDCl}_{3}\right) \delta 0.88(\mathrm{t}, J=7.1 \mathrm{~Hz}, 3 \mathrm{H}), 1.26(\mathrm{bs}, 16 \mathrm{H}), 1.50$ (m, 2H), $2.46(\mathrm{t}, J=7.6 \mathrm{~Hz}, 2 \mathrm{H}), 4.56(\mathrm{~d}, J=5.8 \mathrm{~Hz}, 2 \mathrm{H}), 4.98(\mathrm{bs}, 1 \mathrm{H}), 7.30(\mathrm{~m}, 7 \mathrm{H})$, $7.52(\mathrm{~d}, J=8.2 \mathrm{~Hz}, 2 \mathrm{H}) ;{ }^{13} \mathrm{C}-\mathrm{NMR}\left(150 \mathrm{MHz}, \mathrm{CDCl}_{3}\right) \delta 14.1\left(\mathrm{CH}_{3}\right), 22.5\left(\mathrm{CH}_{2}\right), 22.7$ 
$\left(\mathrm{CH}_{2}\right), 28.5\left(\mathrm{CH}_{2}\right), 29.3\left(\mathrm{CH}_{2}\right), 29.4\left(\mathrm{CH}_{2}\right), 29.5\left(\mathrm{CH}_{2}\right), 29.6\left(\mathrm{CH}_{2}\right), 29.7\left(\mathrm{CH}_{2} \times 2\right)$, $31.9\left(\mathrm{CH}_{2}\right), 47.7\left(\mathrm{CH}_{2}\right), 96.4(\mathrm{C}), 119.2(\mathrm{C}), 121.4(\mathrm{C}), 124.3(\mathrm{C}), 127.8(\mathrm{CH} \times 2)$, $128.1(\mathrm{CH}), 128.8(\mathrm{C}), 128.9(\mathrm{CH} \times 2), 130.4(\mathrm{CH} \times 2), 132.0(\mathrm{CH} \times 2), 137.4(\mathrm{C})$, 143.0 (C), 150.4 (C), 157.2 (C), 174.4 (C), 179.5 (C); EIMS m/z (\%) 578 (M+1, 97), 438 (32), 278 (10); HREIMS 579.1819 (calcd. for $\mathrm{C}_{32} \mathrm{H}_{36} \mathrm{O}_{4} \mathrm{~N}^{81} \mathrm{Br} \quad\left(\mathrm{M}^{+}\right)$579.1807), 577.1823 (calcd. for $\mathrm{C}_{32} \mathrm{H}_{36} \mathrm{O}_{4} \mathrm{~N}^{79} \mathrm{Br}\left(\mathrm{M}^{+}\right)$577.1828).

\section{3-(benzo[d][1,3]dioxol-5-yl)-2-(benzylamino)-5-hydroxy-6-undecylbenzofuran-4,7-}

\section{dione (6d)}

Following the general procedure described above, $20 \mathrm{mg}$ of embelin $(0.068 \mathrm{mmol})$, $10.2 \mathrm{mg}$ of piperonal $(0.068 \mathrm{mmol}), 8.3 \mu \mathrm{L}$ of $t$-butyl isocyanide $(0.068 \mathrm{mmol})$ and 1.2 $\mathrm{mg}$ of EDDA (10 mol\%) in $2 \mathrm{~mL}$ of DCE were irradiated for $15 \mathrm{~min}$ at $180^{\circ} \mathrm{C}$. The solvent was removed under vacuum, and the crude product was purified by preparativeTLC with $20 \%$ hexanes/EtOAc to yield $33.8 \mathrm{mg}(92 \%)$ of $\mathbf{6 d}$ as a dark green oil. ${ }^{1} \mathrm{H}-$ $\operatorname{NMR}\left(500 \mathrm{MHz}, \mathrm{CDCl}_{3}\right) \delta 0.88(\mathrm{t}, J=7.1 \mathrm{~Hz}, 3 \mathrm{H}), 1.25(\mathrm{bs}, 16 \mathrm{H}), 1.48(\mathrm{~m}, 2 \mathrm{H}), 2.45$ (t, $J=7.8 \mathrm{~Hz}, 2 \mathrm{H}), 4.54(\mathrm{~d}, J=5.9 \mathrm{~Hz}, 2 \mathrm{H}), 5.00(\mathrm{bs}, 1 \mathrm{H}), 5.96(\mathrm{~s}, 2 \mathrm{H}), 6.81(\mathrm{~d}, J=8.1$ $\mathrm{Hz}, 1 \mathrm{H}), 6.84(\mathrm{dd}, J=1.2,7.9 \mathrm{~Hz}, 1 \mathrm{H}), 6.89(\mathrm{~d}, J=1.30 \mathrm{~Hz}, 1 \mathrm{H}), 7.31(\mathrm{~m}, 5 \mathrm{H}) ;{ }^{13} \mathrm{C}-$ NMR $\left(150 \mathrm{MHz}, \mathrm{CDCl}_{3}\right) \delta 14.1\left(\mathrm{CH}_{3}\right), 22.6\left(\mathrm{CH}_{2}\right), 22.7\left(\mathrm{CH}_{2}\right), 28.6\left(\mathrm{CH}_{2}\right), 29.3\left(\mathrm{CH}_{2}\right)$, $29.5\left(\mathrm{CH}_{2}\right), 29.6\left(\mathrm{CH}_{2} \times 2\right), 29.7\left(\mathrm{CH}_{2} \times 2\right), 31.9\left(\mathrm{CH}_{2}\right), 47.6\left(\mathrm{CH}_{2}\right), 97.6(\mathrm{C}), 101.3$ $\left(\mathrm{CH}_{2}\right), 108.6(\mathrm{CH}), 109.5(\mathrm{CH}), 119.2(\mathrm{C}), 122.2(\mathrm{CH}), 123.3(\mathrm{C}), 124.5(\mathrm{C}), 127.8(\mathrm{CH}$ x 2), $128.0(\mathrm{CH}), 128.9(\mathrm{CH}$ x 2), $137.6(\mathrm{C}), 142.6$ (C), 147.1 (C), 148.0 (C), 150.3 (C), 157.3 (C), 174.3 (C), 179.6 (C); EIMS m/z (\%) $543\left(\mathrm{M}^{+}, 87\right), 402$ (30), 294 (25), 91 (100); HREIMS 543.2606 (calcd. for $\mathrm{C}_{33} \mathrm{H}_{37} \mathrm{O}_{6} \mathrm{~N}\left(\mathrm{M}^{+}\right)$543.2621).

\section{2-(benzylamino)-3-(3-fluorophenyl)-5-hydroxy-6-undecylbenzofuran-4,7-dione (6e)}

Following the general procedure described above, $20 \mathrm{mg}$ of embelin $(0.068 \mathrm{mmol}), 7.2$ $\mu \mathrm{L}$ of 4 -fluorobenzaldehyde $(0.068 \mathrm{mmol}), 8.3 \mu \mathrm{L}$ of $t$-butyl isocyanide $(0.068 \mathrm{mmol})$ 
and $1.2 \mathrm{mg}$ of EDDA $(10 \mathrm{~mol} \%)$ in $2 \mathrm{~mL}$ of DCE were irradiated for $15 \mathrm{~min}$ at $180^{\circ} \mathrm{C}$. The solvent was removed under vacuum, and the crude product was purified by preparative-TLC with $20 \%$ hexanes/EtOAc to yield $28.3 \mathrm{mg}(80 \%)$ of $6 \mathrm{e}$ as a dark green oil. ${ }^{1} \mathrm{H}-\mathrm{NMR}\left(500 \mathrm{MHz}, \mathrm{CDCl}_{3}\right) \delta 0.88(\mathrm{t}, J=6.9 \mathrm{~Hz}, 3 \mathrm{H}), 1.26(\mathrm{bs}, 16 \mathrm{H}), 1.49$ (m, 2H), $2.47(\mathrm{t}, J=7.7 \mathrm{~Hz}, 2 \mathrm{H}), 4.58(\mathrm{~d}, J=5.9 \mathrm{~Hz}, 2 \mathrm{H}), 5.04(\mathrm{bs}, 1 \mathrm{H}), 6.87$ (bs, 1H), $7.16(\mathrm{dt}, J=2.2,9.9 \mathrm{~Hz}, 1 \mathrm{H}), 7.19(\mathrm{~d}, J=7.8 \mathrm{~Hz}, 1 \mathrm{H}), 7.33(\mathrm{~m}, 6 \mathrm{H}) ;{ }^{13} \mathrm{C}-\mathrm{NMR}(150$ $\left.\mathrm{MHz}, \mathrm{CDCl}_{3}\right) \delta 14.1\left(\mathrm{CH}_{3}\right), 22.5\left(\mathrm{CH}_{2}\right), 22.7\left(\mathrm{CH}_{2}\right), 28.5\left(\mathrm{CH}_{2}\right), 29.3\left(\mathrm{CH}_{2}\right), 29.5$ $\left(\mathrm{CH}_{2}\right), 29.6\left(\mathrm{CH}_{2} \times 2\right), 29.7\left(\mathrm{CH}_{2} \times 2\right), 31.9\left(\mathrm{CH}_{2}\right), 47.6\left(\mathrm{CH}_{2}\right), 96.3(\mathrm{C}), 114.5\left(\mathrm{CH}, J_{\mathrm{C}-}\right.$ $\left.\mathrm{F}_{\mathrm{F}}=22.8 \mathrm{~Hz}\right), 115.8\left(\mathrm{CH}, J_{\mathrm{C}-\mathrm{F}}=22.3 \mathrm{~Hz}\right), 119.1(\mathrm{C}), 124.3\left(\mathrm{CH}, J_{\mathrm{C}-\mathrm{F}}=2.5 \mathrm{~Hz}\right), 127.7(\mathrm{CH}$ x 2), $128.1(\mathrm{CH}), 128.7(\mathrm{C}), 128.9\left(\mathrm{CH}\right.$ x 2), $130.3\left(\mathrm{CH}, J_{\mathrm{C}-\mathrm{F}}=8.9 \mathrm{~Hz}\right), 131.9(\mathrm{C}), 137.4$ (C), $143.0(\mathrm{C}), 150.4(\mathrm{C}), 157.3(\mathrm{C}), 162.9$ (C, $\left.J_{\mathrm{C}-\mathrm{F}}=246.0 \mathrm{~Hz}\right), 174.5$ (C), 179.4 (C); EIMS m/z (\%) $517\left(\mathrm{M}^{+}, 69\right), 377$ (29), 91 (100); HREIMS 517.2637 (calcd. for $\mathrm{C}_{32} \mathrm{H}_{36} \mathrm{O}_{4} \mathrm{NF}\left(\mathrm{M}^{+}\right)$517.2628).

\section{2-(benzylamino)-3-(4-chlorophenyl)-5-hydroxy-6-undecylbenzofuran-4,7-dione (6f)}

Following the general procedure described above, $20 \mathrm{mg}$ of embelin $(0.068 \mathrm{mmol}), 9.6$ $\mathrm{mg}$ of 4-chlorobenzaldehyde $(0.068 \mathrm{mmol}), 8.3 \mu \mathrm{L}$ of $t$-butyl isocyanide $(0.068 \mathrm{mmol})$ and $1.2 \mathrm{mg}$ of EDDA $(10 \mathrm{~mol} \%)$ in $2 \mathrm{~mL}$ of DCE were irradiated for $15 \mathrm{~min}$ at $180^{\circ} \mathrm{C}$. The solvent was removed under vacuum, and the crude product was purified by preparative-TLC with $20 \%$ hexanes/EtOAc to yield $29.4 \mathrm{mg}(81 \%)$ of $\mathbf{6 f}$ as an amorphous dark blue solid. ${ }^{1} \mathrm{H}-\mathrm{NMR}\left(500 \mathrm{MHz}, \mathrm{CDCl}_{3}\right) \delta 0.88(\mathrm{t}, J=7.0 \mathrm{~Hz}, 3 \mathrm{H}), 1.26$ (bs, 16H), $1.49(\mathrm{~m}, 2 \mathrm{H}), 2.46(\mathrm{t}, J=7.9 \mathrm{~Hz}, 2 \mathrm{H}), 4.56(\mathrm{~d}, J=5.9 \mathrm{~Hz}, 2 \mathrm{H}), 4.98(\mathrm{t}, J=6.0$ $\mathrm{Hz}, 1 \mathrm{H}), 7.30(\mathrm{~m}, 3 \mathrm{H}), 7.35(\mathrm{~m}, 6 \mathrm{H}) ;{ }^{13} \mathrm{C}-\mathrm{NMR}\left(150 \mathrm{MHz}, \mathrm{CDCl}_{3}\right) \delta 14.1\left(\mathrm{CH}_{3}\right), 22.5$ $\left(\mathrm{CH}_{2}\right), 22.7\left(\mathrm{CH}_{2}\right), 28.5\left(\mathrm{CH}_{2}\right), 29.3\left(\mathrm{CH}_{2}\right), 29.4\left(\mathrm{CH}_{2}\right), 29.5\left(\mathrm{CH}_{2}\right), 29.6\left(\mathrm{CH}_{2}\right), 29.7$ $\left(\mathrm{CH}_{2} \times 2\right), 31.9\left(\mathrm{CH}_{2}\right), 47.7\left(\mathrm{CH}_{2}\right), 96.4(\mathrm{C}), 119.2(\mathrm{C}), 127.7(\mathrm{CH} \times 2), 128.1(\mathrm{CH})$, $128.3(\mathrm{C}), 128.9$ (CH x 2), 129.0 (CH x 2), 130.1 (CH x 2), 132.7 (C), 133.3 (C), 137.4 
(C), 142.9 (C), 150.4 (C), 157.2 (C), 174.4 (C), 179.5 (C); EIMS m/z (\%) $532\left(\mathrm{M}^{+}, 99\right)$,

392 (41), 90 (100); HREIMS 535.2314 (calcd. for $\mathrm{C}_{32} \mathrm{H}_{36} \mathrm{O}_{4} \mathrm{~N}^{37} \mathrm{Cl}\left(\mathrm{M}^{+}\right)$535.2303), 533.2360 (calcd. for $\mathrm{C}_{32} \mathrm{H}_{36} \mathrm{O}_{4} \mathrm{~N}^{35} \mathrm{Cl}\left(\mathrm{M}^{+}\right)$533.2333).

2-(benzylamino)-3-(4-fluorophenyl)-5-hydroxy-6-undecylbenzofuran-4,7-dione (6g)

Following the general procedure described above, $20 \mathrm{mg}$ of embelin $(0.068 \mathrm{mmol}), 7.3$ $\mu \mathrm{L}$ of 4 -fluorobenzaldehyde $(0.068 \mathrm{mmol}), 8.3 \mu \mathrm{L}$ of $t$-butyl isocyanide $(0.068 \mathrm{mmol})$ and $1.2 \mathrm{mg}$ of EDDA $(10 \mathrm{~mol} \%)$ in $2 \mathrm{~mL}$ of DCE were irradiated for $15 \mathrm{~min}$ at $180^{\circ} \mathrm{C}$. The solvent was removed under vacuum, and the crude product was purified by preparative-TLC with $10 \%$ hexanes/EtOAc to yield $27.3 \mathrm{mg}(76 \%)$ of $\mathbf{6 g}$ as a dark green oil. ${ }^{1} \mathrm{H}-\mathrm{NMR}\left(500 \mathrm{MHz}, \mathrm{CDCl}_{3}\right) \delta 0.88(\mathrm{t}, J=7.1 \mathrm{~Hz}, 3 \mathrm{H}), 1.25$ (bs, $\left.16 \mathrm{H}\right), 1.49$ (m, 2H), $2.46(\mathrm{t}, J=7.8 \mathrm{~Hz}, 2 \mathrm{H}), 4.55(\mathrm{~d}, J=6.2 \mathrm{~Hz}, 2 \mathrm{H}), 4.94(\mathrm{t}, J=5.9 \mathrm{~Hz}, 1 \mathrm{H}), 6.84$ (bs, 1H), 7.09 (t, $J=8.8 \mathrm{~Hz}, 2 \mathrm{H}), 7.30(\mathrm{~m}, 3 \mathrm{H}), 7.37$ (m, 4H); ${ }^{13} \mathrm{C}-\mathrm{NMR}(150 \mathrm{MHz}$, $\left.\mathrm{CDCl}_{3}\right) \delta 14.1\left(\mathrm{CH}_{3}\right), 22.6\left(\mathrm{CH}_{2}\right), 22.7\left(\mathrm{CH}_{2}\right), 28.5\left(\mathrm{CH}_{2}\right), 29.3\left(\mathrm{CH}_{2}\right), 29.5\left(\mathrm{CH}_{2}\right), 29.6$ $\left(\mathrm{CH}_{2} \times 2\right), 29.7\left(\mathrm{CH}_{2} \times 2\right), 31.9\left(\mathrm{CH}_{2}\right), 47.7\left(\mathrm{CH}_{2}\right), 96.7(\mathrm{C}), 115.9\left(\mathrm{CH} \times 2, J_{\mathrm{C}-\mathrm{F}}=22.1\right.$ $\mathrm{Hz}), 119.2(\mathrm{C}), 124.5(\mathrm{C}), 125.7\left(\mathrm{C}, J_{\mathrm{C}-\mathrm{F}}=3.1 \mathrm{~Hz}\right), 127.7(\mathrm{CH} \times 2), 128.0(\mathrm{CH}), 128.9$ (CH x 2), $130.7\left(\mathrm{CH} x 2, J_{\mathrm{C}-\mathrm{F}}=8.2 \mathrm{~Hz}\right), 137.5(\mathrm{C}), 142.9$ (C), $150.4(\mathrm{C}), 157.2$ (C), $162.0\left(\mathrm{C}, J_{\mathrm{C}-\mathrm{F}}=248.8 \mathrm{~Hz}\right), 174.4(\mathrm{C}), 179.6(\mathrm{C})$; EIMS m/z (\%) $517\left(\mathrm{M}^{+}, 100\right), 376$ (35), 90 (94); HREIMS 517.2619 (calcd. for $\mathrm{C}_{32} \mathrm{H}_{36} \mathrm{O}_{4} \mathrm{NF}\left(\mathrm{M}^{+}\right)$517.2628).

2-(benzylamino)-3-(3,4-dimethoxyphenyl)-5-hydroxy-6-undecylbenzofuran-4,7dione (6h)

Following the general procedure described above, $20 \mathrm{mg}$ of embelin $(0.068 \mathrm{mmol}), 11.3$ $\mathrm{mg}$ of 3,4-dimethoxybenzaldehyde $(0.068 \mathrm{mmol}), 8.3 \mu \mathrm{L}$ of $t$-butyl isocyanide $(0.068$ mmol) and $1.2 \mathrm{mg}$ of EDDA (10 mol\%) in $2 \mathrm{~mL}$ of DCE were irradiated for $15 \mathrm{~min}$ at $180^{\circ} \mathrm{C}$. The solvent was removed under vacuum, and the crude product was purified by preparative-TLC with $20 \%$ hexanes/EtOAc to yield $25.0 \mathrm{mg}(66 \%)$ of $\mathbf{6 h}$ as a dark 
green oil. ${ }^{1} \mathrm{H}-\mathrm{NMR}\left(500 \mathrm{MHz}, \mathrm{CDCl}_{3}\right) \delta 0.88(\mathrm{t}, J=7.0 \mathrm{~Hz}, 3 \mathrm{H}), 1.26(\mathrm{bs}, 16 \mathrm{H}), 1.50$ (m, 2H), 2.47 (t, $J=7.8 \mathrm{~Hz}, 2 \mathrm{H}), 3.86(\mathrm{~s}, 3 \mathrm{H}), 3.89$ (s, 3H), $4.58(\mathrm{~d}, J=6.0 \mathrm{~Hz}, 2 \mathrm{H})$, 4.96 (bs, 1H), 6.88 (d, $J=8.3 \mathrm{~Hz}, 1 \mathrm{H}), 6.94$ (dd, $J=2.0,8.2 \mathrm{~Hz}, 1 \mathrm{H}), 6.99$ (d, $J=1.90$ $\mathrm{Hz}, 1 \mathrm{H}), 7.32(\mathrm{~m}, 5 \mathrm{H}) ;{ }^{13} \mathrm{C}-\mathrm{NMR}\left(150 \mathrm{MHz}, \mathrm{CDCl}_{3}\right) \delta 14.1\left(\mathrm{CH}_{3}\right), 22.6\left(\mathrm{CH}_{2}\right), 22.7$ $\left(\mathrm{CH}_{2}\right), 28.6\left(\mathrm{CH}_{2}\right), 29.3\left(\mathrm{CH}_{2}\right), 29.5\left(\mathrm{CH}_{2}\right), 29.6\left(\mathrm{CH}_{2} \times 2\right), 29.7\left(\mathrm{CH}_{2} \times 2\right), 31.9\left(\mathrm{CH}_{2}\right)$, $47.8\left(\mathrm{CH}_{2}\right), 55.9\left(\mathrm{CH}_{3}\right), 56.0\left(\mathrm{CH}_{3}\right), 98.0(\mathrm{C}), 111.3(\mathrm{CH}), 112.6(\mathrm{CH}), 119.1(\mathrm{C}), 120.8$ (CH), $122.2(\mathrm{C}), 124.5(\mathrm{C}), 127.7(\mathrm{CH} \times 2), 128.0(\mathrm{CH}), 128.9(\mathrm{CH} \times 2), 137.7(\mathrm{C})$, 142.7 (C), 148.6 (C), 149.1 (C), 150.3 (C), 157.3 (C), 174.3 (C), 179.7 (C); EIMS m/z (\%) $559\left(\mathrm{M}^{+}\right.$, 36), 430 (19), 294 (34), 91 (100); HREIMS 559.2948 (calcd. for $\mathrm{C}_{34} \mathrm{H}_{41} \mathrm{O}_{6} \mathrm{~N}\left(\mathrm{M}^{+}\right)$559.2934).

\section{2-(benzylamino)-5-hydroxy-3-(4-methoxyphenyl)-6-undecylbenzofuran-4,7-dione}

(6i)

Following the general procedure described above, $20 \mathrm{mg}$ of embelin (0.068 mmol), 8.3 $\mu \mathrm{L}$ of 4-methoxybenzaldehyde $(0.068 \mathrm{mmol}), 8.3 \mu \mathrm{L}$ of $t$-butyl isocyanide $(0.068$ mmol) and $1.2 \mathrm{mg}$ of EDDA (10 mol\%) in $2 \mathrm{~mL}$ of DCE were irradiated for $15 \mathrm{~min}$ at $180^{\circ} \mathrm{C}$. The solvent was removed under vacuum, and the crude product was purified by preparative-TLC with $20 \%$ hexanes/EtOAc to yield $31.4 \mathrm{mg}$ (87\%) of $\mathbf{6 i}$ as dark green oil. ${ }^{1} \mathrm{H}-\mathrm{NMR}\left(500 \mathrm{MHz}, \mathrm{CDCl}_{3}\right) \delta 0.88(\mathrm{t}, J=7.1 \mathrm{~Hz}, 3 \mathrm{H}), 1.26$ (bs, $\left.16 \mathrm{H}\right), 1.49(\mathrm{~m}, 2 \mathrm{H})$, 2.46 (t, $J=7.7 \mathrm{~Hz}, 2 \mathrm{H}), 3.81$ (s, 3H), 4.56 (d, $J=5.6 \mathrm{~Hz}, 2 \mathrm{H}), 4.95$ (bs, 1H), 6.84 (bs, 1H), $6.94(\mathrm{~d}, J=8.8 \mathrm{~Hz}, 1 \mathrm{H}), 7.32(\mathrm{~m}, 7 \mathrm{H}) ;{ }^{13} \mathrm{C}-\mathrm{NMR}\left(150 \mathrm{MHz}, \mathrm{CDCl}_{3}\right) \delta 14.1\left(\mathrm{CH}_{3}\right)$, $22.6\left(\mathrm{CH}_{2}\right), 22.7\left(\mathrm{CH}_{2}\right), 28.6\left(\mathrm{CH}_{2}\right), 29.3\left(\mathrm{CH}_{2}\right), 29.5\left(\mathrm{CH}_{2}\right), 29.6\left(\mathrm{CH}_{2} \mathrm{x}\right), 29.7\left(\mathrm{CH}_{2}\right.$ x 2), $31.9\left(\mathrm{CH}_{2}\right), 47.7\left(\mathrm{CH}_{2}\right), 55.3\left(\mathrm{CH}_{3}\right), 97.7(\mathrm{C}), 114.3(\mathrm{CH} \mathrm{x} 2), 119.2(\mathrm{C}), 121.8$ (C), $127.8(\mathrm{CH} \times 2), 127.9(\mathrm{CH}), 128.9(\mathrm{CH} \times 2), 130.1(\mathrm{CH} \times 2), 134.0(\mathrm{C}), 137.6(\mathrm{C})$, 142.6 (C), 150.3 (C), 157.3 (C), 159.0 (C), 174.3 (C), 179.7 (C); EIMS m/z (\%) 529 
$\left(\mathrm{M}^{+}, 46\right), 528$ (95), 439 (25), 388 (28), 90 (100); HREIMS 529.2847 (calcd. for $\mathrm{C}_{33} \mathrm{H}_{39} \mathrm{O}_{5} \mathrm{~N}\left(\mathrm{M}^{+}\right)$529.2828).

2-(benzylamino)-5-hydroxy-3-(thiophen-3-yl)-6-undecylbenzofuran-4,7-dione (6j)

Following the general procedure described above, $20 \mathrm{mg}$ of embelin $(0.068 \mathrm{mmol}), 6.0$ $\mu \mathrm{L}$ of 3 -thiophenecarboxaldehyde $(0.068 \mathrm{mmol}), 8.3 \mu \mathrm{L}$ of $t$-butyl isocyanide $(0.068$ $\mathrm{mmol})$ and $1.2 \mathrm{mg}$ of EDDA (10 mol\%) in $2 \mathrm{~mL}$ of DCE were irradiated for $15 \mathrm{~min}$ at $180^{\circ} \mathrm{C}$. The solvent was removed under vacuum, and the crude product was purified by preparative-TLC with $20 \%$ hexanes/EtOAc to yield $29.2 \mathrm{mg}(88 \%)$ of $\mathbf{6 j}$ as dark green oil. ${ }^{1} \mathrm{H}-\mathrm{NMR}\left(500 \mathrm{MHz}, \mathrm{CDCl}_{3}\right) \delta 0.88(\mathrm{t}, J=7.1 \mathrm{~Hz}, 3 \mathrm{H}), 1.26(\mathrm{bs}, 16 \mathrm{H}), 1.49(\mathrm{~m}, 2 \mathrm{H})$, $2.47(\mathrm{t}, J=7.7 \mathrm{~Hz}, 2 \mathrm{H}), 4.60$ (d, $J=5.9 \mathrm{~Hz}, 2 \mathrm{H}), 5.03(\mathrm{bs}, 1 \mathrm{H}), 6.90(\mathrm{bs}, 1 \mathrm{H}), 7.34$ (m, 7H), $7.43(\mathrm{dd}, J=1.2,2.9 \mathrm{~Hz}, 1 \mathrm{H}) ;{ }^{13} \mathrm{C}-\mathrm{NMR}\left(150 \mathrm{MHz}, \mathrm{CDCl}_{3}\right) \delta 14.1\left(\mathrm{CH}_{3}\right), 22.6$ $\left(\mathrm{CH}_{2}\right), 22.7\left(\mathrm{CH}_{2}\right), 28.5\left(\mathrm{CH}_{2}\right), 29.3\left(\mathrm{CH}_{2}\right), 29.5\left(\mathrm{CH}_{2}\right), 29.6\left(\mathrm{CH}_{2} \times 2\right), 29.7\left(\mathrm{CH}_{2} \times 2\right)$, $31.9\left(\mathrm{CH}_{2}\right), 47.7\left(\mathrm{CH}_{2}\right), 93.5(\mathrm{C}), 119.2(\mathrm{C}), 122.8(\mathrm{CH}), 124.3(\mathrm{C}), 126.1(\mathrm{CH}), 127.8$ (CH x 3), $128.0(\mathrm{CH}), 128.9$ (CH x 2), $129.8(\mathrm{C}), 137.5$ (C), 142.6 (C), $150.4(\mathrm{C}), 157.5$ (C), 174.3 (C), 179.6 (C); EIMS m/z (\%) 505 (M+1, 85), 389 (31), 294 (45), 90 (100); HREIMS 505.2305 (calcd. for $\mathrm{C}_{30} \mathrm{H}_{35} \mathrm{O}_{4} \mathrm{~S}\left(\mathrm{M}^{+}\right)$505.2287).

\section{2-(benzylamino)-5-hydroxy-3-(pyridin-3-yl)-6-undecylbenzofuran-4,7-dione}

Following the general procedure described above, $20 \mathrm{mg}$ of embelin $(0.068 \mathrm{mmol}), 6.4$ $\mu \mathrm{L}$ of 3-pyridinecarboxaldehyde $(0.068 \mathrm{mmol}), 8.3 \mu \mathrm{L}$ of $t$-butyl isocyanide $(0.068$ $\mathrm{mmol})$ and $1.2 \mathrm{mg}$ of EDDA (10 mol\%) in $2 \mathrm{~mL}$ of DCE were irradiated for $15 \mathrm{~min}$ at $180^{\circ} \mathrm{C}$. The solvent was removed under vacuum, and the crude product was purified by preparative-TLC with DCM to yield $17.2 \mathrm{mg}(51 \%)$ of $\mathbf{6 k}$ as dark green oil. ${ }^{1} \mathrm{H}-\mathrm{NMR}$ $\left(500 \mathrm{MHz}, \mathrm{CDCl}_{3}\right) \delta 0.88(\mathrm{t}, J=7.1 \mathrm{~Hz}, 3 \mathrm{H}), 1.26(\mathrm{bs}, 16 \mathrm{H}), 1.48(\mathrm{~m}, 2 \mathrm{H}), 2.48(\mathrm{t}, J=$ $7.6 \mathrm{~Hz}, 2 \mathrm{H}), 4.59$ (d, J=5.6 Hz, 2H), $5.28(\mathrm{bs}, 1 \mathrm{H}), 7.32(\mathrm{~m}, 6 \mathrm{H}), 7.79$ (d, J=6.6 Hz, $1 \mathrm{H}), 8.47(\mathrm{~s}, 1 \mathrm{H}), 8.74(\mathrm{~s}, 1 \mathrm{H}) ;{ }^{13} \mathrm{C}-\mathrm{NMR}\left(150 \mathrm{MHz}, \mathrm{CDCl}_{3}\right) \delta 14.1\left(\mathrm{CH}_{3}\right), 22.6\left(\mathrm{CH}_{2}\right)$, 
$22.7\left(\mathrm{CH}_{2}\right), 28.5\left(\mathrm{CH}_{2}\right), 29.3\left(\mathrm{CH}_{2}\right), 29.5\left(\mathrm{CH}_{2}\right), 29.6\left(\mathrm{CH}_{2}\right.$ x 2$), 29.7\left(\mathrm{CH}_{2} \times 2\right), 31.9$ $\left(\mathrm{CH}_{2}\right), 47.7\left(\mathrm{CH}_{2}\right), 95.3(\mathrm{C}), 119.4(\mathrm{C}), 127.7(\mathrm{C}), 127.9(\mathrm{CH} \times 4), 128.1(\mathrm{CH} \times 2)$, 128.8 (C), 129.9 (CH x 3), 137.3 (C), 143.4 (C), 151.1 (C), 157.5 (C), 174.6 (C), 179.7 (C); EIMS m/z (\%) $500\left(\mathrm{M}^{+}, 94\right), 409$ (16), 360 (40), 91 (100); HREIMS 500.2660 (calcd. for $\mathrm{C}_{31} \mathrm{H}_{36} \mathrm{O}_{4} \mathrm{~N}_{2}\left(\mathrm{M}^{+}\right)$500.2675).

\section{2-(benzylamino)-3-(furan-3-yl)-5-hydroxy-6-undecylbenzofuran-4,7-dione (6l)}

Following the general procedure described above, $20 \mathrm{mg}$ of embelin $(0.068 \mathrm{mmol}), 5.9$ $\mu \mathrm{L}$ of 3 -furancarboxaldehyde $(0.068 \mathrm{mmol}), 8.3 \mu \mathrm{L}$ of $t$-butyl isocyanide $(0.068 \mathrm{mmol})$ and $1.2 \mathrm{mg}$ of EDDA $(10 \mathrm{~mol} \%)$ in $2 \mathrm{~mL}$ of DCE were irradiated for $15 \mathrm{~min}$ at $180^{\circ} \mathrm{C}$. The solvent was removed under vacuum, and the crude product was purified by preparative-TLC with $20 \%$ hexanes/EtOAc to yield $12.7 \mathrm{mg}(38 \%)$ of $\mathbf{6} \mathbf{1}$ as a dark green oil. ${ }^{1} \mathrm{H}-\mathrm{NMR}\left(400 \mathrm{MHz}, \mathrm{CDCl}_{3}\right) \delta 0.88(\mathrm{t}, J=6.1 \mathrm{~Hz}, 3 \mathrm{H}), 1.26(\mathrm{bs}, 16 \mathrm{H}), 1.49(\mathrm{~m}, 2 \mathrm{H})$, $2.47(\mathrm{t}, J=7.4 \mathrm{~Hz}, 2 \mathrm{H}), 4.61(\mathrm{~d}, J=5.7 \mathrm{~Hz}, 2 \mathrm{H}), 6.69(\mathrm{~s}, 1 \mathrm{H}), 6.89(\mathrm{~s}, 1 \mathrm{H}), 7.35(\mathrm{~m}$, 5H), $7.49(\mathrm{~d}, J=1.3,1 \mathrm{H}), 7.81(\mathrm{~d}, J=1.0 \mathrm{~Hz}, 1 \mathrm{H}) ;{ }^{13} \mathrm{C}-\mathrm{NMR}\left(150 \mathrm{MHz}, \mathrm{CDCl}_{3}\right) \delta 14.1$ $\left(\mathrm{CH}_{3}\right), 22.6\left(\mathrm{CH}_{2}\right), 22.7\left(\mathrm{CH}_{2}\right), 28.5\left(\mathrm{CH}_{2}\right), 29.3\left(\mathrm{CH}_{2}\right), 29.4\left(\mathrm{CH}_{2}\right), 29.5\left(\mathrm{CH}_{2}\right), 29.6$ $\left(\mathrm{CH}_{2}\right), 29.7\left(\mathrm{CH}_{2} \times 2\right), 31.9\left(\mathrm{CH}_{2}\right), 47.9\left(\mathrm{CH}_{2}\right), 89.8(\mathrm{C}), 109.9(\mathrm{CH}), 114.4(\mathrm{C}), 119.3$ (C), $124.5(\mathrm{C}), 127.7(\mathrm{CH}$ x 2), $128.1(\mathrm{CH}), 128.9(\mathrm{CH}$ x 2), $137.5(\mathrm{C}), 140.7(\mathrm{CH})$, 142.9 (C), 143.3 (C), 150.3 (C), 157.2 (C), 174.3 (C), 179.6 (C); EIMS m/z (\%) 489 $\left(\mathrm{M}^{+}, 100\right), 398$ (11), 418 (16), 350 (11), 349 (23); HREIMS 489.2527 (calcd. for $\mathrm{C}_{30} \mathrm{H}_{35} \mathrm{O}_{5} \mathrm{~N}\left(\mathrm{M}^{+}\right)$489.2515).

\section{2'-(benzylamino)-5'-hydroxy-6'-undecyl-[2,3'-bibenzofuran]-4',7'-dione (6m)}

Following the general procedure described above, $20 \mathrm{mg}$ of embelin $(0.068 \mathrm{mmol}), 8.2$ $\mu \mathrm{L}$ of 2-Benzofurancarboxaldehyde $(0.068 \mathrm{mmol}), 8.3 \mu \mathrm{L}$ of $t$-butyl isocyanide $(0.068$ mmol) and $1.2 \mathrm{mg}$ of EDDA (10 mol\%) in $2 \mathrm{~mL}$ of DCE were irradiated for $15 \mathrm{~min}$ at $180^{\circ} \mathrm{C}$. The solvent was removed under vacuum, and the crude product was purified by 
preparative-TLC with $20 \%$ hexanes/EtOAc to yield $23.2 \mathrm{mg}(63 \%)$ of $\mathbf{6 m}$ as dark green oil. ${ }^{1} \mathrm{H}-\mathrm{NMR}\left(500 \mathrm{MHz}, \mathrm{CDCl}_{3}\right) \delta 0.88(\mathrm{t}, J=7.1 \mathrm{~Hz}, 3 \mathrm{H}), 1.26(\mathrm{bs}, 16 \mathrm{H}), 1.50(\mathrm{~m}, 2 \mathrm{H})$, $2.49(\mathrm{t}, J=7.8 \mathrm{~Hz}, 2 \mathrm{H}), 4.79(\mathrm{~d}, J=6.1 \mathrm{~Hz}, 2 \mathrm{H}), 6.65$ (t, $J=6.2 \mathrm{~Hz}, 1 \mathrm{H}), 6.97$ (bs, 1H), $7.23(\mathrm{~m}, 2 \mathrm{H}), 7.34(\mathrm{~m}, 1 \mathrm{H}), 7.41(\mathrm{~m}, 5 \mathrm{H}), 7.58(\mathrm{~m}, 1 \mathrm{H}), 7.65(\mathrm{~s}, 1 \mathrm{H}) ;{ }^{13} \mathrm{C}-\mathrm{NMR}(150$ $\left.\mathrm{MHz}, \mathrm{CDCl}_{3}\right) \delta 14.1\left(\mathrm{CH}_{3}\right), 22.6\left(\mathrm{CH}_{2}\right), 22.7\left(\mathrm{CH}_{2}\right), 28.5\left(\mathrm{CH}_{2}\right), 29.3\left(\mathrm{CH}_{2}\right), 29.5$ $\left(\mathrm{CH}_{2}\right), 29.6\left(\mathrm{CH}_{2} \times 2\right), 29.7\left(\mathrm{CH}_{2} \times 2\right), 31.9\left(\mathrm{CH}_{2}\right), 47.2\left(\mathrm{CH}_{2}\right), 88.4(\mathrm{C}), 103.1(\mathrm{CH})$, $110.4(\mathrm{CH}), 119.4(\mathrm{C}), 120.9(\mathrm{CH}), 122.5(\mathrm{C}), 123.4(\mathrm{CH}), 123.9(\mathrm{CH}), 127.5(\mathrm{CH} x 2)$, $128.0(\mathrm{CH}), 128.9(\mathrm{C}), 129.0(\mathrm{CH} \mathrm{x} \mathrm{2}), 137.4(\mathrm{C}), 142.7$ (C), 148.7 (C), $150.3(\mathrm{C})$, 153.6 (C), 158.0 (C), 174.0 (C), 179.0 (C); EIMS m/z (\%) $544\left(\mathrm{M}^{+}, 55\right), 403$ (24), 294 (13); HREIMS 539.2692 (calcd. for $\mathrm{C}_{34} \mathrm{H}_{37} \mathrm{O}_{5} \mathrm{~N}\left(\mathrm{M}^{+}\right)$539.2672).

\section{2-(benzylamino)-5-hydroxy-3-propyl-6-undecylbenzofuran-4,7-dione (6n)}

Following the general procedure described above, $20 \mathrm{mg}$ of embelin $(0.068 \mathrm{mmol}), 6.2$ $\mu \mathrm{L}$ of butyraldehyde $(0.068 \mathrm{mmol}), 8.3 \mu \mathrm{L}$ of $t$-butyl isocyanide $(0.068 \mathrm{mmol})$ and 1.2 $\mathrm{mg}$ of EDDA $(10 \mathrm{~mol} \%)$ in $2 \mathrm{~mL}$ of DCE were irradiated for $15 \mathrm{~min}$ at $180^{\circ} \mathrm{C}$. The solvent was removed under vacuum, and the crude product was purified by preparativeTLC with $20 \%$ hexanes/EtOAc to yield $21.8 \mathrm{mg}(69 \%)$ of $\mathbf{6 n}$ as dark green oil. ${ }^{1} \mathrm{H}-\mathrm{NMR}$ $\left(500 \mathrm{MHz}, \mathrm{CDCl}_{3}\right) \delta 0.88(\mathrm{~m}, 6 \mathrm{H}), 1.25(\mathrm{bs}, 18 \mathrm{H}), 1.48(\mathrm{~m}, 2 \mathrm{H}), 1.52(\mathrm{~m}, 2 \mathrm{H}), 2.44(\mathrm{~m}$, 2H), $4.30(\mathrm{t}, J=5.8 \mathrm{~Hz}, 1 \mathrm{H}), 4.55(\mathrm{~d}, J=6.1 \mathrm{~Hz}, 2 \mathrm{H}), 7.34(\mathrm{~m}, 5 \mathrm{H}) ;{ }^{13} \mathrm{C}-\mathrm{NMR}(150$ $\left.\mathrm{MHz}, \mathrm{CDCl}_{3}\right) \delta 13.7\left(\mathrm{CH}_{3}\right), 14.1\left(\mathrm{CH}_{3}\right), 22.6\left(\mathrm{CH}_{2}\right), 22.7\left(\mathrm{CH}_{2} \times 2\right), 24.5\left(\mathrm{CH}_{2}\right), 28.6$ $\left(\mathrm{CH}_{2}\right), 29.3\left(\mathrm{CH}_{2}\right), 29.5\left(\mathrm{CH}_{2}\right), 29.6\left(\mathrm{CH}_{2} \times 2\right), 29.7\left(\mathrm{CH}_{2} \times 2\right), 31.9\left(\mathrm{CH}_{2}\right), 48.2\left(\mathrm{CH}_{2}\right)$, $98.3(\mathrm{C}), 119.5$ (C), 126.3 (C), 127.7 (CH x 2), 127.9 (CH), 128.9 (CH x 2), 138.0 (C), 142.6 (C), 150.0 (C), 157.7 (C), 174.0 (C), 180.4 (C); EIMS m/z (\%) 465 (M+1, 62$), 376$ (14), 91 (100); HREIMS 465.2903 (calcd. for $\mathrm{C}_{29} \mathrm{H}_{39} \mathrm{O}_{4} \mathrm{~N}\left(\mathrm{M}^{+}\right)$465.2879).

2-(benzylamino)-3-hexyl-5-hydroxy-6-undecylbenzofuran-4,7-dione (6o) 
Following the general procedure described above, $20 \mathrm{mg}$ of embelin $(0.068 \mathrm{mmol}), 9.5$ $\mu \mathrm{L}$ of heptanaldehyde $(0.068 \mathrm{mmol}), 8.3 \mu \mathrm{L}$ of $t$-butyl isocyanide $(0.068 \mathrm{mmol})$ and 1.2 $\mathrm{mg}$ of EDDA $(10 \mathrm{~mol} \%)$ in $2 \mathrm{~mL}$ of DCE were irradiated for $15 \mathrm{~min}$ at $180^{\circ} \mathrm{C}$. The solvent was removed under vacuum, and the crude product was purified by preparativeTLC with $20 \%$ hexanes/EtOAc to yield $13.8 \mathrm{mg}$ (40\%) of $\mathbf{6 o}$ as dark green oil. ${ }^{1} \mathrm{H}-\mathrm{NMR}$ $\left(500 \mathrm{MHz}, \mathrm{CDCl}_{3}\right) \delta 0.87(\mathrm{~m}, 6 \mathrm{H}), 1.25(\mathrm{bs}, 18 \mathrm{H}), 1.46(\mathrm{~m}, 4 \mathrm{H}), 1.63(\mathrm{~m}, 4 \mathrm{H}), 2.44(\mathrm{t}$, $J=7.8 \mathrm{~Hz}, 4 \mathrm{H}), 4.55(\mathrm{~d}, J=6.1 \mathrm{~Hz}, 2 \mathrm{H}), 7.34(\mathrm{~m}, 5 \mathrm{H}) ;{ }^{13} \mathrm{C}-\mathrm{NMR}\left(150 \mathrm{MHz}, \mathrm{CDCl}_{3}\right) \delta$ $14.0\left(\mathrm{CH}_{3}\right), 14.1\left(\mathrm{CH}_{3}\right), 22.6\left(\mathrm{CH}_{2}\right), 22.7\left(\mathrm{CH}_{2}\right), 28.6\left(\mathrm{CH}_{2}\right), 28.9\left(\mathrm{CH}_{2}\right), 29.3\left(\mathrm{CH}_{2}\right)$, $29.4\left(\mathrm{CH}_{2}\right.$ x 2), $29.5\left(\mathrm{CH}_{2}\right.$ x 2), $29.6\left(\mathrm{CH}_{2} \times 2\right), 29.7\left(\mathrm{CH}_{2} \times 2\right), 31.6\left(\mathrm{CH}_{2}\right), 31.9\left(\mathrm{CH}_{2}\right)$, $48.2\left(\mathrm{CH}_{2}\right), 99.1(\mathrm{C}), 119.7(\mathrm{C}), 126.3(\mathrm{C}), 127.7(\mathrm{CH} x 2), 127.9(\mathrm{CH}), 128.9(\mathrm{CH} x 2)$, 138.5 (C), 142.9 (C), 150.2 (C), 157.4 (C), 174.1 (C), 180.2 (C); EIMS m/z (\%) 507 $\left(\mathrm{M}^{+}, 100\right), 436$ (9), 367 (16); HREIMS 507.3345 (calcd. for $\mathrm{C}_{32} \mathrm{H}_{45} \mathrm{O}_{4} \mathrm{~N}\left(\mathrm{M}^{+}\right.$) 507.3349).

\subsection{Biological evaluation}

\subsubsection{Inhibition of human CK2 holoenzyme}

All compounds in this study were tested for their inhibitory activity towards the human CK2 holoenzyme following the procedure described earlier [24]. The synthetic peptide (RRRDDDSDDD) by CK2 was used as the substrate, which is reported to be most efficiently phosphorylated by CK2. The purity of the CK2 holoenzyme was superior to $99 \%$. For initial testing, inhibition was determined relative to the control at inhibitor concentrations of $10 \mu \mathrm{M}$ in DMSO as a solvent. The reaction with pure solvent without inhibitor was used as a positive control and set to $0 \%$ inhibition. Reactions without CK2 were used as negative control and were taken as $100 \%$ inhibition. $\mathrm{IC}_{50}$ values were determined by measuring CK2 inhibition at eight different concentrations of inhibitors ranging from 0.001 to $100 \mu \mathrm{M}$ in appropriate intervals and calculated from the resulting 
dose-response curve. The capillary electrophoresis based assay was used for testing the inhibitors of human CK2 as described earlier [29]. $\mathrm{IC}_{50}$ values were calculated from the resulting dose-response curves, Prism 6 (GraphPad Software, San Diego, CA, USA) was used to evaluate the $\mathrm{IC}_{50}$ values. For the determination of the mode of inhibition, the ATP concentration in the assay buffer was varied to 5, 10,50 and $100 \mu \mathrm{M}$, while the rest of the procedure was identical to the $\mathrm{IC}_{50}$ determination described above.

\subsubsection{Cell Culture and Proliferation}

MCF7 human breast adenocarcinoma cell, provided by the Department of Clinical Radiology of the University Hospital Münster, Germany, was cultured in DMEM High glucose medium supplemented with $2 \mathrm{mM}$ L-Glutamin and 10\% FCS [30]. Cells were seeded at a density of $5.0 \times 10^{4}$ cells per well into 24 -well culture plates. After overnight incubation, seeding medium was removed and replaced with fresh medium containing one of the tested compounds at $0.1,1,5$ or $10 \mu \mathrm{M}$. DMSO, at a final concentration of $1 \%$, served as a control. Cells were incubated for 24 or $48 \mathrm{~h}$ at $37^{\circ} \mathrm{C}$ in a humidified atmosphere $\left(5 \% \mathrm{CO}_{2}\right)$. Cell proliferation was quantified by the EdU-click assay (Baseclick BCK-EdU555-1, Baseclick GmbH, Munich, Germany). The nucleoside analog 5-ethynyl-2'-deoxyuridine is incorporated during active DNA synthesis, and the 5-TAMRA-PEG3-azide fluorophore, used for detection, is coupled by click reaction. The results were calculated as a percent ratio of proliferating cells versus total number of untreated cells. CK2 inhibitor was assayed in triplicates, and the experiments were repeated three times.

\subsubsection{Cell viability assay}

The effect of CK2 inhibitors on the viability of MCF7 cells was evaluated using MTT assay [31]. This assay is a colorimetric assay, which measures the conversion of MTT into violet formazan that is produced by succinate dehydrogenase of the intact 
mitochondria in viable cells. MTT assay was performed in 96-well plates. Cells were seeded at a density of $1 \times 10^{5}$ cells per well. Cells were incubated for 24 or $48 \mathrm{~h}$ at 37 ${ }^{\circ} \mathrm{C}$ in a humidified atmosphere $\left(5 \% \mathrm{CO}_{2}\right)$. After overnight incubation, seeding medium was removed and replaced with fresh medium containing the inhibitor at $0.1,1,5$ or 10 $\mu \mathrm{M}$. DMSO, at a final concentration of $1 \%$, served as a control. Afterwards MTT reagent (Sigma Aldrich, Germany) was added at a final concentration of $0.5 \mathrm{mg} / \mathrm{mL}$. After incubation for $2 \mathrm{~h}$ at $37{ }^{\circ} \mathrm{C}$ medium was discarded and $200 \mu \mathrm{L}$ DMSO was added for solubilization the formazan. After mixing, the absorption was determined at $570 \mathrm{~nm}$ with a reference wavelength of $630 \mathrm{~nm}$ using a microplate reader. CK2 inhibitor was assayed in triplicates, and the experiments were repeated three times.

\subsection{Protein Preparation and Docking.}

The X-ray coordinates of human protein kinase CK2 alpha subunit in complex with the inhibitor CX-4945 (PDB 3PE1). The PDB structures were prepared for docking using the Protein Preparation Workflow (Schrodinger, LLC, New York, NY, 2018) accessible from within the Maestro program (Maestro, version 11.6; Schrodinger, LLC: New York, NY, 2018). The substrate and water molecules were removed beyond $5 \AA$, bond corrections were applied to the cocrystallized ligands and an exhaustive sampling of the orientations of groups was performed. Finally, the receptors were optimized in Maestro 11.6 by using OPLS3 force field before docking study. In the final stage the optimization and minimization on the ligand-protein complexes were carried out with the OPLS3 force field and the default value for rmsd of $0.30 \AA$ for non-hydrogen atoms were used. The receptor grids were generated using the prepared proteins, with the docking grids centered on the center of the bound ligand for each receptor. A receptor grid was generated using a 1.00 van der Waals (vdW) radius scaling factor and 0.25 partial charge cutoff. The binding sites were enclosed in a grid box of $20 \AA^{3}$ with 
default parameters and without constrains. The three-dimensional structures of the ligands to be docked were generated and prepared using LigPrep as implemented in Maestro 11.6 (LigPrep, Schrodinger, LLC: New York, NY, 2018) to generate the most probable ionization states at $\mathrm{pH} 7 \pm 1$ (retain original ionization state). These conformations were used as the initial input structures for the docking. In this stage a series of treatments are applied to the structures. Finally, the geometries are optimized using OPLS3 force field. These conformations were used as the initial input structures for the docking. The ligands were docked using the extra precision mode (XP) [32] without using any constraints and a 0.80 van der Waals $(\mathrm{vdW})$ radius scaling factor and 0.15 partial charge cutoff. The dockings were carried out with flexibility of the residues of the pocket near to the ligand. The generated ligand poses were evaluated with empirical scoring function, GlideScore a modified version of ChemScore [33], GlideScore implemented in Glide, was used to estimate binding affinity and rank ligands [34]. The XP Pose Rank was used to select the best-docked pose for each ligand. The best correlation with the human protein kinase CK2 alpha subunit was achieved when the PDB 3PE1 was used.

\section{ACKNOWLEDGMENT}

We gratefully acknowledge the financial support from the Spanish MINECO SAF 2015-65113-C2-1-R, MICINN (RTI2018-094356-B-C21) and Gobierno Autónomo Canario (ProID2017010071). These projects are also co-funded by the European Regional Development Fund (FEDER). AAA and SOR thank the Cabildo de Tenerife (Agustin de Betancourt Program) and PMA thanks the ACIISI for a predoctoral grant.

\section{References}

1. Burnett G.; Kennedy E.P. The enzymatic phosphorylation of proteins. J. Biol. Chem. 1954, 211, 969-980. 
2. Litchfield, D.W. Protein kinase ck2: Structure, regulation and role in cellular decisions of life and death. Biochem. J., 2003, 369, 1-15.

3. Trembley, J.H.; Wu, J.; Unger, G.M.; Kren, B.T.; Ahmed, K. Ck2 Suppression of Apoptosis and its implication in cancer biology and therapy; WileyBlackwell: Ames, IA, USA, 2013; pp. 219-343.

4. Seldin, D.C.; Landesman-Bollag, E. The oncogenic potential of CK2; WileyBlackwell: Ames, IA, USA, 2013.

5. Ruzzene, M.; Pinna, L.A. Addiction to protein kinase ck2: A common denominator of diverse cancer cells? Biochim. Biophys. Acta 2010, 1804, 499504.

6. Seldin, D.C.; Landesman-Bollag, E.; Farago, M.; Currier, N.; Lou, D.; Dominguez, I. $\mathrm{Ck} 2$ as a positive regulator of wnt signalling and tumourigenesis. Mol. Cell. Biochem. 2005, 274, 63-67.

7. Dominguez, I.; Sonenshein, G.E.; Seldin, D.C. Protein kinase CK2 in health and disease: $\mathrm{Ck} 2$ and its rolein wnt and nf-kappa $\beta$ signaling: Linking development and cancer. Cell. Mol. Life Sci. 2009, 66, 1850-1857.

8. Zhang, H.X.; Jiang, S.S.; Zhang, X.F.; Zhou, Z.Q.; Pan, Q.Z.; Chen, C.L.; Zhao, J.J.; Tang, Y.; Xia, J.C.;Weng, D.S. Protein kinase CK2 $\alpha$ catalytic subunit is overexpressed and serves as an unfavorable prognostic marker inprimary hepatocellular carcinoma. Oncotarget 2015, 6, 34800-34817.

9. Pinna, L.A.; Meggio, F. Protein kinase CK2 ("casein kinase-2") and its implication in cell division and proliferation. Prog. Cell. Cycle Res. 1997, 3, 7797.

10. Ahmed, K.; Davis, A.T.; Wang, H.; Faust, R.A.; Yu, S.; Tawfic, S. Significance of protein kinase CK2 nuclear signaling in neoplasia. J. Cell. Biochem. 2000, 79 (Suppl. 35), 130-135.

11. Ahmad, K.A.; Wang, G.; Unger, G.; Slaton, J.; Ahmed, K. Protein kinase ck2A key suppressor of apoptosis. Adv. Enzyme Regul. 2008, 48, 179-187.

12. Ahmed, K.; Gerber, D.A.; Cochet, C. Joining the cell survival squad: An emerging role for protein kinase ck2. Trends Cell. Biol. 2002, 12, 226-230.

13. Kramerov, A.A.; Saghizadeh, M.; Caballero, S.; Shaw, L.C.; Li Calzi, S.; Bretner, M.; Montenarh, M.; Pinna, L.A.; Grant, M.B.; Ljubimov, A.V. Inhibition of protein kinase ck2 suppresses angiogenesis andhematopoietic stem cell recruitment to retinal neovascularization sites. Mol. Cell. Biochem. 2008, 316, 177-186.

14. Montenarh, M. Protein kinase CK2 and angiogenesis. Adv. Clin. Exp. Med. 2014, 23, 153-158.

15. Canton, D.A.; Litchfield, D.W. The shape of things to come: An emerging role for protein kinase CK2 in the regulation of cell morphology and the cytoskeleton. Cell. Signal. 2006, 18, 267-275.

16. Filhol, O.; Deshiere, A.; Cochet, C. Role of CK2 in the Control of Cell Plasticity in Breast Carcinoma Progression;Wiley-Blackwell: Ames, IA, USA, 2013.

17. Hochscherf, J.; Lindenblatt, D.; Witulski, B.; Birus, R.; Aichele, D.; Marminon, C.; Bouaziz, Z.; Le Borgne, M.; Jose, J.; Niefind, K. Unexpected binding mode of a potent indeno[1,2-b]indole-type inhibitor of protein kinase CK2 revealed by complex structures with the catalytic subunit CK2 $\alpha$ and its paralog CK2 $\alpha$ '. Pharmaceuticals 2017, 10, 98/1-98/19.

18. Haidar, S.; Bouaziz, Z.; Marminon, C.; Laitinen, T.; Poso, A.; Le Borgne, M.; Jose, J. Development of pharmacophore model for indeno[1,2-b]indoles as 
human protein kinase CK2 inhibitors and database mining. Pharmaceuticals 2017, 10, 8/1-8/13.

19. Bollacke, A.; Nienberg, C.; Le Borgne, M.; Jose, J. Toward selective CK2alpha and CK2alpha' inhibitors: Development of a novel whole-cell kinase assay by autodisplay of catalytic CK2alpha'. J. Pharm. Biomed. Analysis 2016, 121, 253260.

20. www.clinicaltrials.gov. Identifiers: NCT02128282and NCT01639625

21. Cozza, G.; Pinna, L.A.; Moro, S. Kinase CK2 Inhibition: An Update. Curr. Med. Chem., 2013, 20, 671-693.

22. Martín-Acosta, P.; Haidar, S.; Amesty, A.; Aichele, D.; Jose, J. EstévezBraun, A. A new family of densely functionalized fused-benzoquinones aspotent human protein kinase CK2 inhibitors. Eur. J. Med. Chem . 2018, 144, 410-423.

23. Jimenez-Alonso, S.; Guasch, J.; Estévez-Braun, A.; Ratera, I.; Veciana, J.; Ravelo, A. G. Electronic and Cytotoxic Properties of 2-Amino-naphtho[2,3b]furan-4,9-diones. J. Org. Chem. 2011, 76, 1634-1643.

24. Olgen, S.; Gotz, C.; Jose, J., Synthesis and biological evaluation of 3(substituted-benzylidene)-1,3-dihydro-indolin derivatives as human protein kinase CK2 and p60(c-Src) tyrosine kinase inhibitors. Biol Pharm Bull 2007, 30 , 715-718.

25. Glide software, Glide, Version 11.6, Schrodinger, LLC, New York, NY, 2018.

26. Traxler P.; Furet, P. Strategies toward the design of novel and selective protein tyrosine kinase inhibitors. Pharmacol Ther 1999, 82, 195-206.

27. Traxler, P.; Green, J.; Mett, H.; Sequin, U.; Furet, P. 1999. Use of a pharmacophore model for the design of EGFR tyrosine kinase inhibitors: isoflavones and 3-phenyl-4(1H)-quinolones. J. Med. Chem. 1999, 42, 10181026.

28. Feresin, G. E.; Tapia, A.; Sortino, M.; Zacchino, S.; de Arias, A. R.; Inchausti, A.; Yaluff, J.;Rodriguez, G.; Theoduloz, C.; Schmeda-Hirschmann, G. J. Ethnopharmacol. 2003, 88, 241-247.

29. Gratz, A.; Gotz, C.; Jose, J. A CE-based assay for human protein kinase CK2 activity measurement and inhibitor screening. Electrophoresis 2010, 31, 634640.

30. Xue, L. Y.; Chiu, S. M.; Oleinick, N. L., Staurosporine-induced death of MCF-7 human breast cancer cells: a distinction between caspase-3-dependent steps of apoptosis and the critical lethal lesions. Exp. Cell Res. 2003, 283, 135-45.

31. Mosmann, T. Rapid colorimetric assay for cellular growth and survival: application to proliferation and cytotoxicity assays. J. Immunol. Methods 1983, 65, 55-63.

32. Friesner, R.A.; Murphy, R.B.; Repasky, M.P.; Frye, L.L.; Greenwood, J.R.; Halgren, T.A.; Sanschagrin, P.C.; Mainz, D.T. Extra precision glide: docking and scoring incorporating a model of hydrophobic enclosure for protein-ligand complexes, J. Med. Chem. 2006, 49, 6177-6196.

33. Eldridge, M.D.; Murray, C.W.; Auton, T.R.; Paolini, G.V.; Mee, R.P. Empirical scoring functions: I. The development of a fast empirical scoring function to estimate the binding affinity of ligands in receptor complexes, J. Comput. Aided Mol. Des. 1997, 11, 425.

34. Friesner, R.A.; Banks, J.L.; Murphy, R.B.; Halgren, T.A.; Klicic, J.J.; Mainz, D.T.; Repasky, M.P.; Knoll, E.H.; Shelley, M.; Perry, J.K.; Shaw, D.E.; Francis, P.; Shenkin, P.S. Glide: a new approach for rapid, accurate docking and scoring. 
1. Method and assessment of docking accuracy, J. Med. Chem. 2004, 47, 17391749. 